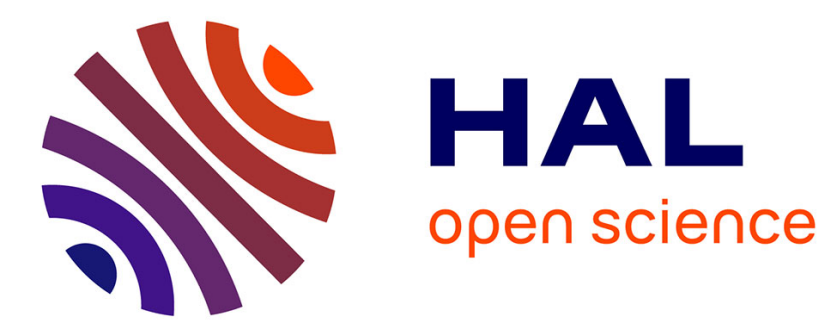

\title{
Asymmetric Wholesale Pricing: Theory and Evidence
} Sourav Ray, Haipeng Allan Chen, Mark Bergen, Daniel Levy

\section{To cite this version:}

Sourav Ray, Haipeng Allan Chen, Mark Bergen, Daniel Levy. Asymmetric Wholesale Pricing: Theory and Evidence. Marketing Science, 2006, 25 (2), pp.131-154. 10.1287/mksc.1050.0138 . hal-02387421

\section{HAL Id: hal-02387421 \\ https://hal.science/hal-02387421}

Submitted on 29 Nov 2019

HAL is a multi-disciplinary open access archive for the deposit and dissemination of scientific research documents, whether they are published or not. The documents may come from teaching and research institutions in France or abroad, or from public or private research centers.
L'archive ouverte pluridisciplinaire HAL, est destinée au dépôt et à la diffusion de documents scientifiques de niveau recherche, publiés ou non, émanant des établissements d'enseignement et de recherche français ou étrangers, des laboratoires publics ou privés. 


\title{
Asymmetric Wholesale Pricing: Theory and Evidence*
}

\author{
Sourav Ray \\ Department of Marketing, McMaster University \\ 1280 Main Street, Hamilton, ON L8S-4M4, Canada \\ Phone: (905) 525-9140 ext. 22370; Fax: (905) 521-8995 \\ Email: sray@mcmaster.ca \\ Haipeng (Allan) Chen \\ Department of Marketing, University of Miami \\ Coral Gables, FL 33124, USA \\ Mark E. Bergen \\ Department of Marketing and Logistics Management \\ Carlson School of Management, University of Minnesota \\ Minneapolis, MN 55455, USA \\ Daniel Levy \\ Department of Economics, Bar-Ilan University \\ Ramat-Gan 52900, Israel \\ and \\ Department of Economics, Emory University \\ Atlanta, GA 30322, USA \\ ECONDL@Emory.edu
}

JEL Codes: E31, E12, L11, L16, L22, L81, M21, M31

Keywords: Asymmetric Pricing, Channel Pricing, Costs of Price Adjustment, Menu Costs, Wholesale Prices, Channels of Distribution, Retailing, Economic Model, Scanner Data

January 2005

\footnotetext{
* We thank two anonymous referees, an area editor, and the editor Steve Shugan for constructive comments, suggestions and guidance through the revision process. Special thanks to our discussant Justin Johnson, and the participants at the 2002 INFORMSCornell University Conference on Pricing Research in Ithaca, NY, the 2002 Marketing Science conference in Edmonton, AB; the marketing department seminars at JMSB - Concordia University, HEC, and McGill University, all in Montreal, and at CSOM University of Minnesota, Minneapolis; and Bianca Grohmann for their valuable feedback. Research assistance by Manish Aggarwal is gratefully acknowledged. Parts of this research have been funded by FRDP of Concordia University and by the INE program of SSHRC, Canada. All authors contributed equally. The usual disclaimer applies.
} 


\title{
Asymmetric Wholesale Pricing: Theory and Evidence
}

\begin{abstract}
Asymmetric pricing is the phenomenon where prices rise more readily than they fall. We articulate, and provide empirical support for, a theory of asymmetric pricing in wholesale prices. In particular, we show how wholesale prices may be asymmetric in the small but symmetric in the large, when retailers face costs of price adjustments. Such retailers will not adjust prices for small changes in their costs. Upstream manufacturers then see a region of inelastic demand where small wholesale price changes do not translate into commensurate retail price changes. The implication is asymmetric - small wholesale increases are more profitable because manufacturers will not lose customers from higher retail prices; yet, small wholesale decreases are less profitable, because these will not create lower retail prices, hence no extra revenue from greater sales. For larger changes, this asymmetry at wholesale vanishes as the costs of changing prices are compensated by increases in retailers' revenue that result from correspondingly large retail price changes. We first present a formal economic model of a channel with forward looking retailers facing costs of price adjustment to derive the testable propositions. Next, we test these on manufacturer prices in a supermarket scanner dataset to find support for our theory. We discuss the contributions of the results for the asymmetric pricing, distribution channels and cost of price adjustment literatures, and implications for public policy.
\end{abstract}




\section{Introduction}

Asymmetric pricing is a phenomenon where prices rise readily but fall slowly. Frequent reports in the popular press lament the fact that prices are asymmetric. It is not uncommon to read headlines about prices "rising like rockets ...(but)... falling like feathers" (Octane, v.13-3, June 1999, pp.6-7); retail pork prices not coming down even if hog prices do (New York Times, Jan. 7, 1999) and government subsidies to dairy farmers not lowering dairy products prices, even if a hike in the price of industrial milk paid to farmers, raises such prices at the store (Canadian Press Newswire, Dec. 18, 2000). The resulting public interest in the phenomenon has spawned a large academic literature devoted to the issue. Asymmetry has been studied across a broad range of product markets (Peltzman, 2000), including gasoline (Bacon, 1991; Borenstein and Shepard, 1996; Karrenbrock, 1991); fruit and vegetables (Pick et al., 1991; Ward, 1982); pork (Boyde and Brorsen, 1988); and banking (Hannan and Berger, 1991; Neumark and Sharpe, 1992).

Yet, despite the substantial research in asymmetric pricing, the theoretical literature in the area is still in its nascent stages. Peltzman (2000) for example, comments that "Economic theory suggests no pervasive tendency for prices to respond ... (asymmetrically) ...” Most existing research is empirically driven, attempting to establish the scale and scope of asymmetry. Only a few papers develop formal theories. These include explanations based on monopoly power (Benabou and Gertner, 1993; Borenstein and Shepard, 1996), inflation with costs of price adjustment (Ball and Mankiw, 1994), elasticity differences in a channel with costs of price adjustment (Madsen and Yang, 1998) and information processing costs of consumers (Chen et al. 2004). Yet, in the context of the broad evidence of asymmetric pricing, the theoretical field is still largely unexplored. For authors like Peltzman (2000) this represents a "serious gap in a fundamental area of economic theory." Similar sentiments are echoed by Ball and Mankiw (1994), Borenstein et al. (1997), and Blinder et al. (1998), all calling for further theory development to close this gap. Surprisingly, given 
the ubiquity of the phenomenon and the rich marketing literature in pricing ( $c f$. DeSarbo et al., 1987; Hess and Gerstner, 1987; Ratchford and Srinivasan, 1993; Tellis and Zufryden, 1995;

Kadiyali et al., 2000), marketing's contribution to research in asymmetric pricing has been marginal till date. To the best of our knowledge, marketing has not directly studied asymmetric pricing. ${ }^{1}$

In this paper we hope to address this gap by offering, and providing empirical support for, a theory of asymmetric pricing. Our theory combines insights from the literature on channels of distribution with insights from the literature on costs of price adjustment to suggest why wholesale prices may be asymmetric. This is a natural direction to explore for two very important reasons.

First, we know little about the role played by the distribution channel and the business-tobusiness linkages implied therein, in determining asymmetric pricing at any level of the channel. Yet, such linkages have been consistently argued to have important influences on the channel's pricing practices. ${ }^{2}$ There is no reason to believe asymmetric pricing will be an exception. Quite to the contrary, Peltzman (2000) suggests, “an explanation for asymmetry may require a fuller understanding of those vertical market linkages." By focusing on asymmetry in wholesale prices in the context of a distribution channel, we help to clarify the role of such vertical linkages.

Second, while there is a large literature on the importance of costs of price adjustment for price rigidity we are only beginning to develop our understanding of the implications of these costs on both pricing decisions of other members of the distribution channel, and asymmetric pricing. ${ }^{3}$ For example, Levy et al. (1997) attempt to calibrate the source and magnitude of these costs, but do not explore asymmetry or the implications for channel pricing. On the other hand, Ball and Mankiw

\footnotetext{
${ }^{1}$ The marketing literature on price adjustment costs is limited. See the paper on haggling by Desai and Purohit (2004) as an example of how these costs might impact marketing strategy. On asymmetry, see Greenleaf, (1995); Kopalle et al. (1996) etc. for their consideration of asymmetric reference price effects which is the closest related work.

${ }^{2}$ See Jeuland and Shugan (1983); Moorthy (1988); Choi (1991); Messinger and Narasimhan (1995); Ingene and Parry (1995); Bergen et al. (1996) etc.

${ }^{3}$ For the literature on these costs, see Mankiw, 1985; Ball and Mankiw, 1994, 1995; Danziger, 1987; Levy et al., 1997; Basu, 1995; Blinder et al., 1998; Dutta et al., 1999; Slade, 1998; Zbaracki et al., 2004 etc.
} 
(1994) combine costs of price adjustment with inflation to offer an explanation of asymmetric pricing. There are also authors who combine channels of distribution and costs of price adjustment. For example, Basu (1995) has addressed both price adjustment costs and channels of distribution in his work on stages of processing, although he focuses on the implications for price rigidity rather than any asymmetry issues in his paper. And Madsen and Yang (1998) look at differences in price elasticities in channels of distribution with costs of price adjustment to offer an explanation for asymmetric pricing. We develop this literature to increase our understanding of the implications of costly price adjustment on prices throughout the channel of distribution, and asymmetry.

We suggest that retail costs of price adjustment may result in asymmetric pricing by manufacturers. If retailers face costs of price adjustment, they will not adjust retail prices for small changes in wholesale prices. This changes the demand curve faced by the manufacturers. In essence, they then see a region of inelastic demand where small wholesale price changes do not translate into commensurate retail price changes. The implication is asymmetric for manufacturers it will make small wholesale price increases more profitable because they will not lose customers from higher retail prices. Yet, they will find it less profitable to make small wholesale price decreases, because these will not translate into lower retail prices, and therefore no extra revenue will be generated by these wholesale price cuts.

For larger wholesale price changes however, retail prices move readily because the cost of changing prices is compensated by increases in retailers' revenue. As a result, wholesale prices adjust symmetrically to large changes. To formalize this idea we present an economic model with costly price adjustment in a distribution channel where members have rational expectations because they are forward looking and therefore behave with foresight. Using the model we derive testable predictions about patterns of wholesale price adjustment. 
In order to test this theory we need data on upstream prices in a channel where we believe price adjustment is costly for the retailer. A natural place to look is in the grocery industry, where these costs have been shown to exist (Levy et. al. 1997, 1998; Dutta et. al.1999). Specifically, we use the Dominick's scanner data set because it has a measure of upstream prices that the retailer paid for its products (wholesale prices), and because the existence of retail costs of price adjustment in this industry has been documented in the earlier studies. The data consist of up to 400 weekly observations of this measure of wholesale prices in 29 different product categories, covering the period of about eight years between 1989 and 1997.

We conduct the analysis for each of the 29 categories and find almost uniform support for our theoretical propositions - asymmetry in the small, but symmetry in larger wholesale price changes. In order to check if our results are due to inflation, we redo each category level analysis, first for non-inflationary, and then for deflationary periods in the dataset. In both cases we find our results to be robust across the categories considered. Yet, one limitation of the wholesale data in the Dominick's dataset is that the reported numbers are not actual wholesale prices but weighted averages of the inventory. Therefore, we also check if the results could be an artifact of the manner in which wholesale prices have been calculated, and conclude that this cannot explain our results.

In the rest of the paper, we first present the model, followed by an account of the data, analysis and the results. We then discuss the theoretical and managerial implications for the literatures spanning asymmetric pricing, distribution channels and costs of price adjustment. The implications for public policy are discussed next. We finish the paper by highlighting the principal conclusions, important limitations and opportunities for future research. 


\section{Theoretical Model}

In this section we offer a theory where asymmetric pricing at wholesale level is driven by the presence of downstream costs of price adjustment. Thus, at a minimum, we need to consider a 2level distribution channel, with pricing decisions for each member, and downstream costs of price adjustment.

Specifically, we model a channel with one manufacturer selling through one retailer to end customers. The customer demand is a continuously differentiable function, decreasing in $p: D(p)$, in each period. For feasibility, we assume the demand function is such that there is at least one price above cost at which demand is positive. We let the manufacturer set the wholesale price $w_{\mathrm{i}}$ and retailer set the retail price $p_{\mathrm{i}}$ in each period $i$. Both manufacturer and retailer choose prices to maximize their profits. To explore price adjustment from one period to the other, we need to consider at least two periods. We denote the initial pricing period as $\mathrm{t}_{0}$, where channel members set the initial price of the product. The second, or the "adjustment period" is denoted $t_{1}$. In the adjustment period firms will decide whether, and how much, to adjust prices given the costs of price adjustment and any changes in market conditions.

We assume the retailers must bear a fixed $\operatorname{cost} x$ whenever they change retail prices. Thus, in period $t_{1}$, if the retailer decides to change prices from those they set in the initial period $t_{0}$, they must incur a cost of $x$. If the retailer chooses not to adjust prices in period $t_{1}$, then they do not have to bear this cost.

The manufacturers are also assumed to have a fixed cost $y$ whenever they change wholesale prices. They can avoid this cost in period $t_{1}$ by not changing their $t_{0}$ period prices. ${ }^{4}$

\footnotetext{
${ }^{4}$ In the analysis we consider a case with $y=0$ for expositional simplicity. The general case with $y>0$ is dealt with in the appendix.
} 
The impetus for price changes comes from changing market conditions. We focus on changes in manufacturers' costs as a proxy for such an impetus. ${ }^{5}$ More specifically, the manufacturer faces a unit production $\operatorname{cost} c$ in the initial period $\mathrm{t}_{0}$, and this cost changes by an amount $\Delta c$ in the adjustment period $\mathrm{t}_{1}$. We assume $\Delta c$ is a single-peaked symmetric distribution with mean zero. ${ }^{6}$

In terms of how the channel prices are set in each period we will assume a Stackelberg game with the manufacturers as price leaders, i.e. they set wholesale prices anticipating the retailers' reactions to these prices. The retailers then take the wholesale prices as given and set retail prices. In setting these prices across periods, we let both the retailer and manufacturer act with foresight, i.e. in period $t_{0}$ both consider the pricing actions they will take in $t_{1}$.

In this setup asymmetric pricing occurs when the likelihood of positive price adjustments are systematically greater than those of negative ones given similar changes in market conditions. For example, given $\Delta c \neq 0$ of a given magnitude, asymmetric pricing is exhibited if the likelihood of prices rising following $\Delta c>0$ is greater than the likelihood of prices falling following $\Delta c<0$. Asymmetry is also exhibited if the magnitude of the positive price adjustment is greater than the magnitude of the negative adjustment. For $\Delta c=0$, asymmetric pricing would be exhibited if the likelihood of prices rising is greater than the likelihood of prices falling or remaining the same.

In the following paragraphs we first set up the general problem. We then explore a model of this channel without any costs of price adjustment to illustrate that asymmetric pricing is not a result of the vertical separation in a channel setting, per se. Subsequently, we investigate this model with only retail costs of price adjustment $(x)$. This illustrates that by itself, costly price adjustment leads

\footnotetext{
${ }^{5}$ There are many other ways market conditions can change. These include changing demand, entry or exit of competitors, change in the macro-economy (inflation or recession), change in government regulation (price or produce control), as well as acts of God (unseasonal weather patterns) etc. The spirit of these results would remain unchanged, regardless of the specific situation.

${ }^{6}$ Note that if there are inflationary trends, the expected value of $\Delta c$ would be non-zero. So, our results are essentially derived for a zero inflation scenario.
} 
to price rigidity but not asymmetry. However, this also allows us to illustrate how these downstream costs of adjustment, lead to upstream asymmetry in wholesale prices during the adjustment period. In the appendix we explore the general model with the manufacturer costs of adjustment $(y)$ to investigate its effects on our results.

\subsection{General case of channel with costs of price adjustment}

The retail profit functions in the initial period $t_{0}$ and in the adjustment period $t_{1}$ are respectively:

$\Pi_{\mathrm{r} 0}=\operatorname{Max}\left(p_{0}\right):\left\{\left(p_{0}-w_{0}\right) D\left(p_{0}\right)\right\}$

$\Pi_{\mathrm{r} 1}=\operatorname{Max}\left(p_{1}, \delta\right):\left\{\left(p_{1}-w_{1}\right) D\left(p_{1}\right)-\delta x\right\}$ where $\delta=1$ if $p_{1} \neq p_{0}$, otherwise 0

Similarly, the manufacturer profit functions are respectively:

$\Pi_{\mathrm{m} 0}=\operatorname{Max}\left(w_{0}\right):\left\{\left(w_{0}-c\right) D\left(p_{0}\right)\right\}$

$\Pi_{\mathrm{m} 1}=\operatorname{Max}\left(w_{1}, \delta\right):\left\{\left(w_{1}-c-\Delta c\right) D\left(p_{1}\right)-\delta y\right\}$ where $\delta=1$ if $w_{1} \neq w_{0}$, otherwise 0 .

where, $w_{\mathrm{i}}$ and $p_{\mathrm{i}}$ are the wholesale and retail prices in period $i$ and $\Pi_{\mathrm{mi}}, \Pi_{\mathrm{ri}}$ being the corresponding profits.

Both the manufacturer and retailer maximize total profits over the two periods. We assume that the feasibility conditions of profit maximization are satisfied, i.e. positive profit maximizing prices are feasible and that demand is positive at such prices.

The retailer and the manufacturer must take their expected $t_{1}$ period solutions into account, in solving for their initial $\left(\mathrm{t}_{0}\right)$ period prices. These $\mathrm{t}_{0}$ prices are then considered when solving for the adjustment $\left(t_{1}\right)$ period prices. Our solution process therefore, is to proceed backward by first solving for the $\mathrm{t}_{1}$ period prices $w_{1}$ and $p_{1}$, given the $\mathrm{t}_{0}$ prices $p_{0}$ and $w_{0}$. We then derive the equilibrium $\mathrm{t}_{0}$ prices using the $t_{1}$ period solutions. The equilibrium $t_{1}$ prices can then be obtained by substituting these $t_{0}$ solutions. 
Additionally, in each period, we solve for the prices in a Stackelberg fashion where the manufacturer takes into account the retail reaction function $p(w)$ in setting its wholesale price. For example, the $t_{0}$ period solutions are derived in two stages.

First, the retail reaction function $p_{0}\left(w_{0}\right)$ is obtained from: ${ }^{7}$

$\operatorname{Max}\left(p_{0} ; p_{1}{ }^{\mathrm{e}}\right):\left\{\left(p_{0}-w_{0}\right) D\left(p_{0}\right)\right\}+\left\{\left(p_{1}{ }^{\mathrm{e}}-w_{1}{ }^{\mathrm{e}}\right) D\left(p_{1}{ }^{\mathrm{e}}\right)\right\}$

where, $p_{1} \mathrm{e}=p_{0}+\Delta p^{\mathrm{e}}$ and $w_{1} \mathrm{e}^{\mathrm{e}}=w_{0}+\Delta w^{\mathrm{e}}$, the superscript " $\mathrm{e}$ " denoting the prices expected by the retailer in the adjustment period. Next, this is substituted into the manufacturer problem to solve:

$\operatorname{Max}\left(w_{0} ; w_{1}{ }^{\mathrm{e}}\right):\left\{\left(w_{0}-c\right) D\left(p_{0}\left(w_{0}\right)\right\}+\left\{\left(w_{1}{ }^{\mathrm{e}}-c-\mathrm{E}(\Delta c)\right) D\left(p_{1}{ }^{\mathrm{e}}\right)\right\}\right.$

where, $\mathrm{E}(\Delta c)$ is the expectation of $\Delta c$ based on the distributional assumptions made earlier.

Having set up the general problem, we now consider below the implications for asymmetric pricing.

\subsection{Channel pricing without costs of price adjustment}

We begin by exploring the pricing decisions of channel members when there are no costs of price adjustment $(x=0, y=0)$.

\section{$\underline{\text { Adjustment Period } t_{1}}$}

With no costs of price adjustment in $t_{1}$, from $(1), \delta$ is not a factor in the retail problem. Hence the initial period price has no affect on the adjustment period solutions and we can directly solve for the equilibrium adjustment period prices. The retailer sets $p$ to maximize $\left(p-w_{1}\right) D(p)$, which gives the retailer's price reaction function $p_{1}\left(w_{1}\right)$ that solves:

$p_{1}\left(w_{1}\right)=p\left(w_{1}\right)$ s.t. $p=\frac{w_{1}}{1-1 / \varepsilon_{r 1}}$ where $\varepsilon_{r 1}=\varepsilon_{r 1}\left(w_{1}\right)=-\frac{\partial \log D}{\partial \log p}$

\footnotetext{
${ }^{7}$ We do not include a discount factor for the second period profits. Such a factor does not affect our central results but makes the notations more complex.
} 
Similarly, from (2), the manufacturer sets $w$ to maximize $\left\{(w-(c+\Delta c)) D\left(p_{1}(w)\right)\right\}$. This gives the wholesale price $w_{1}{ }^{*}$ which solves: ${ }^{8}$

$\mathrm{W}=\frac{c+\Delta c}{1-1 / \varepsilon_{m 1}}$, where $\varepsilon_{m 1}=\varepsilon_{m 1}\left(p_{1}(w)\right)=-\frac{\partial \log D}{\partial \log w}$

The equilibrium retail price $p_{1}{ }^{*}$ is then given by: $p_{1}{ }^{*}=p_{1}\left(w_{1}{ }^{*}\right)$.

From (5) and (6), in equilibrium,

$$
w_{1}^{*}=\frac{c+\Delta c}{\left(1-1 / \varepsilon_{m 1}^{*}\right)} \text { and } p_{1}^{*}=\frac{c+\Delta c}{\left(1-1 / \varepsilon_{r 1}^{*}\right)\left(1-1 / \varepsilon_{m 1}^{*}\right)}
$$

\section{$\underline{\text { Initial Period t }} 0$}

In the initial period, since there are no costs of price adjustment, neither the manufacturer nor retailer needs to take into account the impact of initial pricing decisions on later adjustment period actions. The maximization problems therefore become identical to that of the adjustment period except that costs will be $c+\mathrm{E}(\Delta c)$ rather than $c+\Delta c$. By our distributional assumption of $\Delta c$, $\mathrm{E}(\Delta c)=0$. Hence the equilibrium solutions with the appropriate notations are:

$$
w_{0}^{*}=\frac{c}{\left(1-1 / \varepsilon_{m 0}^{*}\right)} \text { and } p_{0}^{*}=\frac{c}{\left(1-1 / \varepsilon_{r 0}^{*}\right)\left(1-1 / \varepsilon_{m 0}^{*}\right)}
$$

Notice from (7) that both $w_{1}{ }^{*}$ and $p_{1}{ }^{*}$ exhibit symmetric pricing pattern - both negative and positive cost changes of similar magnitudes elicits the same magnitude of wholesale and retail price changes. Hence, the channel per se does not lead to any asymmetric price adjustment.

\subsection{Channel pricing with Downstream Costs of Price Adjustment}

Consider now the case, when we allow for downstream costs of price adjustment, $x$ in the earlier set up. In the context of the vertical separation of a distribution channel, these costs lead to asymmetric adjustment of prices. For ease of exposition, we keep $y=0$ in the following discussion.

\footnotetext{
${ }^{8}$ Subsequently, the superscript "**" will be used to denote equilibrium solutions.
} 
When $x>0$, the price adjustment decision of the retailer changes. In the adjustment period $t_{1}$, the retailer will not change prices unless market forces change sufficiently to make such price adjustment worthwhile.

\section{$\underline{\text { Adjustment Period } t_{1}}$}

The retailer's objective function in $\mathrm{t}_{1}$, given the initial pricing decision $p_{0}$ is:

$\Pi_{\mathrm{r} 1}=\operatorname{Max}(p, \delta):\left\{\left(p-w_{1}\right) D(p)-\delta x\right\}$ where $\delta=1$ if $p_{1} \neq p_{0}$, otherwise 0

Here it incurs a cost $x$ when it changes price $(\delta=1)$ from the $t_{0}$ period price $p_{0}$. When it does not change price $(\delta=0)$, it does not incur this cost.

The solutions are obtained first by solving for $\delta=1$ and then for $\delta=0$. In the first case, $x$ is a fixed exogenous parameter, and does not affect the first order conditions. So the retailer's desired price in the adjustment period is the same as previously solved in (7). The retailer's solution is a price reaction function $p_{1}\left(w_{1}\right)$ that solves:

$p_{1}\left(\mathrm{w}_{1}\right)=p\left(\mathrm{w}_{1}\right)$ s.t. $p=\frac{\mathrm{w}_{1}}{1-1 / \varepsilon_{r 1}}$, where $\varepsilon_{r 1}=\varepsilon_{r 1}\left(\mathrm{w}_{1}\right)=-\frac{\partial \log D}{\partial \log p}$

Now, the retailer will implement a new price $(\delta=1)$ only if by doing so it is going to be better off than by staying at $p_{0}$. Therefore, it will not change price $(\delta=0)$ if: $\left(p_{1}\left(w_{1}\right)-w_{1}\right) D\left(p_{1}\left(w_{1}\right)\right)-x \leq\left(p_{0^{-}}\right.$ $\left.w_{1}\right) D\left(p_{0}\right)$. The retailer's solution therefore is:

$p_{1}\left(w_{1}\right)= \begin{cases}p_{1}\left(w_{1}\right) & \text { if } \Gamma\left(p_{1}\left(w_{1}\right), p_{0}, x\right) \\ p_{0} & \text { otherwise }\end{cases}$

where, $\Gamma\left(p_{1}\left(w_{1}\right), p_{0}, x\right)$ denotes that the following condition is satisfied:

$\left\{\Pi_{\mathrm{R}}\left(p_{1}\left(w_{1}\right)\right)-x>\Pi_{\mathrm{R}}\left(p_{0}\right)\right\}$, with $\Pi_{\mathrm{R}}(p)=(p-w) D(p)$.

$\Gamma^{\mathrm{C}}(\bullet)$ therefore denotes complementary condition: $\left\{\Pi_{\mathrm{R}}\left(p_{1}\left(w_{1}\right)\right)-x \leq \Pi_{\mathrm{R}}\left(p_{0}\right)\right\}$ 
To solve the manufacturer problem, recall from (7) that if the retailer reacts to the manufacturer's price change, the optimal wholesale price will be $w_{1}=\frac{c+\Delta c}{\left(1-1 / \varepsilon_{m 1}\right)}$. But the existence of downstream costs of price adjustment creates a region defined by $\Gamma^{\mathrm{C}}(\bullet)$ above, where the retailer does not change its own price. Hence demand would be inelastic to any wholesale price change in that region and the manufacturer will not find it optimal to price as in (7). For wholesale price changes where $\Gamma(\bullet)$ is satisfied however, the retailer will change its price and the manufacturer will find it optimal to price as in (7). Taking this into account the manufacturer's wholesale pricing decision in the adjustment period is:

$w_{1}= \begin{cases}w_{1}=\operatorname{Argmax}_{w}\left((w-(c+\Delta c)) D\left(p_{1}(w)\right)\right. & \text { if } \Gamma\left(p_{1}\left(w_{1}\right), p_{0}, x\right) \\ w_{11}=\operatorname{Argmax}_{w}\left((w-(c+\Delta c)) D\left(p_{0}\right)\right. & \text { otherwise }\end{cases}$

Since $\delta \neq 0$, from (9), the $t_{1}$ period solutions are a function of the $t_{0}$ period prices. We therefore first solve for the $\mathrm{t}_{1}$ prices given the $\mathrm{t}_{0}$ prices $p_{0}$ and $w_{0}$. Subsequently, the $\mathrm{t}_{0}$ solutions $p_{0}{ }^{*}$ and $w_{0}{ }^{*}$ are derived by incorporating the $\mathrm{t}_{1}$ results. These are substituted back, to get the final $\mathrm{t}_{1}$ solutions $p_{1}{ }^{*}$ and $w_{1}{ }^{*}$. In the following we discuss these price adjustment decisions.

Retailer price adjustment decision - Rigidity, but not Asymmetry

Equation (11) implies that there exists a region of small wholesale price changes around zero where retail prices are rigid. To see this, consider the retail solution in (11). Substituting $w_{0}{ }^{*}$ and $p_{0}{ }^{*}$, the $\Gamma^{\mathrm{C}}\left(p_{1}\left(w_{1}\right), p_{0}, x\right)$ condition can be written as $\left\{\Pi_{\mathrm{R}}\left(p_{1}\left(w_{1}\right)\right)-x \leq \Pi_{\mathrm{R}}\left(p_{0}{ }^{*}\right)\right\}$ or $\left(p_{1}\left(w_{1}\right)-w_{1}\right) \mathrm{D}\left(p_{1}\left(w_{1}\right)\right)$ $x \leq\left(p_{0}{ }^{*}-w_{1}\right) \mathrm{D}\left(p_{0}{ }^{*}\right)$. Substituting $w_{1}=w_{0}{ }^{*}+\Delta w$ and rearranging: $\left(p_{1}\left(w_{1}\right)-w_{0}{ }^{*}\right) \mathrm{D}_{1}-\left(p_{0}{ }^{*}-w_{0}{ }^{*}\right) \mathrm{D}_{0}+\left(\mathrm{D}_{0}-\mathrm{D}_{1}\right) \Delta w$ $-x \leq 0$, where $\mathrm{D}_{0}=\mathrm{D}\left(p_{0}{ }^{*}\right)$ and $\mathrm{D}_{1}=\mathrm{D}\left(p_{1}\left(w_{1}\right)\right)$. 
Now, let $K=\left(p_{1}\left(w_{1}\right)-w_{0}{ }^{*}\right) \mathrm{D}_{1}-\left(p_{0}{ }^{*}-w_{0}{ }^{*}\right) \mathrm{D}_{0}$. It must be the case that $K<0$. This is because $p_{0}{ }^{*}$ being the profit maximizing price; the profit $\left(p_{0}{ }^{*}-w_{0}{ }^{*}\right) \mathrm{D}_{0}$ must be greater than profit determined by any other retail price. Therefore, rewrite the $\Gamma^{\mathrm{C}}(\bullet)$ condition as: $-|K|+\left(\mathrm{D}_{0}-\mathrm{D}_{1}\right) \Delta w-x \leq 0$

For $\Delta w=0$ : the condition is identically satisfied.

For $\Delta w>0$ : by assumptions of a well behaved profit function, $p_{1}\left(w_{1}\right)>p_{0}{ }^{*}$. Consequently, $\mathrm{D}_{0}>\mathrm{D}_{1}$, since the demand function is downward sloping. We can then rewrite the $\Gamma^{\mathrm{C}}(\bullet)$ condition as: $-|K|+\left|\left(\mathrm{D}_{0}-\mathrm{D}_{1}\right)\right| \Delta w-x \leq 0$. Clearly therefore, there exists a $\Delta w_{r}=\frac{|K|+x}{\left|D_{0}-D_{1}\right|}>0$ such that the $\Gamma^{\mathrm{C}}(\bullet)$ condition is satisfied only if $\Delta w \leq \Delta w_{\mathrm{r}}$.

For $\Delta w<0$ : by similar logic as above, $p_{1}\left(w_{1}\right)<p_{0}{ }^{*}$ and consequently, $\mathrm{D}_{0}<\mathrm{D}_{1}$. The $\Gamma^{\mathrm{C}}(\bullet)$ condition can then be rewritten as: $-|K|-\left|\left(\mathrm{D}_{0}-\mathrm{D}_{1}\right)\right| \Delta w-x \leq 0$. Therefore, there exists a $\Delta w_{r}=-\frac{|K|+x}{\left|D_{0}-D_{1}\right|}<0$ such that the $\Gamma^{\mathrm{C}}(\bullet)$ condition is satisfied only if $\Delta w \geq \Delta w_{\mathrm{r}}$.

Taken together, the $\Gamma^{\mathrm{C}}(\bullet)$ condition implies a region of small wholesale price changes where the retailer does not change its price. This is given by $-\left|\Delta w_{\mathrm{r}}\right| \leq \Delta w \leq\left|\Delta w_{\mathrm{r}}\right|$ where,

$$
\Delta w_{r}=\frac{\left|\left(p_{1}\left(w_{1}\right)-w_{0}^{*}\right) D\left(p_{1}\left(w_{1}\right)\right)-\left(p_{0}^{*}-w_{0}^{*}\right) D\left(p_{0}^{*}\right)\right|+x}{\left|D\left(p_{0}^{*}\right)-D\left(p_{1}\left(w_{1}\right)\right)\right|}
$$

Since the retail reaction function is of the form $p_{1}(\Delta w)=\frac{w_{0}^{*}+\Delta w}{1-1 / \varepsilon_{r 1}}$, this region of price rigidity still does not suggest asymmetry. In fact, when $|\Delta w|>\left|\Delta w_{\mathrm{r}}\right|$, the retail price adjustment is symmetric in that both negative and positive $\Delta w$ will elicit matching positive and negative retail price adjustments. If we abstract away from the channel and look at the price adjustment decisions of the retailer as an individual economic agent, we are led to conclude that while it leads to price rigidity, 
price adjustment cost per se does not lead to asymmetric pricing. This is a standard result in the costs of adjustment literature ( $c f$. Carlton, 1986; Danziger, 1987; Kashyap, 1995 etc.).

\section{Manufacturer decision - Asymmetry}

When the retail solutions are folded back into the manufacturer problem, the region of retail rigidity can now be obtained as $-\left|\Delta w_{\mathrm{r}}^{*}\right| \leq \Delta w^{*} \leq\left|\Delta w_{\mathrm{r}}^{*}\right|$ where,

$\Delta w_{r}^{*}=\frac{\left|\left(p_{1}^{*}-w_{0}^{*}\right) D\left(p_{1}^{*}\right)-\left(p_{0}^{*}-w_{0}^{*}\right) D\left(p_{0}^{*}\right)\right|+x}{\left|D\left(p_{0}^{*}\right)-D\left(p_{1}^{*}\right)\right|}$

Substituting this, the manufacturer solution is:

$w_{1}=\left\{\begin{array}{lll}w_{1}^{*} & \text { if }\left|\Delta w^{*}\right|>\left|\Delta w_{r}^{*}\right|, & \text { where } w_{1}^{*}=w_{0}^{*}+\Delta w^{*} \\ w_{11}^{*} & \text { if }\left|\Delta w^{*}\right| \leq\left|\Delta w_{r}^{*}\right|, & \text { where } w_{11}^{*}=\operatorname{Argmax}_{w}(w-c-\Delta c) D\left(p_{0}^{*}\right)\end{array}\right.$

Notice in solving for $w_{11}{ }^{*}$ that demand $D\left(p_{0}{ }^{*}\right)$ is unaffected by changes in wholesale costs. Consequently, the maximization problem reduces to one of maximizing $w$, which gives $w_{11}{ }^{*}=w_{0}{ }^{*}+\left|\Delta w_{r}{ }^{*}\right|$ as the solution.

Consider now the nature of the region defined by $\left|\Delta w^{*}\right| \leq\left|\Delta w_{\mathrm{r}}{ }^{*}\right|$. First, note that $\Delta w^{*}$ is the wholesale price adjustment that the manufacturer would make in the absence of any retail costs of price adjustment. Now, if $\Delta c=0$, we have $\Delta w^{*}=0$ and therefore, $w_{1}{ }^{*}=w_{0}{ }^{*}$. Therefore, since $w_{1}^{*}=\frac{c+\Delta c}{\left(1-1 / \varepsilon_{m 1}^{*}\right)}$, we can write $\Delta w^{*}=\frac{\Delta c}{\left(1-1 / \varepsilon_{m 1}^{*}\right)}$. Since $\left(1-1 / \varepsilon_{\mathrm{m} 1}{ }^{*}\right)>0,\left|\Delta w^{*}\right| \leq\left|\Delta w_{\mathrm{r}}{ }^{*}\right|$ can now be rewritten in terms of $\Delta c$ as:

$-\left|\Delta c_{r}\right| \leq \Delta c \leq\left|\Delta c_{r}\right|$ where $\left|\Delta c_{r}\right|=\left|\Delta w_{\mathrm{r}}^{*}\right|\left(1-1 / \mathcal{E}_{\mathrm{m} 1}{ }^{*}\right)$

Substituting this, the manufacturer solutions can now be expressed as:

$$
w_{1}= \begin{cases}\frac{c+\Delta c}{\left(1-1 / \varepsilon_{m 1}^{*}\right)} & \text { if }|\Delta c|>\left|\Delta c_{r}\right| \\ w_{0}^{*}+\left|\Delta w_{r}^{*}\right| & \text { if }-\left|\Delta c_{r}\right| \leq \Delta c \leq\left|\Delta c_{r}\right|\end{cases}
$$


Consider the implication of the above solution for wholesale prices. For changes in costs that are large, whether positive or negative - i.e. when $|\Delta c|>\left|\Delta c_{r}\right|$, we have symmetric adjustment because wholesale price changes by commensurate amounts in either directions.

However, for changes in costs that are small, i.e. in the range $-\left|\Delta c_{r}\right| \leq \Delta c \leq\left|\Delta c_{r}\right|$, we have asymmetric adjustment. The asymmetry can be seen from the following: when the cost change is non-negative $\left(0 \leq \Delta c \leq \Delta c_{r}\right)$, the wholesale price goes up by the amount $\left|\Delta w_{r}{ }^{*}\right|$ but when the cost change is negative $\left(-\Delta c_{r} \leq \Delta c<0\right)$, not only does the wholesale price not come down, but it actually increases by the same magnitude. To relate it back to our earlier definitions of asymmetry - given identical magnitudes of small positive and negative cost changes in the range $-\left|\Delta c_{r}\right| \leq \Delta c \leq\left|\Delta c_{r}\right|$, the likelihood of prices rising following $\Delta c \geq 0$ is greater than the likelihood of prices falling following $\Delta c<0$

The asymmetry above is driven by the retail costs of price adjustment, $x$ and the concomitant retail rigidity. If the manufacturer knows that the retailer's price adjustment is costly, it will have an incentive to raise wholesale prices, and a disincentive to lower them, in the region of rigidity for the retailers. The incentives these retail costs of price adjustment create for asymmetric pricing by manufacturers is the heart of our argument in this paper.

\section{$\underline{\underline{\text { Initial Period t }}} \underline{0}$}

In the initial period the retailer's solution would take into account the expected wholesale prices in the next period, $w_{1}{ }^{\mathrm{e}}=w_{0}+\Delta w^{\mathrm{e}}$. In equilibrium, $w_{1}{ }^{\mathrm{e}}=w_{0}{ }^{*}+\mid \Delta w_{r}{ }^{*}$. The retailer changes price in $\mathrm{t}_{1}$ only if $|\Delta w|>\left|\Delta w_{r}{ }^{*}\right|$, otherwise its price remains unchanged. Hence, the retailer solves for the price that will maximize profits over the two periods $t_{0}$ and $t_{1}$ as per the following:

$\Pi_{r}=\operatorname{Max}_{p}\left\{\left(p-w_{0}{ }^{*}\right) D(p(w))+\left(p-w_{0}{ }^{*}-\left|\Delta w_{r}{ }^{*}\right|\right) D(p(w))\right\}$

The solution gives $p_{0}{ }^{*}$ which gives: 
$p_{0}^{*}=\frac{2 w_{0}^{*}+\left|\Delta w_{r}^{*}\right|}{2\left(1-1 / \varepsilon_{r 0}^{*}\right)}$, where $\varepsilon_{r 0}^{*}=\varepsilon_{0}\left(p_{0}^{*}\right)=-\frac{\partial \log D}{\partial \log p}$

The forward looking retailer therefore compensates for its cost of adjustment by charging $\frac{\left|\Delta w_{r}^{*}\right|}{2\left(1-1 / \varepsilon_{r 0}^{*}\right)}$ more in the initial period than what it would charge if it did not have any such costs.

To derive the manufacturer price $w_{0}{ }^{*}$, we fold the retail solution into the manufacturer problem. Now, the manufacturer's wholesale prices change in both directions in $t_{1}$ only for large enough cost changes $\left(|\Delta c|>\left|\Delta c_{r}\right|\right)$. For smaller cost changes however, wholesale prices change only upwards, by $\left|\Delta w_{r}{ }^{*}\right|$. In fact, this is true even if there is no change in costs. Since $\mathrm{E}(\Delta c)=0$, in equilibrium, the manufacturer solution must incorporate this upwards adjustment in $\mathrm{t}_{1}$.

To set $w_{0}{ }^{*}$ therefore, the manufacturer maximizes over the two periods as:

$\Pi_{m}=\operatorname{Max}_{w}\left\{(w-c) D\left(p_{0}(w)\right)+\left(w+\left|\Delta w_{r}^{*}\right|-c\right) D\left(p_{0}(w)\right)\right\}$

The solution gives,

$w_{0}^{*}=\frac{2 c-\left|\Delta w_{r}^{*}\right|}{2\left(1-1 / \varepsilon_{m 0}^{*}\right)}$, where $\varepsilon_{m 0}^{*}=\varepsilon_{0}\left(p_{0}^{*}\left(w_{0}^{*}\right)\right)=-\frac{\partial \log D}{\partial \log w}$

Notice that the $\mathrm{t}_{0}$ prices of the manufacturer are $\frac{\left|\Delta w_{r}^{*}\right|}{2\left(1-1 / \varepsilon_{m 0}^{*}\right)}$ less than the price that would be if there were no costs of price changes in the channel.

To summarize, the equilibrium channel prices are:

$$
\left(p_{1}, w_{1}\right)= \begin{cases}\left(\frac{c+\Delta c}{\left(1-1 / \varepsilon_{r 1}^{*}\right)\left(1-1 / \varepsilon_{m 1}^{*}\right)}, \frac{c+\Delta c}{\left(1-1 / \varepsilon_{m 1}^{*}\right)}\right) & \text { if }|\Delta c|>\left|\Delta c_{r}\right| \\ \left(p_{0}^{*}, w_{0}^{*}+\left|\Delta w_{r}^{*}\right|\right) & \text { if }-\left|\Delta c_{r}\right| \leq \Delta c \leq\left|\Delta c_{r}\right|\end{cases}
$$


$\left(p_{0}^{*}, w_{0}^{*}\right)=\left(\frac{2 c-\left|\Delta w_{r}^{*}\right|\left(1 / \varepsilon_{m 0}^{*}\right)}{2\left(1-1 / \varepsilon_{r 0}^{*}\right)\left(1-1 / \varepsilon_{m 0}^{*}\right)}, \frac{2 c-\left|\Delta w_{r}^{*}\right|}{2\left(1-1 / \varepsilon_{m 0}^{*}\right)}\right)$

In the adjustment period, for retail prices, the solutions imply symmetric adjustment for large cost changes $\left(|\Delta c|>\left|\Delta c_{r}\right|\right)$, but rigidity when cost changes are small enough $\left(-\left|\Delta c_{r}\right| \leq \Delta c \leq\left|\Delta c_{r}\right|\right)$. For wholesale prices however, the implications are different. While, for large cost changes, the adjustments are symmetric, for small changes we now have asymmetry. Retailers take this into account in setting their initial prices and manufacturers take retailers into account in setting the initial wholesale price as well. Thus we have rational expectations for all channel participants.

The above discussions lead to the following research proposition:

Proposition 1: There is a range of cost changes for which the manufacturer will adjust its wholesale prices asymmetrically. In particular, the manufacturer will only adjust its prices upwards regardless of the direction of cost changes, in a region of cost changes of small magnitudes: $-\left|\Delta c_{r}\right| \leq \Delta c \leq\left|\Delta c_{r}\right|$. For cost changes of larger magnitudes, the wholesale prices will adjust symmetrically.

We address the consequences of upstream costs of price adjustment, $y$ in the Appendix. These costs imply regions of wholesale price rigidity, but not asymmetry. Our main results are robust to reasonable specifications of $y$. More specifically, when $y$ is small relative to $x(y \ll x)$ and does not cause wholesale prices to remain unchanged, the asymmetry results are identical.

\section{Empirical Validation}

Our general empirical approach is to test the main implications of the model using upstream price data. Typically however, upstream data are difficult to get. Therefore, we first choose a context that broadly satisfies some of the key assumptions of the model and then use the available scanner data that also has upstream prices. Specifically, we use scanner data from a large Midwestern supermarket chain. 


\section{3a. Implications of the Model}

Our theory predicts that for small cost changes (indirectly observed by small wholesale changes) wholesale prices are more likely to change in the positive direction than in the negative, but for large cost changes (indirectly observed by large wholesale changes) wholesale prices should not exhibit any such systematic pattern. It follows, therefore, that positive wholesale price changes are more likely than negative wholesale price changes when the magnitude of change is small but they are equally likely when the magnitude of change is large. In other words, wholesale prices will exhibit asymmetry in the small but not in the large.

Moreover, recall that our results were derived in the absence of inflationary trends. Therefore, this pattern should be independent of inflation. In other words, we expect that the pattern of asymmetry in the small will be observed in non-inflationary periods as well. ${ }^{9}$ The availability of data that cover a long time span enables us to examine this implication by separating the data into inflation-period, low-inflation-period, and deflation-period sub-samples.

\section{$\underline{\text { 3b. Data }}$}

To examine the empirical validity of the model's implications, we use data from Dominick's Finer Food (DFF), which is one of the largest retail supermarket chains in the larger Chicago metropolitan area, operating 94 stores with a market share of about 25 percent. Large multi-store U.S. Supermarket chains of this type made up about $\$ 310,146,666,000$ in total annual sales in 1992 , which was $86.3 \%$ of total retail grocery sales (Supermarket Business, 1993). In 1999 the retail grocery sales has reached $\$ 435$ billion. Thus the chain we study is a representative of a major class of the retail grocery trade. Moreover, Dominick's type multi-store supermarket chains' sales

\footnotetext{
${ }^{9}$ Note that we abstain from defining what might constitute a "small" price change because its precise magnitude will vary with the size of the price adjustment cost as well as with various demand factors. Instead, we focus on what it implies in terms of the observable behavior of the wholesale price by letting the data tell us what may constitute a "small" price change. See the discussion in the results' section below.
} 
constitute about 14 percent of the total retail sales of about $\$ 2,250$ billion in the US. Since retail sales account for about 9.3 percent of the GDP, our data set is a representative of as much as 1.28 percent of the GDP, which seems substantial. Thus the market we are studying has a quantitative economic significance as well.

The data consist of up to 400 weekly observations of wholesale prices covering the period from September 14, 1989 to May 8, 1997. ${ }^{10}$ The length of individual product's price time series, however, varies depending on when the data collection for the specific category began and ended. Note that Dominick's UPC-level database does not include all products the chain sells. The database includes 29 different product categories, representing approximately 30 percent of Dominick's revenues (see Table 4). ${ }^{11}$

Dominick's sets its prices on a chain-wide basis at the corporate headquarters, but there may still be some price variation across the chain's stores depending on the competitive market structure in and around the location of the individual stores (Levy, et al., 2002, Dutta et al., 2002). According to Barsky et al. (2003), Dominick's in general maintains three price zones depending on the local market conditions. For example, if a particular store of the chain is located in the vicinity of a Cub Food store, then the store may be designated a "Cub-fighter" and as such, it may pursue a more aggressive pricing policy in comparison to the stores located in other zones. In the analysis described below we have used all the data available from all stores.

The wholesale price data we have is not direct. Rather, they are calculated indirectly, from the retail prices reported in the chain's scanner database, which are the actual retail transaction prices (i.e., the price customers paid at the cash register each week), and the profit margin the supermarket makes on each product. Thus, the wholesale price series we use are calculated according to the

\footnotetext{
${ }^{10}$ The wholesale prices here are the Average Acquisition Costs (AAC) - see a later section for a discussion.

${ }^{11}$ Note that the data for Beer and Cigarette categories may be problematic. Unlike the others, they are subject to various kinds of tax rules and government regulations such as restrictions on sales and promotional practices. We nevertheless present the results for all 29 categories for the sake of completeness.
} 
formula $\mathrm{P}_{\mathrm{w}}=(1-\mathrm{m}) \mathrm{P}_{\mathrm{r}}$, where $\mathrm{P}_{\mathrm{w}}$ denotes the wholesale price, $\mathrm{m}$ denotes the gross margin measured as a percentage of the retail price, and $\mathrm{P}_{\mathrm{r}}$ denotes the retail price. ${ }^{12}$

\section{3c. Relevance of the Empirical Context}

Before discussing the data analysis results, let us briefly consider the similarity of the data we are studying - wholesale price data, and their source - a large retail supermarket chain, to the environment envisioned by the model described in the theoretical section of the paper. In particular we want to assess the empirical validity of some of the assumptions on which the model is based.

The first assumption of the model is that the retailer faces costs of price adjustment. How valid is this assumption? In a recent series of papers, a group of scholars from marketing, economics, and organizational behavior, study price change process and its cost at five large US supermarket chains each operating between 100 to over 1,000 stores, and demonstrate “...that changing prices in these establishments is a complex process, requiring dozens of steps, and nontrivial amount of resources" (Levy, et al., 1997, p. 791). They provide direct measures of these costs, finding that they lead to over $\$ 100,000$ per store annually (over 35 percent of the net margin) at major grocery chains like the one examined in this study. ${ }^{13}$ Slade (1998) also estimates these costs to be as high as $\$ 2.72$ per price change in grocery store chains of similar characteristics. Thus, it has been documented in these studies that retail supermarket chains not only face costs of price adjustment, but that the costs are quite substantial.

A second assumption concerns the relative magnitudes of the manufacturer and retailer costs of price adjustment $(y<<x)$. Although manufacturers also face costs of price adjustment, they may not be as substantial in this industry because of the Robinson-Patman act. This requires that all

\footnotetext{
${ }^{12}$ The dataset reports the variable "profit" which is defined as "the gross margin in percent that DFF makes on the sale of the UPC." See Peltzman (2000) page 501 for a discussion.

${ }^{13}$ The follow-up studies by Levy, et al. (1998), Dutta, et al. (1999), and Zbaracki, et al. (2002), which explore other retail and wholesale settings, further confirm and reinforce the original findings. See also Blinder, et al. (1998).
} 
retailers have access to the same terms and conditions for goods of like grade and quality. Branded consumer packaged goods are often of like grade and quality in this industry (for consumer and logistical reasons). As such, much of the manufacturer pricing is setting the schedule that all retailers have access to. Although this may require a large amount of resources in aggregate, the costs for any particular retailer would be minimal. ${ }^{14}$

Our third assumption is about the fixed nature of the costs of price adjustment. In this regard we have followed the existing theoretical studies of costly price adjustment models, which typically treat the costs as fixed. ${ }^{15}$ But more importantly, the studies by Levy, et al. $(1997,1998)$, Dutta, et al. (1999) and Slade (1998) find that the price adjustment costs the supermarkets face are indeed fixed. ${ }^{16}$ In fact, Slade (1998) estimates that the magnitude of the fixed component of theses costs exceed that of any variable component by a magnitude of about fifteen times. According to Levy et al. (1997), the major steps required to change shelf prices include: tag change preparation, tag change itself, tag change verification, and resolution of price mistakes at the store, zone or corporate level (pp. 798-799; also see their Figure 1). Therefore, many of the cost components, such as the labor time spent during the price tag change process, the cost of printing and delivering new price tags, and the cost of the in-store supervision time, do not change with the size of price change. Thus, our assumption that price adjustment costs the supermarkets face are fixed (as opposed to convex), is consistent with the existing evidence on the nature of such costs in the retail supermarket setting. ${ }^{17}$

\footnotetext{
${ }^{14}$ See Levy et al. (1997) for a discussion of the impact of centralized pricing to reduce the costs of price adjustment. ${ }^{15}$ See, for example, Mankiw (1985) and Danziger (1987).

${ }^{16}$ Alternatively, these costs could vary with the size of price change (i.e., the bigger the price change, the larger is its cost), which is known as "convex price adjustment cost."

${ }^{17}$ However, these costs of price adjustments could be a function of such variables as market share of the products, whether a brand is a national brand or private label, and whether item pricing law is required in the areas where the retailer is operating (Levy et. al. 2003). Examining how retailer's menu cost varies with these variables and its implications on asymmetric pricing are interesting avenues for future research. We thank an anonymous reviewer for pointing us in that direction.
} 
Our fourth assumption is that the manufacturers are aware of the existence of the retail price adjustment costs. This assumption seems reasonable. The retail price change processes and procedures are common knowledge amongst the practitioners. For example, dozens of articles have been published in numerous trade publications covering the supermarket industry on electronic shelf label systems and how can they reduce the price adjustment costs faced by retail supermarket chains, especially in states with item pricing laws. Moreover, many manufacturers of direct store delivery products are themselves engaged in price change management and implementation in these retail stores. These manufacturers are, therefore, intimately familiar with price adjustment complexities and their costs.

Finally, we believe the assumption on demand stability is also reasonable. Most of the product categories included in our data set are mature categories, which have likely reached the limit of their market growth. Moreover, most of the products in these categories are staple goods, which suggest that large demand variations, which would be typical to fashion or fad goods, are unlikely. ${ }^{18}$

\section{$\underline{\text { 3d. Empirical Findings }}$}

Below we analyze the predictions of our theory for the entire data set as well as for each of the individual categories. In each case, we consider the entire sample period as well as two subsamples. One sub-sample includes only those weeks in which the monthly inflation rate was below 0.1 percent, which we call the low-inflation period sample. The other sub-sample includes only those weeks in which the monthly inflation rate was zero percent or less, which we call the deflation period sample. For each sub-sample, we first consider price changes in cents (i.e. in absolute terms and then in percent (i.e. in relative terms). ${ }^{19}$

\footnotetext{
${ }^{18}$ See Cagan (1974), Roll (1984), and Dutta, et al. (2002).

${ }^{19}$ The statistical analysis of these various combinations of sample periods/categories/units of measurement has yielded a total of 180 tables of 50 rows each ( 29 categories +1 all categories combined $\times 3$ samples/sub-samples $\times 2$ units of
} 


\section{Analysis of the Data for the Entire Sample Period}

Recall that according to our theory, we expect to see more positive price changes "in the small." That is, we expect to see more small price increases than decreases. However, as the magnitude of the price change gets larger, we expect these differences to disappear.

The question that naturally arises is what we mean by "small?" Because the answer is not obvious, we have chosen to let the data tell us what may constitute a "small" price change in this market. To accomplish this, we have calculated the frequency of positive and negative price changes for each possible size of price change in cents, 1 cent, 2 cents, 3 cents, etc., up to 100 cents, as well as in percents, 1 percent, 2 percent, 3 percent, etc., up to 100 percent. The results are displayed in Figures $1-3$ and Tables $1-3$, corresponding to the entire sample, the low inflation subsample, and the deflation sub-samples, respectively.

In Figure 1 we report the frequency of positive and negative price changes found in the entire Dominick's database of wholesale prices, that is, when we use all available wholesale price series for all products and all 29 categories, during the entire 8-year sample period. Figure 1(a) displays the frequency of price changes in cents while Figure 1(b) displays the frequency of price changes in percents.

According to Figure 1a, indeed, for small price changes we find systematically more priceincreases than decreases. The difference appears particularly large for price changes of up to about 30 cents. Beyond that, the difference between the frequency of positive and negative price changes quickly disappears as the size of price changes increases. In fact, the two series become virtually indistinguishable beyond that point, at least visually. According to Table 1a, the frequency of price increases exceeds the frequency of price decreases in statistical terms as well: the higher frequency

measurement $=180$ ). While these tables are too many to be included even in the referee's appendix, they are available to interested readers on request. 
of positive price changes is systematically significant for absolute price changes of up to 36 cents. Beyond that the two series crisscross each other without any systematic pattern.

A similar pattern is observed when we consider the frequency of price changes in relative terms, i.e., in percents. For price changes of up to about 8-10 percent, we indeed see more priceincreases than decreases. Beyond that point the two series do not exhibit a clear systematic pattern, as they crisscross each other. Further, the differences between positive and negative price changes slowly disappear. According to the figures in Table 1b, the higher frequency of positive price changes is systematically significant for relative price changes of up to 8 percent. Beyond that the two series crisscross each other without any systematic pattern. Thus, the results we find in terms of both absolute as well as relative terms are consistent with the model's prediction: for small price changes there are more price increases than decreases. The asymmetry disappears, for larger price changes.

Next we consider the behavior of the wholesale price data for individual categories. We looked at the frequency of negative and positive price changes first as a function of the size of price change in cents, and then in percents. ${ }^{20}$

We find that, the frequency of positive price changes exceeds the frequency of negative price changes "in the small" for all 29 categories displayed. For most categories, the difference appears particularly strong for price changes of up to 10-15 cents. Beyond that the two time series exhibit a very similar behavior, often merging with each other. We have conducted formal statistical significance tests for each of the 29 individual categories, and they confirm our interpretation of the results: the frequency of positive price changes exceeds the frequency of negative price changes for all 29 categories included in our sample. According to these tests, for most categories the

\footnotetext{
${ }^{20}$ Only the plots for Toothpastes are given in Figure 5. Due to sheer volume, the rest of the category level plots are included in the technical appendix available at the Marketing Science website.
} 
asymmetry holds for absolute price changes of between 5-20 cents. Table 4 reports these cutoff points for each category.

Now consider the price change behavior in percents. We find that for all categories considered (the category of Beer being the only exception), the frequency of positive price changes exceeds the frequency of negative price changes "in the small." In most cases, "small” visually appears to mean about 5-8 percent change. The results of a formal statistical testing of the hypothesis of asymmetry confirm this conclusion: they indicate that the asymmetry in relative terms holds for price changes in the range of 2-9 percents with the majority of the categories falling in the range of 5-8 percent. Table 4 reports these cutoff points for each category. Thus, the analysis of asymmetry in relative terms reveals a greater homogeneity across the 29 product categories. Overall, we conclude that the wholesale prices of every product category exhibit asymmetric pricing in the small, in both absolute and relative terms.

\section{Analysis of the Data for Low Inflation and Deflation Periods}

A possible criticism of the findings we have reported so far, however, is the fact that during the sample period covered in this study, US was experiencing inflation. In Figure 4 we plot the monthly inflation rate in the US as measured by the Producer Price Index. We use the Producer Price Index because it is likely to be a better indicator of the wholesalers' costs than the more commonly used Consumer Price Index. Given that during the period we study there was inflation in the US, it is possible that the finding we are documenting is merely a reflection of that fact. That is, during inflation period, even if prices go up and down, we would expect that ceteris paribus, prices will go up more often than down.

One possible answer to this criticism, however, is that if the reason for the asymmetry we are documenting is inflation, then we should see more positive than negative price changes not only "in 
the small" but also "in the large." As discussed above, however, the data do not indicate such an asymmetry.

A direct, and perhaps more methodical, response to the above criticism can be given by conducting the following analysis. Let us try and see whether the asymmetric pricing we document "in the small" for the entire sample period, also exists in the data when the observations pertaining to the inflationary periods are excluded from the analysis. Given our large sample of observations, such an analysis is possible.

We have conducted two versions of such an analysis. In the first, we included only those observations during which the monthly Producer Price Index inflation rate did not exceed 0.1 percent, a very low inflation rate by any historical standard. We call this a low/zero inflation sample. In the second version, we took an even more conservative stand by including in the analysis only these observations in which the monthly inflation rate was zero or negative. We call this a deflation period sample.

In Figures $2 \mathrm{a}$ and $2 \mathrm{~b}$ we report the frequency of positive and negative price changes found in the Dominick's wholesale prices during low/zero inflation periods. In Figures $3 \mathrm{a}$ and $3 \mathrm{~b}$ we report the frequency of positive and negative price changes during deflation periods. Figures $2 \mathrm{a}$ and $3 \mathrm{a}$ display the frequency of price changes in cents, and Figures $2 \mathrm{~b}$ and $3 \mathrm{~b}$ in percents. In both low inflation and deflation periods, our substantive conclusions remain the same - we find significantly more price increases than decreases for small price changes. For absolute changes, the difference appears especially big for price changes of up to about 10-15 cents. For percentage changes the difference appears large for changes up to about 5 percent. Beyond these, the difference in the frequency of positive and negative price changes quickly disappears as the size of price change increases. 
The findings remain unchanged for individual categories as well. The results are very similar to the findings reported for the entire data set. With the exception of Beer, the frequency of positive price changes exceeds the frequency of negative price changes "in the small" for all others. Formal statistical significance tests for each of the 28 categories confirmed that the asymmetry holds for absolute price changes of between 5- 20 cents, with the difference being particularly strong between 10-15 cents. In terms of percentage changes, the asymmetry holds for price changes of 11 percent or less, with the majority of the categories falling in the range of 5-8 percent. Beyond these the two time series exhibit a very similar behavior, often merging with each other, in both (cents and \%) cases. Thus, the analysis of asymmetry in relative terms again reveals a greater homogeneity across the 29 product categories. Table 4 reports these cutoff points for each category.

Could the Results be an Artifact of How the Wholesale Prices Are Calculated?

Yet another criticism of our results could be that our findings are a direct result of the manner in which the wholesale prices are calculated. Our wholesale price, as reported in the Dominick's database, is based on the average acquisition cost (AAC). The AAC per unit is calculated as follows:

$$
A A C(t)=\frac{\{\text { Purch }(t) \times \text { price }(t)\}+\{\text { EndInventory }(t-1)-\operatorname{sales}(t)\} \times A A C(t-1)}{\text { TotalInventory }(t)}
$$

where,

$\operatorname{Purch}(\mathrm{t})=$ Inventory bought in $\mathrm{t}$;

price $(\mathrm{t})=$ Per unit wholesale price paid in $\mathrm{t}$;

EndInventory $(\mathrm{t}-1)=$ Inventory at end of $\mathrm{t}-1$;

$\operatorname{Sales}(\mathrm{t})=$ Retail sales at $\mathrm{t}$;

TotalInventory $(\mathrm{t})=$ Total Inventory at $\mathrm{t}$ 


\section{The role of forward buying by retailers}

Can it be claimed that our results could be just an artifact of the manner in which AAC is calculated? Manufacturers often inform the retailer in advance of an impending temporary price reduction, permitting the retailer to completely deplete its inventory and then "forward-buying" to overstock at the lower price (Peltzman, 2000). Since new purchases form a large proportion of the total inventory in this case, the large discount shows up as a commensurately large reduction in AAC. On the other hand, a retailer buys less when the wholesale price goes up. Consequently, a wholesale price increase of the same large magnitude as the decrease considered earlier, will translate into a relatively smaller increase in AAC. Ceteris paribus, it is reasonable to expect that the observed asymmetry in the small therefore may be driven by such forward buying phenomenon. $^{21}$

In the absence of actual wholesale prices, how do we conduct a direct test to check for the above effect? Note that the forward buying rationale suggests that if the manner of calculating AAC was the major driver of the observed asymmetry, it should be more pronounced for products that are subjected to greater degree of forward buying. For products not subject to major fluctuations in its purchases driven by promotional prices, we should expect much lesser degree of such systematic distortion. This leads to the following null proposition which holds true if the manner of computing AAC was the major driver of our results. ${ }^{22}$

Forward Buying Proposition: Products subject to greater degree of forward buying will exhibit greater asymmetry than products that are subject to lesser degree of forward buying.

Unfortunately, we do not have direct data on the degree of forward buying. However, several authors (Hoch and Banerji, 1993; Rao, 1991; Lal, 1990) have suggested that in general, private

\footnotetext{
${ }^{21}$ We thank an anonymous reviewer for alerting us to this potential rival explanation of our results.

22 This is not to be confused with our theoretical proposition earlier. Here we intend to check if the "null," (forward buying is a key driver of the observed asymmetry), can be rejected in favor of the "alternate" (that it is not).
} 
labels are not promoted as heavily, and hence are likely to be forward-bought less than national brands. ${ }^{23}$ Therefore, a comparison of national brands to private labels provides a natural context to test the above proposition. In essence, if forward buying is the main driver of our results, the predicted asymmetry should be stronger for national brands than for private labels. We therefore undertook two additional analyses to explore whether, and to what extent, can our results be attributed to the method of computing AAC. In the paragraphs below we discuss the data used for the test and briefly summarize the findings.

\section{National Brand versus Private Label Data}

For the purposes of the test we need data on comparable national brand (NB)-private label (PL) product pairs. We base our identification of such NB-PL pairs on a recently published study of Barsky, et al (2003), who use the same Dominick's data to investigate the size of markups for nationally branded products sold in the U.S. retail grocery industry. Their measure of markup is based on a comparison of the prices of matched pairs of NB-PL products. To implement their strategy, therefore, Barsky, et al. (2003) had to identify the product pairs based on several comparability criteria, which included, among other attributes, product's quality, size, packaging, etc. For quality comparison, they used Hoch and Banerji's (1993) PL product quality rankings.

After filtering out the product pairs that were not comparable for various reasons (for example, size differences, quality differences, insufficient number of observations, etc.), Barsky, et al. (2003) were left with 231 matched NB-PL product pairs of comparable size and quality, covering 19 product categories. ${ }^{24}$ These categories are Analgesics, Bottled Juices, Cereals, Cheeses,

\footnotetext{
${ }^{23}$ Hoch and Banerji (1993) suggest national brands will promote more to reduce private label market share (page 61). Also see Pauwels and Srinivasan (2004). Rao (1991) presents evidence from three product categories that shows private labels are promoted less frequently than national brands (Table 1, page 140). Lal (1990) argues based on his theoretical model that "...(the private label) has a constant retail price - that is, it is never promoted" (page 433) and that "... (the empirical evidence) do not contradict the second hypothesis that the local/store brand is promoted less often than the national brands" (page 439).

${ }^{24}$ See Barsky, et al. (2003), Tables 7A.1-7A.19 for a detailed list of the NB-PL product pairs.
} 
Cookies, Crackers, Canned Soups, Dish Detergent, Frozen Entrees, Frozen Juices, Fabric Softeners, Grooming Products, Laundry Detergent, Oatmeal, Snack Crackers, Tooth Pastes, Toothbrushes, Soft Drinks, and Canned Tuna. However, Barsky, et al. (2003) argue that Toothbrushes category is an outlier for its unusually high markup ratio, in comparison to the remaining 18 categories. Consequently, they omit the Toothbrushes category from much of their analysis. ${ }^{25}$ Following their strategy, therefore, we also exclude the category of Toothbrushes from our analysis, which leaves us with 18 categories of matched NB-PL pairs for the analyses.

The first analysis compared the aggregate asymmetries between national brands and private labels. No significant difference was found either in the absolute (cents) or relative (\%) asymmetry thresholds. We also did not find any statistical difference in the degrees of asymmetry, when we considered the difference between the number of positive and negative changes expressed as a percentage of the number of positive changes.

The second analysis compared category level asymmetries between national brands and private labels. Again, we found no evidence to suggest that there is a significant difference between the two groups either in absolute (cents) or relative (\%) terms. ${ }^{26}$

Forward-buying is not a key driver of the observed asymmetry in the small

To conclude, it is unlikely that our empirical results are an artifact of the manner in which the wholesale prices have been calculated. We subject the data to a series of tests to check if there are patterns consistent with the forward buying hypotheses. None of the analyses, whether descriptive, or statistical, provide support for these hypotheses.

Such a conclusion must however, be tempered with the knowledge that we are after all dealing with a derived measure of wholesale prices and a better test of our theory would be with

\footnotetext{
${ }^{25}$ See Barsky, et al., 2003, p. 194.

${ }^{26}$ Details of these tests are in a separate technical appendix available at the Marketing Science website.
} 
actual wholesale prices. Unfortunately, such data is not available. We are not unique in dealing with this problem. A number of other authors who have dealt with it bemoan the lack of proper wholesale price data ( $c f$. Cecchetti, 1986; Peltzman, 2000; Chintagunta, 2002; Levy, et al. 2002; Chevalier, et al. 2003 etc.). Creative approaches like estimating wholesale prices from regression which is particularly common in the empirical industrial organization literature (see Carlton and Perloff, 1994), using aggregate price indexes as a proxy, such as wholesale price index (Cecchetti, 1986), rough accounting estimates (Nevo, 2001), even simulation (Tellis and Zufryden, 1995) are the norm in such cases. Others may ignore explicit consideration of wholesale prices altogether (Gerstner et al., 1994; Pesendorfer, 2001).

While the lack of accurate wholesale price data is unfortunate, we believe that should not hinder theory building in the domain of wholesale prices. Nevertheless, the onus is on the researcher to ensure that any empirical test of theory using weak wholesale data is actually robust to the weakness of the data. It is in that spirit that we conducted these additional checks.

To keep things in perspective therefore, it is necessary to understand that while we stand behind the spirit of our results, we recognize that the verity of the exact magnitudes of the asymmetry we report is subject to some uncertainty.

Overall, by ruling out inflation and forward buying as potential rival explanations of our results, we conclude that our theory offers the most consistent explanation of the observed asymmetry in the small. ${ }^{27}$

\footnotetext{
${ }^{27}$ Other authors using this dataset (e.g. Peltzman, 2000) restrict their sample till September 1994 because of a change in manufacturers' pricing policies from that point in time. To maintain comparability and to rule out this policy change as a driver of our results, we conduct an additional analysis by restricting our sample to the pre-September 1994 period. The details of this test are in the technical appendix available at the Marketing Science website. Our central result remains unaffected by this change, thereby ruling it out as a central driver of our results. We thank an anonymous reviewer for suggesting this additional check.
} 


\section{Discussion}

Our primary goal in this paper is to offer and empirically validate a theory of asymmetric pricing. To this end, we offer a channel based theory of asymmetric pricing - that costs of price adjustment for downstream channel members can create an incentive for asymmetric pricing by upstream channel members. We go on to present evidence of asymmetric wholesale pricing "in the small" with symmetric wholesale pricing "in the large," which is consistent with this theory. To the best of our knowledge, no other paper reports such patterns of asymmetries at the wholesale level.

Theoretically, this paper merges two different lines of research - costs of price adjustment in economics and distribution channels in marketing. By themselves, neither implies asymmetry. Traditional economic theories based on costs of price adjustment suggest that nominal rigidities are usually symmetric, with "prices (responding) similarly to positive and negative shocks" (Ball and Mankiw, 1994; p. 247). Similarly, channels of distribution are often argued to be a source of many pricing distortions, (e.g. double marginalization - Jeuland and Shugan, 1983; free riding - Bergen and John, 1997), but not asymmetry. Taken together however, costs of price adjustment and channels of distribution suggest ranges of asymmetric pricing by the upstream firm.

Since most of the existing research has focused on asymmetric pricing by a single decision maker (primarily, the retailer), we expand the scope of asymmetry research by explicitly exploring the implications of the business-to-business linkages in a channel. This builds on a long tradition in marketing of using the distribution channel to improve our understanding of a variety of marketing issues beyond the traditional scope of the channels literature. ${ }^{28}$.

By combining a channels perspective with the costs of price adjustment perspective, we generate predictions and empirical findings that cannot be easily explained by the existing theories

\footnotetext{
${ }^{28}$ Examples include product introduction and design (Rao and McLaughlin, 1989; Villas-Boas, 1998), unbundling (Wilson et al., 1990), advertising (Bergen and John 1997) etc.
} 
of asymmetric pricing. For example, asymmetry that is driven by inflation (Ball and Mankiw, 1994) cannot account for asymmetry in non-inflationary periods, or deflationary periods that we observe in our data. Similarly, market power based explanations for wholesale asymmetry suggest that asymmetric adjustments may be a means to extract monopoly rent from retailers (Benabou and Gertner, 1993; Borenstein and Shepard, 1996). Yet this does not explain why we observe asymmetry in small but not in large wholesale price changes. In the same way, the differences in elasticities and costs across levels of the distribution channel, required to explain asymmetry in Madsen and Yang (1998), does not explain why asymmetry occurs in the small, but not in the large. More generally, Peltzman (2000) concludes, “....attributing asymmetries to imperfect competition is unlikely to be rewarding."

There are also some promising cross-disciplinary theoretical directions this paper suggests. We extend the marketing literature on channels of distribution to explicitly considering the costs of price adjustment and its implications on channels pricing behavior. Traditionally, these costs of price adjustment have been known as "menu costs" (Ball and Mankiw, 1994) and are associated primarily with price rigidity. Although we focus on asymmetric pricing issues, there are many other natural applications for marketers to explore. One direction is how these costs of price adjustment impact pass-through of manufacturer price changes ( $c f$. Kim and Staelin, 1999; Tyagi, 1999). There is a literature in economics called "stages of processing" that is related to channels of distribution. It has considered the extent of pass-through in the context of studying price rigidity/flexibility in stages of processing, but has not explored price asymmetry. The main focus of these studies has been on the effect of the number of stages of processing on the degree of price flexibility. For example, Blanchard (1983) focuses on the role of price adjustment costs on the degree of price rigidity in markets with a stages of processing structure (which though not identical, quite resembles the channels structure), and Basu (1995) who studies the role of price adjustment costs in 
economies with the input-output structure, which is an alternative way of looking at the organization of production in market economies. See also Gordon (1990).

In expanding the costly price adjustment theory to include channels of distribution, we explore how the presence of these costs may fundamentally alter the nature of transactions within the channel, as well. The implications are not just price rigidity, which is a direct effect of these costs, but asymmetric pricing, which is more strategic in nature. This suggests that this literature broaden its consideration to look at the impacts of these costs on the incentives and actions of related parties to transactions.

Empirically, we document systematic evidence of asymmetric pricing that, taken in the context of previous empirical research, is particularly surprising. Specifically, Peltzman (2000) studies the same Dominick's dataset and reports finding no systematic evidence of asymmetry. Yet, our results are actually more complementary than contradictory to Peltzman's. The key differences between the papers are the location and size of asymmetry within the distribution channel. While Peltzman looked downstream, we look for asymmetry in upstream channel prices. This in turn addresses one of Peltzman's own conclusions that the "vertical market linkages" of a distribution channel may be key factors in asymmetric adjustment. Additionally, Peltzman looks for asymmetry overall, both the large and the small without distinguishing between the two. Our results suggest the need to consider differences in asymmetry within the magnitude continuum as well.

Finally, our paper has public policy implications. Generally speaking, marketing scholars over the years have consistently called for greater involvement of marketers in shaping public policy (cf. Alderson, 1937; Guiltinan and Gundlach, 1996). More specifically, policy implications of pricing strategies have been a central concern for a number of marketing researchers (Gerstner and Hess, 1990; Wilkie et al., 1998 etc.). Yet, the literature is relatively sparse and in a recent editorial, Grewal and Compeau (1999) point out that, “...(there is a need for)... marketing researchers to 
examine the public policy issues raised by the strategic pricing practices firms employ."

Asymmetric pricing is such a strategy and has not escaped the view of policy makers who worry about prices that are too quick to rise, but are not clear about the central causes. This is evidenced in headlines such as: "California politicians ask for price caps on electricity" (CNN.com, May 22, 2001), or in comments such as US Vice President Dick Cheney's: “We get politicians who want to go out and blame somebody and allege there is some kind of conspiracy, instead of dealing with the real issues" (CNN.com, May 22, 2001). Our perspective suggests that there may be asymmetric pricing upstream in the channel. But this upstream asymmetry may be bounded by the size of the costs of price adjustment of downstream channel members. Any concern with asymmetric pricing must therefore factor in the efficiency issues inherent in such costs. For example, asymmetric pricing is less likely to be a significant concern for channels that invest in reducing such costs.

\section{Conclusions}

This paper is only another step in our understanding of asymmetric pricing. It does suggest future theoretical work to explore additional implications of costs of price adjustment on pricing, contracting and design of channels of distribution. Presently this theory is only applicable in upstream channel pricing. The logic of asymmetric pricing may be extended to retail pricing decisions as well. A couple of recent papers (Chen et al. 2004; Müller and Ray, 2003) explore the implications for retail pricing decisions. We call for more investigations in the same vein. We did not have access to wholesaler's cost data. If such data were to become available, future empirical work could take advantage of it in order to directly assess the implications of this theory. In addition, future work could explore the cross-category differences (Hoch et al., 1995) in the extent of asymmetry. 
On another note recall that we show asymmetric adjustment of wholesale prices is a subgame perfect equilibrium in a 2-period model. One especially promising area of future theoretical research would be to explore the implications for the results if we extend the model to longer time horizons. Such an extension can be done in several ways. If we merely extend the game to $n$ periods, the results are unlikely to be substantively different from the conclusions we draw from our simpler model. However, the outcomes are not intuitive in a model with repeated strategic interactions between manufacturers and retailers. In this context, note that a benefit of having forward looking retailers in our current model is that - in equilibrium retailers are not disadvantaged by asymmetric pricing in the small - they adjust their initial pricing decisions to reflect this economic reality. So it is not clear that a richer space of punishments, relationships or prices would necessarily be of any improvement to the retailer in this situation. The costs are real, and as such any solution would have to factor them into the equilibrium. Nevertheless, while we suspect that asymmetry will still be an equilibrium outcome, more rigorous theoretical efforts are needed before a definitive answer can be given.

Finally, we hope this paper reinforces the value of bringing scholars in marketing and economics together to study issues of common interest. This paper brings a marketing perspective to this dialog by conducting this investigation in the context of a distribution channel and by considering store-level marketing data. We believe this is the first paper in marketing to incorporate costs of price adjustment explicitly into their analysis. There are a variety of issues in marketing that may benefit from a consideration of these costs of price adjustment in the area of pass-through, promotional pricing, EDLP, etc. It also brings an economic perspective to this dialogue in the work on asymmetric pricing and costs of price adjustment, areas where marketing researchers are relative newcomers but may have important insights and evidence to bring to these areas of inquiry. We feel both disciplines can benefit greatly from these kinds of cross-disciplinary explorations. 


\section{APPENDIX}

\section{A.0 General case of channel with costs of price adjustment}

The general set up of the model is given in the main body of the paper. The solution proceeds by first solving for the $\mathrm{t}_{1}$ prices $w_{1}$ and $p_{1}$, given any $\mathrm{t}_{0}$ prices $p_{0}$ and $w_{0}$. Subsequently, the $\mathrm{t}_{0}$ results are obtained by incorporating the $t_{1}$ solutions. Substituting these back into the $t_{1}$ period solutions gives the final results.

\section{$\underline{\text { Adjustment Period } t_{1}}$}

The solutions are obtained first by solving for $\delta=1$ and then for $\delta=0$. In the first case, $x$ is a fixed exogenous parameter, and does not affect the first order conditions: Hence, $\operatorname{Argmax}_{p}\{(p-$ $w) D(p)-x\}=\operatorname{Argmax}_{p}(p-w) D(p)$. The retailer's price reaction function $p_{1}(w)$ solves:

$$
p(w)=p_{1}(w) \text { s.t. } p=\frac{w}{1-1 / \varepsilon_{r 1}} \text { where } \varepsilon_{r 1}=\varepsilon_{r 1}(w)=-\frac{\partial \log D}{\partial \log p}
$$

Now, the retailer will implement a new price $(\delta=1)$ only if by doing so it is going to be better off than by staying at $p_{0}$. It will not change price $(\delta=0)$ if: $\left(p_{1}(w)-w\right) D\left(p_{1}(w)\right)-x \leq\left(p_{0}-w\right) D\left(p_{0}\right)$. The retailer's solution therefore is:

$$
p(w)= \begin{cases}p_{1}(w), & \text { if } \Gamma\left(\mathrm{p}_{1}(\mathrm{w}), \mathrm{p}_{0}, x\right) \\ p_{0}, & \text { otherwise }\end{cases}
$$

where,

$\Gamma\left(p_{1}(w), p_{0}, x\right) \equiv\left[\Pi_{\mathrm{R}}\left(p_{1}(w)\right)-x>\Pi_{\mathrm{R}}\left(p_{0}\right)\right]$ and $\Pi_{\mathrm{R}}(p)=(p-w) D(p)$.

The $t_{1}$ period wholesale prices for the manufacturer is obtained by solving:

$\Pi_{\mathrm{m} 1}=\operatorname{Max}\left(w_{1}, \delta\right):\left\{\left(w_{1}-c-\Delta c\right) D\left(p_{1}\right)-\delta y\right\}$

The manufacturer incurs a cost $y$ when it changes price $(\delta=1)$ from $w_{0}$. When it does not 
change price, $\delta=0$.

The manufacturer solutions must also internalize the effects of $x$. There are three possible outcomes. The first is, both the manufacturer and the retailer readjust their prices. The second is, the manufacturer does but the retailer does not readjust. The third is, neither readjusts. ${ }^{29}$

The wholesale solutions then are expressed as:

$$
w_{1}= \begin{cases}w_{1} & \text { if } \Gamma\left(p_{1}\left(w_{1}\right), p_{0}, x\right) \text { and } \Phi\left(w_{1}, w_{0}, p\left(w_{1}\right), y\right) \\ w_{11} & \text { if } \Gamma^{C}\left(p_{1}\left(w_{11}\right), p_{0}, x\right) \text { and } \Phi\left(w_{11}, w_{0}, p\left(w_{11}\right), y\right) \\ w_{0} & \text { if } \Phi^{C}\left(w_{11}, w_{0}, p\left(w_{0}\right), y\right)\end{cases}
$$

where, $p(w)$ is the retail reaction function to wholesale prices;

$\Gamma\left(p_{1}(w), p_{0}, x\right) \equiv\left[\Pi_{\mathrm{R}}\left(p_{1}(w)\right)-x>\Pi_{\mathrm{R}}\left(p_{0}\right)\right] ; \Gamma^{\mathrm{C}}(\bullet) \equiv\left[\Pi_{\mathrm{R}}\left(p_{1}(w)\right)-x \leq \Pi_{\mathrm{R}}\left(p_{0}\right)\right] ;$

$\Phi\left(w_{1}, w_{0}, p(w), y\right) \equiv\left[\Pi_{\mathrm{M}}\left(w_{1}\right)-y>\Pi_{\mathrm{M}}\left(w_{0}\right)\right] ; \Phi^{\mathrm{C}}(\bullet) \equiv\left[\Pi_{\mathrm{M}}\left(w_{1}\right)-y \leq \Pi_{\mathrm{M}}\left(w_{0}\right)\right] ;$

$\Pi_{\mathrm{R}}(p)=(p-w) D(p) ; \Pi_{\mathrm{M}}(w)=(w-c-\Delta c) D(p(w))$

$w_{1}=\operatorname{Argmax}_{w}\left\{(w-(c+\Delta c)) D\left(p_{1}(w)\right)\right\}$ s.t. $\Gamma\left(p_{1}\left(w_{1}\right), p_{0}, x\right)$ and $\Phi\left(w_{1}, w_{0}, p\left(w_{1}\right), y\right)$

$w_{11}=\operatorname{Argmax}_{w}\left\{(w-(c+\Delta c)) D\left(p_{0}\right)\right\}$ s.t. $\Gamma^{\mathrm{C}}\left(p_{1}\left(w_{11}\right), p_{0}, x\right)$ and $\Phi\left(w_{11}, w_{0}, p\left(w_{11}\right), y\right)$.

The corresponding retail prices are given by:

$p_{1}= \begin{cases}p_{1} & \text { if } \Gamma\left(p_{1}\left(w_{1}\right), p_{0}, x\right) \text { and } \Phi\left(w_{1}, w_{0}, p\left(w_{1}\right), y\right) \\ p_{0} & \text { otherwise }\end{cases}$

The $\Gamma$ and $\Phi$ conditions in the first rows of both the manufacturer and retailer solutions can now be redefined in terms of the cost changes. In particular, using procedures similar to that used earlier in the main paper, we can show the existence of $\Delta c_{\mathrm{r}}$ and $\Delta c_{\mathrm{m}}$ with properties $\partial\left|\Delta c_{\mathrm{r}}\right| \partial x>0$ and $\partial\left|\Delta c_{\mathrm{m}}\right| / \partial y>0$ respectively, such that:

\footnotetext{
${ }^{29}$ The alternative where the retailer readjusts but the manufacturer does not is not feasible in our setup because if the wholesale prices do not change, retail prices remain unchanged as well.
} 
$\Gamma(\bullet) \Rightarrow|\Delta c|>\left|\Delta c_{\mathrm{r}}\right|$ and, $\Phi(\bullet) \Rightarrow|\Delta c|>\left|\Delta c_{\mathrm{m}}\right|$

\section{$\underline{\text { Initial Period } t_{0}}$}

The $\mathrm{t}_{1}$ solutions are then incorporated into the $\mathrm{t}_{0}$ problem to solve for $p_{0}{ }^{*}$ and $w_{0}{ }^{*}$. First, the retail reaction function $p_{0}\left(w_{0}\right)$ is obtained from:

$\operatorname{Max}\left(p_{0} ; p_{1}^{\mathrm{e}}\right):\left\{\left(p_{0}-w_{0}\right) D\left(p_{0}\right)\right\}+\left\{\left(p_{1}{ }^{\mathrm{e}}-w_{1}{ }^{\mathrm{e}}\right) D\left(p_{1}{ }^{\mathrm{e}}\right)\right\}$

where, $p_{1}{ }^{\mathrm{e}}=p_{0}+\Delta p^{\mathrm{e}}$ and $w_{1}{ }^{\mathrm{e}}=w_{0}+\Delta w^{\mathrm{e}}$, the superscript "e" denoting the prices expected by the retailer in the adjustment period. Next, this is substituted into the manufacturer problem to solve:

$\operatorname{Max}\left(w_{0} ; w_{1}{ }^{\mathrm{e}}\right):\left\{\left(w_{0}-c\right) D\left(p_{0}\left(w_{0}\right)\right\}+\left\{\left(w_{1}{ }^{\mathrm{e}}-c-\mathrm{E}(\Delta c)\right) D\left(p_{1}{ }^{\mathrm{e}}\right)\right\}\right.$

where, $\mathrm{E}(\Delta c)$ is the expectation of $\Delta c$ based on the distributional assumptions made earlier.

The solutions $p_{0}{ }^{*}$ and $w_{0}{ }^{*}$ are then substituted back into the $\mathrm{t}_{1}$ solutions to get $p_{1}{ }^{*}$ and $w_{1}{ }^{*}$.

With this general problem as the background, we will now consider the role of the upstream costs of price adjustment, $y$ for our results. ${ }^{30}$

\section{A.1 Pricing with only upstream costs of price adjustment $(y>0, x \approx 0)$ : Rigidity}

We start by exploring the role of $y$ in isolation of any channel effects. For this we set $x \approx 0$ and let $y>0$. The results show that $y$ by itself only leads to price rigidity but not asymmetry. Adjustment Period $\mathrm{t}_{1}$

The manufacturer will not implement a new price if it is better off by staying at $w_{0}{ }^{*}$. Since $p_{0}{ }^{*}$ remains the profit maximizing retail price if wholesale prices remain at $w_{0}{ }^{*}$, the condition when the wholesale does not change can be written as:

$$
\left\{w_{1}^{*}-(c+\Delta c)\right\} D\left(p_{1}\left(w_{1}^{*}\right)\right)-y \leq\left\{w_{0}^{*}-(c+\Delta c)\right\} D\left(p_{0}^{*}\right) .
$$

The equilibrium channel prices can then be expressed as,

\footnotetext{
${ }^{30}$ For ease of exposition and notational economy, we will henceforth derive the $\mathrm{t}_{1}$ period solutions as functions of $w_{0}{ }^{*}$ and $p_{0}{ }^{*}$ and solve for the functional forms of $w_{0}{ }^{*}$ and $p_{0}{ }^{*}$ later when solving the $\mathrm{t}_{0}$ period problem.
} 
$\left(w_{1}, p_{1}\right)= \begin{cases}\left(w_{1}^{*}, p_{1}^{*}\right) & \text { if } \Phi\left(w_{1}^{*}, w_{0}^{*}, p(w), y\right) \\ \left(w_{0}^{*}, p_{0}^{*}\right) & \text { otherwise }\end{cases}$

where, $w_{1}{ }^{*}$ solves $w=\frac{c+\Delta c}{1-1 / \varepsilon_{m 1}} ; p_{1}{ }^{*}=p_{1}\left(w_{1}{ }^{*}\right) ; \Phi$ as defined earlier in (A-5), is given by

$\Phi\left(w_{1}, w_{0}, p(w), y\right) \equiv\left[\Pi_{\mathrm{M}}\left(w_{1}\right)-y>\Pi_{\mathrm{M}}\left(w_{0}\right)\right]$ with $\Pi_{\mathrm{M}}(w)=(w-c-\Delta c) D(p(w))$.

Using procedures similar to earlier, it follows from (A-10) and (A-11) that there exists a $\Delta c_{x 0}$ with the property $\partial\left|\Delta c_{x 0}\right| / \partial y>0$ such that prices are unchanged for $|\Delta c| \leq\left|\Delta c_{x 0}\right|$

Hence the primary contribution of price adjustment costs at the manufacturer end in this setup is price rigidity at both wholesale and retail when cost changes are small enough. For $|\Delta c|>\left|\Delta c_{x 0}\right|$, wholesale prices adjust to $w_{1}{ }^{*}$ and retail prices to $p_{1}{ }^{*}$. Notice that this adjustment pattern is symmetric in that both negative and positive $\Delta c$ will elicit matching positive and negative price adjustments. In fact, if we abstract away from the channel and look at the price adjustment decisions of an individual economic agent (i.e. when $p(w)=w),{ }^{31}$ we are led to conclude that while it leads to price rigidity, price adjustment cost per se does not lead to asymmetric pricing. This is a standard result in the costs of adjustment literature ( $c f$. Carlton, 1986; Danziger, 1987; Kashyap, 1995 etc.).

\section{$\underline{\underline{\text { Initial Period }} \underline{\mathrm{O}}_{0}}$}

Now, note that the rigidity imposed by $y$ creates a potential marginal distortion for the manufacturer of magnitude $\left|\Delta c_{x 0}\right|$. In this region of small costs changes, there would be no change in demand as there would be no change in manufacturer prices. In other words, even if costs were to go up by $\left|\Delta c_{x 0}\right|$ (with the commensurate negative effect on profits), the manufacturer will not adjust its prices in $\mathrm{t}_{1}$. A profit-maximizing manufacturer would incorporate this in its $\mathrm{t}_{0}$ solution. The $\mathrm{t}_{0}$ solution for manufacturer prices therefore, is obtained by setting $\mathrm{E}(\Delta c)=\left|\Delta c_{x 0}\right|$ :

\footnotetext{
${ }^{31}$ Essentially, completely ignoring the existence of the retailer in the above case.
} 
$\operatorname{Max}(w):\left\{(w-c) D\left(p_{0}^{*}\right)+\left(w-c-\left|\Delta c_{x 0}\right|\right) D\left(p_{0}^{*}\right)\right\}$

The solution gives $w_{0}{ }^{*}$ which solves:

$w=\frac{2 c+\left|\Delta c_{x 0}\right|}{2\left(1-1 / \varepsilon_{m 0}\right)}$, where $\varepsilon_{m 0}=\varepsilon_{0}\left(p_{0}(w)\right)=-\frac{\partial \log D}{\partial \log w}$

This price would remain in effect in $\mathrm{t}_{1}$ unless $|\Delta c|>\left|\Delta c_{x 0}\right|$, when as per the $\mathrm{t}_{1}$ period solutions, prices will adjust symmetrically. The manufacturer acting in a forward looking manner, therefore, compensates for its cost of adjustment by charging $\frac{\left|\Delta c_{x 0}\right|}{2\left(1-1 / \varepsilon_{m 0}\right)}$ more in the initial period than what it would charge if it did not have any such costs.

\section{A.2 Pricing with both up- and down-stream costs of price adjustment $(y>0, x>0)$}

We now consider the more general case discussed earlier $(x>0, y>0)$. This explores how $y$ may affect the asymmetry results obtained earlier. The main conclusion is that $y$ implies regions of wholesale price rigidity, but not asymmetry. We start by considering the different cases dependent on the relative magnitude of $y$.

First, for convenience, we present the general solution for period $t_{1}$ in terms of the ranges of cost changes:

$$
\left(w_{1}, p_{1}\right)= \begin{cases}\left(w_{1}^{*}, p_{1}^{*}\right) & \text { if }|\Delta c|>\left|\Delta c_{r}\right| \text { and }|\Delta c|>\left|\Delta c_{m}\right| \\ \left(w_{1}^{*}, p_{0}^{*}\right) & \text { if }|\Delta c| \leq\left|\Delta c_{r}\right| \text { and }|\Delta c|>\left|\Delta c_{m}\right| \\ \left(w_{0}^{*}, p_{0}^{*}\right) & \text { if }|\Delta c| \leq\left|\Delta c_{m}\right|\end{cases}
$$

\section{Large y: Rigidity}

Suppose now, $y$ is large $(y>>x)$. In particular, let $y$ be large enough such that $\left|\Delta c_{m}\right| \geq\left|\Delta c_{\mathrm{r}}\right|{ }^{32}$ $\underline{\text { Adjustment Period } t_{1}}$

\footnotetext{
${ }^{32}$ Recall that $\partial\left|\Delta c_{\mathrm{m}}\right| / \partial y>0$.
} 
When $\left|\Delta c_{m}\right| \geq\left|\Delta c_{\mathrm{r}}\right|$ the condition in the second row of the manufacturer solution is not feasible.

We can then rewrite the equilibrium channel prices in $t_{1}$ as,

$$
\left(w_{1}, p_{1}\right)= \begin{cases}\left(w_{1}^{*}, p_{1}^{*}\right) & \text { if }|\Delta c|>\left|\Delta c_{m}\right| \\ \left(w_{0}^{*}, p_{0}^{*}\right) & \text { otherwise }\end{cases}
$$

Hence, for large $y$, the main implication of price adjustment costs is still one of rigidity in channel prices for small enough cost changes.

\section{$\underline{\text { Initial Period, } \mathrm{t}_{0}}$}

In to, the retailer solution is simply: $p_{0}^{*}=\frac{w_{0}^{*}}{1-1 / \varepsilon_{r 0}^{*}}$.

The manufacturer solution on the other hand is obtained in a manner similar to the earlier subsection, by considering $\Delta c_{m}$ instead of $\Delta c_{x 0}$ :

$$
w_{0}^{*}=\frac{2 c+\left|\Delta c_{m}\right|}{2\left(1-1 / \varepsilon_{m 0}^{*}\right)}, \text { where } \varepsilon_{m 0}^{*}=\varepsilon_{0}\left(p_{0}^{*}\left(w_{0}^{*}\right)\right)=-\frac{\partial \log D}{\partial \log w}
$$

\section{Small y: Asymmetry}

Let $y$ be small: $y<<x$. In particular, let $y$ small enough such that $\left|\Delta c_{m}\right|<\left|\Delta c_{r}\right|$. In this subsection, we will first solve the $t_{1}$ prices and derive the $t_{0}$ prices for the special cases of different magnitudes of $y$ discussed subsequently.

The $t_{1}$ equilibrium prices can be derived from (A-4) and (A-15) which are equivalent. From (A-15), if $\left|\Delta c_{m}\right|<\left|\Delta c_{r}\right|$, then $|\Delta c|>\left|\Delta c_{m}\right|$ is identically satisfied whenever $|\Delta c|>\left|\Delta c_{r}\right|$ and $\left(w_{1}{ }^{*}, p_{1}{ }^{*}\right)$ are the equilibrium prices. Then, $w_{1}^{*}=\frac{c+\Delta c}{1-1 / \varepsilon_{m 1}^{*}}$ is the solution to $\operatorname{Max}_{w}\left\{(w-(c+\Delta c)) D\left(p_{1}(w)\right)\right\}$ s.t. $|\Delta c|>\left|\Delta c_{r}\right|$. 
From the functional form it is clear that, given small $y$, for large enough cost changes $\left(|\Delta c|>\left|\Delta c_{r}\right|\right)$, the wholesale price here is still symmetric with respect to positive and negative directions of cost changes.

$p_{1}{ }^{*}$ can be obtained from the retail reaction function: $p_{1}^{*}=\frac{w_{1}^{*}}{1-1 / \varepsilon_{r 1}^{*}}$.

Now, what happens when the costs changes are small - specifically, $|\Delta c| \leq\left|\Delta c_{\mathrm{r}}\right|$ ? From (A-15) $w_{11}{ }^{*}$ is the solution to $\operatorname{Max}_{w}\left\{(w-(c+\Delta c)) D\left(p_{0}{ }^{*}\right)\right\}$. Using the equivalency between (A-4) and (A-15), since demand is independent of $w$, this maximization boils down simply to maximizing $w$ subject to the conditions $\Gamma^{\mathrm{C}}(\bullet)$ and $\Phi(\bullet)$ in $(\mathrm{A}-4)$. The $\Gamma^{\mathrm{C}}(\bullet)$ implies: $\left(p_{1}{ }^{*}-w_{11}\right) D\left(p_{1}{ }^{*}\right)-x \leq\left(p_{0}{ }^{*}-w_{11}\right) D\left(p_{0}{ }^{*}\right)$. Using procedures similar to that employed earlier, we can express this as

$-\left|\Delta w_{\mathrm{r}}^{*}\right| \leq \Delta w^{*} \leq\left|\Delta w_{\mathrm{r}}^{*}\right|$ where, $\Delta w_{r}^{*}=\frac{\left|\left(p_{1}^{*}-w_{0}^{*}\right) D\left(p_{1}^{*}\right)-\left(p_{0}^{*}-w_{0}^{*}\right) D\left(p_{0}^{*}\right)\right|+x}{\left|D\left(p_{0}^{*}\right)-D\left(p_{1}^{*}\right)\right|}$

Since the maximization exercise involves maximizing the wholesale price, $w_{11}{ }^{*}=w_{0}{ }^{*}+\mid \Delta w_{r}{ }^{*}$ is the profit maximizing solution. ${ }^{33}$ The corresponding $\Phi$ condition can therefore be written as $\left(w_{0}+\left|\Delta w_{\mathrm{r}}^{*}\right|-c-\Delta c\right) D\left(p_{0}^{*}\right)-y>\left(w_{0}^{*}-c-\Delta c\right) D\left(p_{0}^{*}\right)$ or:

$\left|\Delta w_{\mathrm{r}}^{*}\right| D\left(p_{0}^{*}\right)>y$

So, as expected, for small cost changes $\left(|\Delta c| \leq\left|\Delta c_{r}\right|\right)$, the results predict asymmetry. However, this asymmetry appears contingent on certain magnitudes of $y$. So, now let us consider the implication the magnitude of $y$ has on the final solutions.

Let $y^{*}=\left|\Delta w_{r}^{*}\right| D\left(p_{0}^{*}\right)$

\section{Case A: $y>y^{*}$}

\footnotetext{
${ }^{33} w_{11}>w_{11}{ }^{*}$ is not profit maximizing here. In that case, $\Delta w>\Delta w_{r}{ }^{*}$ and the $\Gamma^{\mathrm{C}}$ condition is violated - in other words, the retail price will change and our maximization exercise will be different, with $w_{1}{ }^{*}$ as the profit maximizing outcome.
} 


\section{$\underline{\text { Adjustment period } \mathrm{t}_{1}}$}

If $y>y^{*}$ the corresponding $\Phi$ condition (A-19) is always violated $\left(|\Delta c| \leq\left|\Delta c_{m}\right|\right)$ and manufacturer prices remain unchanged at $w_{0}{ }^{*}$. Without any change in wholesale prices, the retail prices also remain unchanged at ${p_{0}}^{*}$.

Hence, when y is large enough, the results predict rigidity for both upstream and downstream prices.

\section{$\underline{\text { Initial Period } \mathrm{t}_{0}}$}

Since $\left|\Delta c_{m}\right|$ represents the marginal distortion due to its costs of price changes, the manufacturer sets the $w_{0}{ }^{*}$ that maximizes:

$\Pi_{m}=\operatorname{Max}_{\mathrm{w}}\left\{(w-c) D(p(w))+\left(w-c-\left|\Delta c_{m}\right|\right) D(p(w))\right\}$.

The solution gives: $w_{0}{ }^{*}$ which solves:

$w_{0}^{*}=\frac{2 c+\left|\Delta c_{m}\right|}{2\left(1-1 / \varepsilon_{m 0}^{*}\right)}$, where $\varepsilon_{m 0}^{*}=\varepsilon_{0}\left(p_{0}\left(w_{0}^{*}\right)\right)=-\frac{\partial \log D}{\partial \log w}$

As before, the manufacturer, acting in a forward looking manner, therefore, compensates for its cost of adjustment by charging $\frac{\left|\Delta c_{m}\right|}{2\left(1-1 / \varepsilon_{m 0}^{*}\right)}$ more in the initial period than what it would charge if it did not have any such costs.

$p_{0}{ }^{*}$ is obtained by substituting $w_{0}{ }^{*}$ into the retail reaction function: $p_{0}^{*}=\frac{w_{0}^{*}}{1-1 / \varepsilon_{r 1}^{*}}$.

\section{Case B: $0 \leq y \leq y^{*}$}

\section{$\underline{\text { Adjustment Period } \mathrm{t}_{1}}$}

If $y$ is quite small, in particular, if $y \leq y^{*}$, the $\Phi$ condition (A-19) is identically satisfied for all $\Delta c$. When (A-19) is thus satisfied, $w_{11}{ }^{*}=w_{0}{ }^{*}+\mid \Delta w_{r}{ }^{*}$ is the solution. 
The equilibrium channel prices when $0<y \leq y^{*}$ then are:

$\left(w_{1}, p_{1}\right)= \begin{cases}\left(w_{1}^{*}, p_{1}^{*}\right) & \text { if }|\Delta c|>\left|\Delta c_{r}\right| \\ \left(w_{0}^{*}+\left|\Delta w_{r}^{*}\right|, p_{0}^{*}\right) & \text { otherwise }\end{cases}$

$p_{1}{ }^{*}$ can be derived by substituting $w_{1}{ }^{*}$ in the reaction function: $p_{1}^{*}\left(w_{1}^{*}\right)=\frac{w_{1}^{*}}{1-1 / \varepsilon_{r 1}^{*}}$, which would be symmetric to any changes in wholesale prices.

Hence, when $y$ is small enough, the results predict asymmetry for upstream prices. This is very similar to the effect illustrated in the main paper.

\section{$\underline{\text { Initial Period } \mathrm{t}_{0}}$}

The initial period solutions are obtained as solved in the main paper. Essentially, the retailer's solution would take into account the expected wholesale prices in the next period. This price would remain in effect unless $|\Delta w|>\left|\Delta w_{r}{ }^{*}\right|$. The equilibrium retail price at $\mathrm{t}_{0}$ therefore is obtained from:

$\Pi_{r}=\operatorname{Max}_{p}\left\{\left(p-w_{0}{ }^{*}\right) D(p(w))+\left(p-w_{0}{ }^{*}-\left|\Delta w_{r}^{*}\right|\right) D(p(w))\right\}$

The solution gives $p_{0}{ }^{*}$ :

$p_{0}^{*}=\frac{2 w_{0}^{*}+\left|\Delta w_{r}^{*}\right|}{2\left(1-1 / \varepsilon_{r 0}^{*}\right)}$, where $\varepsilon_{r 0}^{*}=\varepsilon_{0}\left(p_{0}^{*}\right)=-\frac{\partial \log D}{\partial \log p}$

To derive the manufacturer prices, we fold the retail solution back into the manufacturer problem. In doing so, we consider the magnitude of the expected cost change and the upward adjustment of the wholesale prices as discussed earlier in the main body of the paper. To set $w_{0}{ }^{*}$ therefore, the manufacturer maximizes over the two periods as:

$\Pi_{m}=\operatorname{Max}_{w}\left\{(w-c) D\left(p_{0}(w)\right)+\left(w+\left|\Delta w_{r}^{*}\right|-c\right) D\left(p_{0}(w)\right)\right\}$

The solution gives, 
$w_{0}{ }^{*}=\frac{2 c-\left|\Delta w_{r}^{*}\right|}{2\left(1-1 / \varepsilon_{m 0}^{*}\right)}$, where $\varepsilon_{m 0}^{*}=\varepsilon_{0}\left(p_{0}^{*}\left(w_{0}^{*}\right)\right)=-\frac{\partial \log D}{\partial \log w}$

These $t_{0}$ prices remain in effect unless the magnitude of the cost change is large enough $\left(|\Delta c|>\left|\Delta c_{r}\right|\right)$ to effect a change in channel prices.

Consider now the implications of the solutions for channel prices. For retail prices, we still predict symmetric adjustment for large cost changes $\left(|\Delta c|>\left|\Delta c_{r}\right|\right)$ but (symmetric) rigidity when cost changes are small enough $\left(|\Delta c| \leq\left|\Delta c_{r}\right|\right)$.

For wholesale prices the results are a function of the magnitude of $y$. When $y$ is large $\left(y>y^{*}\right)$, we get (symmetric) rigidity for small costs changes $\left(|\Delta c| \leq\left|\Delta c_{r}\right|\right)$. When the cost change is large enough $\left(|\Delta c|>\left|\Delta c_{r}\right|\right)$, we get symmetric adjustment. When $y$ is small $\left(y \leq y^{*}\right)$ however, we get asymmetry for small costs changes $\left(|\Delta c| \leq\left|\Delta c_{r}\right|\right)$ and symmetric adjustment for large ones $\left(|\Delta c|>\left|\Delta c_{r}\right|\right)$.

The intuition behind the asymmetry results is derived from the impact of the retailer's costs of price adjustment, $x$ and the resulting retail price rigidity. This creates a region of wholesale price changes (both positive and negative) where the demand is inelastic, leading to the asymmetric adjustment of wholesale prices. The manufacturer costs, $y$ however, does not play any direct role in this asymmetry. Its primary role in this setup is to determine when the manufacturer will not find it profitable to change its wholesale prices. Since retail prices only change following wholesale price changes, this implies that $y$ 's primary contribution is in determining regions of wholesale, and by corollary, retail price rigidity.

Interestingly, wholesale asymmetry (when wholesale price changes in the adjustment period) persists even for very small cost changes in spite of the fact that manufacturer costs of price adjustment $y>0$. This happens because, in the region of retail rigidity, the manufacturer can compensate $y$ by the increase in profits that follows asymmetric positive adjustment. However, this 
is only true for small enough $y$. For large enough $y$, this asymmetry will not happen because the manufacturer cannot compensate $y$ by the increase in profits due to the asymmetric adjustment. If $y$ is so large that the manufacturer will implement only a large wholesale price change, we may not see any rigidity at retail because the magnitude of wholesale price change may be larger than the region of retail rigidity.

It is worthwhile to note that even if wholesale asymmetry is a direct result of retail rigidity, it does not imply that retailers will be taken advantage of. The fact that forward-looking retailers will take these costs into account when setting initial and future prices is a standard result in the economics literature. In our case, the nature of the expected distortions in the adjustment period, introduced by these costs, is incorporated in the initial period prices.

In conclusion, when $y$ is large $(y>>x)$, the main prediction is rigidity in channel prices for small enough cost changes. However, generally speaking, $y<<x .{ }^{34}$ In this case, wholesale price changes are symmetric with respect to large positive and negative cost changes. However, for small cost changes the results predict asymmetry depending on the magnitude of $y$. Specifically, when $y>y^{*}$ where $y^{*}=\left|\Delta w_{r}{ }^{*}\right| D\left(p_{0}{ }^{*}\right)$, the results predict rigidity for both upstream and downstream prices. However, when $y \leq y^{*}$ the results predict asymmetry for upstream prices. This is stated in the following research proposition:

Proposition 1A: When $y$ is small $\left(0<y \leq y^{*}\right)$, there is a range of cost changes for which the manufacturer will adjust its wholesale prices asymmetrically. In particular, the manufacturer will only adjust its prices upwards regardless of the direction of cost changes, in a region of cost changes of small magnitudes: $-\left|\Delta c_{r}\right| \leq \Delta c \leq\left|\Delta c_{r}\right|$. For cost changes of larger magnitudes, the wholesale prices will adjust symmetrically.

\footnotetext{
${ }^{34}$ See the empirical section of the main paper for a discussion.
} 


\section{References}

Alderson, Wroe (1937); “A Marketing View of Competition;” Journal of Marketing, v.1(3), 189190.

Bacon, Robert W. (1991); "Rockets and Feathers: The Asymmetric Speed of Adjustment of UK Retail Gasoline Prices to Cost Changes;” Energy Economics, v.13(3), 211-218.

Ball, Laurence, and N. Gregory Mankiw (1994), “A Sticky-Price Manifesto,” Carnegie-Rochester Conference Series on Public Policy, 127-152.

Ball, Laurence, and N. Gregory Mankiw (1995), "Relative Price Changes as Aggregate Supply Shocks," Quarterly Journal of Economics, Volume 110, No. 1 (February), 161-193.

Barsky, Robert, Mark Bergen, Shantanu Dutta, and Daniel Levy (2003), "What Can the Price Gap between Branded and Generic Products Tell Us About Markups?” in Scanner Data and Price Indexes, edited by R. Feenstra and M. Shapiro, National Bureau of Economic Research, the University of Chicago Press, 165-225.

Basu, Susanto (1995), "Intermediate Goods and Business Cycles: Implications for Productivity and Welfare," American Economic Review, 85, No. 3, 512-531.

Benabou, Roland and Robert Gertner (1993), "Search with Learning from Prices - Does Increased Inflationary Uncertainty lead to Higher Markups?” Review of Economic Studies, Vol. LX, 69-93.

Bergen, Mark, and George John (1997): “Understanding Cooperative Advertising Participation Rates in Conventional Channels;" Journal of Marketing Research, v.XXXIV (Aug), 357369.

Bergen, Mark, Shantanu Dutta and Steven M. Shugan (1996): "Branded Variants: A Retail Perspective;" Journal of Marketing Research, v.XXXIII, 9-19.

Blanchard, Olivier J. (1983), "Price Asynchronization and Price-Level Inertia," in R. Dornbusch and M. Simonsen, Inflation, Debt, and Indexation (Cambridge, MA: MIT Press), 3-24.

Blinder, Alan S., Elie R.D. Canetti, David E. Lebow, and Jeremy B. Rudd (1998), Asking about Prices: A New Approach to Price Stickiness (New York: Russel Sage Foundation).

Borenstein, Severin and Andrea Shepard (1996), "Dynamic Pricing in Retail Gasoline Markets," Rand Journal of Economics, Vol. XXVII, 429-51. 
Borenstein, Severin, Colin A. Cameron and Richard Gilbert (1997), "Do Gasoline Prices Respond Asymmetrically to Crude Oil Price Changes?" Quarterly Journal of Economics, Vol. 112(1), 305-339.

Boyde, Milton S. and Wade B. Brorsen (1988); "Price Asymmetry in the U.S. Pork Marketing Channel;" North Central Journal of Agricultural Economics, v.10(1), 103-109.

Cagan, Philip (1974), "The Hydra-Headed Monster: The Problem of Inflation in the United States," Domestic Affairs Case Study No. 26, American Enterprise Institute, Washington, DC.

Carlton, Dennis W. (1986), “The Rigidity of Prices,” American Economic Review, Vol. 76(4), 63758.

Carlton, Dennis, and Jeffrey Perloff (1994), Modern Industrial Organisation (NY, NY: Harper Collins).

Cecchetti, Steve (1986), "The Frequency of Price Adjustment: A study of the Newsstand Prices of Magazines," Journal of Econometrics 31, 255-274.

Chen, Haipeng, Sourav Ray, Mark Bergen and Daniel Levy (2004); “Asymmetric Price Adjustment "in the Small:" An Implication of Rational Inattention;" manuscript, Winter 2002 North American Meeting of the Econometric Society, Atlanta, USA, January 3-6, 2002.

Chevalier, Judith, Anil Kashyap, and Peter Rossi (2003), "Why Don’t Prices Rise During Periods of Peak Demand? Evidence from Scanner Data," American Economic Review 93(1), 15-37. Chintagunta, Pradeep (2002); "Investigating Category Pricing Behavior in a Retail Chain," Journal of Marketing Research, v.39(2), 141-154.

Choi, S.Chan (1991), "Price Competition in a Channel with a Common Retailer;" Marketing Science, v.10(4), 271-296.

Danziger, Leif (1987), "Inflation, fixed cost of price adjustments, and measurement of relative price variability," American Economic Review, v.77(4), 704-713.

Desai, Preyas S., and Devavrat Purohit (2004), ““'Let Me Talk to My Manager:” Haggling in a Competitive Environment," Marketing Science, v.23(2), 219-233.

DeSarbo, Wayne S., Vithala R. Rao, Joel H. Steckel, Jerry Wind and Richard Colombo (1987); “A Friction Model for Describing and Forecasting Price Changes;" Marketing Science, v.6(4), 299-319.

Dutta, Shantanu, Mark Bergen, and Daniel Levy (2002), "Price Flexibility in Channels of Distribution: Evidence From Scanner Data," Journal of Economic Dynamics and Control, Vol. 26, No. 11, 1845-1900. 
Dutta, Shantanu, Mark Bergen, Daniel Levy, and Robert Venable (1999); "Menu Costs, Posted Prices, and Multiproduct Retailers," Journal of Money, Credit, and Banking, Vol. 31(4), $683-703$.

Gerstner, Eitan and James D. Hess (1990); “Can Bait and Switch Benefit Consumers?” Marketing Science, v.9(2), 114-124.

Gerstner, Eitan; James D. Hess and Duncan M. Holthausen (1994); "Price Discrimination Through a Distribution Channel: Theory and Evidence," American Economic Review, v.84(5), 14371445.

Gordon, Robert J. (1990); "What is New-Keynesian Economics?” Journal of Economic Literature, Vol. 28, No. 3, 1115-1171.

Greenleaf, Eric A. (1995); “The impact of reference price effects on the profitability of price promotions;" Marketing Science, v.14(1), 82-104.

Grewal, Dhruv and Larry D. Compeau (1999); "Pricing and Public Policy: A Research Agenda and an Overview of the Special Issue;" Journal of Public Policy and Marketing, v.18(1), 3-10.

Guiltinan, Joseph P. and Greogory T. Gundlach (1996); “Aggressive and Predatory Pricing: A Framework for Analysis;" Journal of Marketing, v.60(3), 87-102.

Hannan, Timothy H. and Allen N. Berger (1991); "The Rigidity of Prices: Evidence from the Banking Industry;" American Economic Review, v.81(4), 938-945.

Hess, James D. and Eitan Gerstner (1987); "Loss Leader Pricing and Rain Check Policy;” Marketing Science, v.6(4), 358-374.

Hoch, Stephen J., Byung Do Kim, Alan L. Montgomery and Peter E. Rossi (1995), “Determinants of Store-Level Price Elasticity," Journal of Marketing Research, Vol. 32, 17-29.

Hoch, Steve and Shumeet Banerji (1993), “When Do Private Labels Succeed?” Sloan Management Review 34(4), Summer, 57-67.

Ingene, Charles A. and Mark E. Parry (1995); "Channel Coordination When Retailers Compete;" Marketing Science, v.14(4), 360-377.

Iyer, Ganesh (1998); “Coordinating Channels Under Price and Nonprice Competition;” Marketing Science, v.17(4), 338-355.

Jeuland, Abel P. and Steven M. Shugan (1983): "Managing Channel Profits;” Marketing Science, v.2(3), Summer, 239-272. 
Kadiyali, Vrinda, Pradeep Chintagunta and Naufel Vilcassim (2000); "Manufacturer-Retailer Channel Interactions and Implications for Channel Power: An Empirical Investigation of Pricing in a Local Market;" Marketing Science, v.19(2), 127-148.

Karrenbrock, Jeffrey D. (1991); "The Behavior of Retail Gasoline Prices: Symmetric or Not?" Federal Reserve Bank of St. Louis Review, v.73(4), 19-29.

Kashyap, Anil K. (1995), "Sticky Prices: New Evidence from Retail Catalogues,” Quarterly Journal of Economics, Volume 110, No. 1, February, 245-274.

Kim, San Yong and Richard Staelin (1999); "Manufacturer Allowances and Retailer Pass-Through Rates in a Competitive Environment;" Marketing Science, v.18(1), 59-76.

Kopalle, Praveen K., Ambar G. Rao, and Joao L. Assuncao (1996); “Asymmetric Reference Price Effects and Dynamic Pricing Policies;" Marketing Science, v.15(1), 60-85.

Lal, Rajiv (1990), "Manufacturer Trade Deals and Retail Price Promotions," Journal of Marketing Research 27, 428-444.

Levy, Daniel, Benjamin Zeliger, Paul Rubin, Sourav Ray, and Mark Bergen (2003), "On the Inefficiency of Item Pricing Laws", manuscript, Law and Economics Workshop, Summer 2003 NBER, Cambridge, MA, Aug. 1 and 2, 2003.

Levy, Daniel, Mark Bergen, Shantanu Dutta, and Robert Venable (1997), "The Magnitude of Menu Costs: Direct Evidence from Large U.S. Supermarket Chains," Quarterly Journal of Economics, Vol. 112, 791-825.

Levy, Daniel, Shantanu Dutta, and Mark Bergen (2002), "Heterogeneity in Price Rigidity: Evidence from a Case Study Using Micro-Level Data," Journal of Money, Credit, and Banking 34 (1), $197-220$.

Madsen, Jakob B. and Bill Z. Yang (1998), "Asymmetric Price Adjustment in a Menu-cost Model," Journal of Economics, Vol. 68(3), 295-309.

Mankiw, N. Gregory (1985), "Small menu costs and large business cycles: a macroeconomic model of monopoly," Quarterly Journal of Economics, Volume 100, May, 529-539.

Messinger, Paul R. and Chakravarti Narasimhan (1995); "Has Power Shifted in the Grocery Channel?" Marketing Science, v.14(2), 189-223.

Moorthy, K. Sridhar (1988): "Strategic Decentralization in Channels;” Marketing Science, v.7(4), Fall, 335-355.

Müller, Georg and Sourav Ray (2003); “Asymmetric Price Adjustments: A Retail Perspective;" Working Paper, 2001 Midwest Marketing Camp, University of Michigan, Ann Arbor. 
Neumark, David and Steven A. Sharpe (1992), "Market Structure and the Nature of Price Rigidity: Evidence from the Market for Consumer Deposits," Quarterly Journal of Economics, Vol. 107(2), 657-680.

Nevo, Aviv (2001), "Measuring Market Power in the Ready-to-Eat Cereal Industry," Econometrica, v.69(2), 307-342.

Pauwels, Koen, and Shuba Srinivasan (2004), "Who Benefits from Store Brand Entry?” Marketing Science, v.23(3), 364-390.

Peltzman, Sam (2000), "Prices Rise Faster Than They Fall," Journal of Political Economy, Vol. 108(3), 466-502.

Pesendorfer, Martin (2002); "Retail Sales: A Study of Pricing Behavior in Supermarkets," Journal of Business, v.75(1), 33-66.

Pick, Daniel H., Jeffrey Karrenbrock and Hoy F. Carmen, (1991); "Price Asymmetry and Marketing Margin Behavior: An Example for California-Arizona Citrus;" Agribusiness, v.6(1), 75-84

Rao, Ram C. (1991), "Pricing and Promotions in Asymmetric Duopolies," Marketing Science, 10 (2), 131-144.

Rao, Vithala R. and Edward W. McLaughlin (1989); "Modeling the Decision to Add New Products by Channel Intermediaries;" Journal of Marketing, v.53(Jan), 80-88.

Ratchford, Brian T. and Narasimhan Srinivasan (1993); "An Empirical Investigation of Returns to Search," Marketing Science, v.12(1), 73-87.

Roll, Richard (1984), “Orange Juice and Weather," American Economic Review, 74, 861-880.

Slade, Margaret E. (1998): “Optimal Pricing with Costly Adjustment: Evidence from RetailGrocery prices;" Review of Economic Studies, v.65, 87-107.

Tellis, Gerard J. and Fred S. Zufryden (1995), “Tackling the Retailer Decision Maze: Which Brands to Discount, How Much, When and Why?” Marketing Science, v.14(3), 271-299.

Tyagi, Rajeev K. (1999): "A characterization of retailer response to manufacturer trade deals;” Journal of Marketing Research, v.36(4), 510-516.

Villas-Boas, J. Miguel (1998); “Product Line Design for a Distribution Channel;" Marketing Science, v.17(2), 156-169.

Ward, Ronald W. (1982); "Asymmetry in Retail, Wholesale and Shipping Point Pricing for Fresh Vegetables;" American Agricultural Economics Association, v.14 (May), 205-215.

Wilkie, William L., Carl F. Mela and Gregory T. Gundlach (1998); "Does "Bait and Switch" Really Benefit Consumers?” Marketing Science, v.17(3), 273-282. 
Wilson, Lynn O., Allen M. Weiss, and George John (1990); “Unbundling of Industrial Systems;" Journal of Marketing Research, v.XXVII, 123-38.

Zbaracki, Mark, Mark Ritson, Daniel Levy, Shantanu Dutta, and Mark Bergen (2004), “The Managerial and Customer Costs of Price Adjustment: Direct Evidence from Industrial Markets," Review of Economics and Statistics, Vol. 86, No. 2, 514-533. 
Table 1a. All Categories Combined, Entire Sample, Price Changes in Cents

\begin{tabular}{|c|c|c|c|}
\hline Price Change in Cents & Positive & Negative & Z-Value \\
\hline 1 & 2895106 & 2098539 & 356.46 \\
\hline 2 & 1676572 & 1300313 & 218.07 \\
\hline 3 & 1247860 & 1001943 & 163.95 \\
\hline 4 & 986016 & 810011 & 131.33 \\
\hline 5 & 836345 & 662900 & 141.65 \\
\hline 6 & 702145 & 564634 & 122.18 \\
\hline 7 & 619595 & 514363 & 98.82 \\
\hline 8 & 520394 & 448388 & 73.16 \\
\hline 9 & 409297 & 345331 & 73.63 \\
\hline 10 & 357570 & 305687 & 63.71 \\
\hline 11 & 317809 & 282220 & 45.94 \\
\hline 12 & 297657 & 274928 & 30.04 \\
\hline 13 & 283681 & 255998 & 37.68 \\
\hline 14 & 256040 & 233362 & 32.42 \\
\hline 15 & 234609 & 207550 & 40.69 \\
\hline 16 & 204458 & 194157 & 16.32 \\
\hline 17 & 198795 & 177999 & 33.88 \\
\hline 18 & 179168 & 167727 & 19.43 \\
\hline 19 & 182573 & 172934 & 16.17 \\
\hline 20 & 163876 & 154406 & 16.79 \\
\hline 21 & 147867 & 138684 & 17.15 \\
\hline 22 & 140236 & 136270 & 7.54 \\
\hline 23 & 132603 & 127776 & 9.46 \\
\hline 24 & 127366 & 118553 & 17.77 \\
\hline 25 & 132680 & 127664 & 9.83 \\
\hline 26 & 120090 & 112526 & 15.68 \\
\hline 27 & 114587 & 106147 & 17.96 \\
\hline 28 & 98560 & 94870 & 8.39 \\
\hline 29 & 98055 & 94940 & 7.09 \\
\hline 30 & 97295 & 96314 & 2.23 \\
\hline 31 & 89961 & 89116 & 2.00 \\
\hline 32 & 101094 & 92851 & 18.72 \\
\hline 33 & 86914 & 83416 & 8.48 \\
\hline 34 & 85815 & 81700 & 10.05 \\
\hline 35 & 89367 & 85005 & 10.45 \\
\hline 36 & 80315 & 75532 & 12.12 \\
\hline 37 & 85957 & 88666 & -6.48 \\
\hline 38 & 85041 & 80912 & 10.14 \\
\hline 39 & 78067 & 72677 & 13.88 \\
\hline 40 & 70122 & 65406 & 12.81 \\
\hline 41 & 64565 & 60255 & 12.20 \\
\hline 42 & 63398 & 61014 & 6.76 \\
\hline 43 & 70939 & 69516 & 3.80 \\
\hline 44 & 62361 & 61711 & 1.85 \\
\hline 45 & 60022 & 59303 & 2.08 \\
\hline 46 & 58291 & 63867 & -15.95 \\
\hline 47 & 51194 & 51552 & -1.12 \\
\hline 48 & 51733 & 54594 & -8.77 \\
\hline 49 & 46529 & 47104 & -1.88 \\
\hline 50 & 45186 & 46693 & -4.97 \\
\hline
\end{tabular}


Table 1b. All Categories Combined, Entire Sample, Price Change in Percents

\begin{tabular}{|c|c|c|c|}
\hline Price Change in \% & Positive & Negative & Z-Value \\
\hline 1 & 3040097 & 2369790 & 288.19 \\
\hline 2 & 1833178 & 1467749 & 201.13 \\
\hline 3 & 1340358 & 1117787 & 141.96 \\
\hline 4 & 1072180 & 899292 & 123.13 \\
\hline 5 & 765355 & 668618 & 80.78 \\
\hline 6 & 631352 & 592735 & 34.90 \\
\hline 7 & 524601 & 506774 & 17.55 \\
\hline 8 & 480713 & 452409 & 29.30 \\
\hline 9 & 393397 & 393734 & -0.38 \\
\hline 10 & 351780 & 362894 & -13.15 \\
\hline 11 & 322287 & 331016 & -10.80 \\
\hline 12 & 288412 & 326835 & -48.99 \\
\hline 13 & 280326 & 291078 & -14.22 \\
\hline 14 & 250000 & 300384 & -67.91 \\
\hline 15 & 225027 & 271375 & -65.78 \\
\hline 16 & 242802 & 249251 & -9.19 \\
\hline 17 & 221687 & 252551 & -44.82 \\
\hline 18 & 201737 & 234925 & -50.22 \\
\hline 19 & 180080 & 214481 & -54.77 \\
\hline 20 & 201395 & 196250 & 8.16 \\
\hline 21 & 160135 & 192749 & -54.90 \\
\hline 22 & 163640 & 163501 & 0.24 \\
\hline 23 & 144710 & 152282 & -13.89 \\
\hline 24 & 142030 & 138348 & 6.95 \\
\hline 25 & 123762 & 126999 & -6.46 \\
\hline 26 & 126984 & 113861 & 26.74 \\
\hline 27 & 116047 & 111207 & 10.15 \\
\hline 28 & 102891 & 113362 & -22.52 \\
\hline 29 & 97362 & 118163 & -44.81 \\
\hline 30 & 86047 & 90755 & -11.20 \\
\hline 31 & 76570 & 88536 & -29.45 \\
\hline 32 & 77578 & 79606 & -5.12 \\
\hline 33 & 65036 & 72268 & -19.52 \\
\hline 34 & 69211 & 63321 & 16.18 \\
\hline 35 & 63195 & 58258 & 14.17 \\
\hline 36 & 60660 & 54383 & 18.51 \\
\hline 37 & 58841 & 44385 & 44.99 \\
\hline 38 & 55280 & 43987 & 35.84 \\
\hline 39 & 53907 & 38740 & 49.83 \\
\hline 40 & 46866 & 41935 & 16.55 \\
\hline 41 & 67823 & 40201 & 84.04 \\
\hline 42 & 43074 & 35005 & 28.88 \\
\hline 43 & 45052 & 34840 & 36.13 \\
\hline 44 & 40879 & 35856 & 18.13 \\
\hline 45 & 41584 & 39883 & 5.96 \\
\hline 46 & 41443 & 31647 & 36.23 \\
\hline 47 & 30251 & 28806 & 5.95 \\
\hline 48 & 29130 & 31172 & -8.32 \\
\hline 49 & 33433 & 24716 & 36.15 \\
\hline 50 & 28534 & 27389 & 4.84 \\
\hline
\end{tabular}


Table 2a. All Categories Combined, Low Inflation, Price Changes in Cents

\begin{tabular}{|c|c|c|c|}
\hline Price Change in Cents & Positive & Negative & Z-Value \\
\hline 1 & 1563081 & 1145605 & 253.66 \\
\hline 2 & 901586 & 703395 & 156.44 \\
\hline 3 & 670891 & 538954 & 119.95 \\
\hline 4 & 521048 & 430541 & 92.78 \\
\hline 5 & 449189 & 356776 & 102.94 \\
\hline 6 & 374921 & 306464 & 82.93 \\
\hline 7 & 324646 & 273707 & 65.85 \\
\hline 8 & 276121 & 244961 & 43.17 \\
\hline 9 & 214997 & 186572 & 44.86 \\
\hline 10 & 186824 & 171666 & 25.32 \\
\hline 11 & 166624 & 152614 & 24.80 \\
\hline 12 & 155122 & 148049 & 12.85 \\
\hline 13 & 151697 & 140288 & 21.11 \\
\hline 14 & 132013 & 121424 & 21.03 \\
\hline 15 & 123295 & 114419 & 18.20 \\
\hline 16 & 108076 & 106859 & 2.63 \\
\hline 17 & 102463 & 95490 & 15.67 \\
\hline 18 & 95988 & 89244 & 15.67 \\
\hline 19 & 93151 & 92083 & 2.48 \\
\hline 20 & 83270 & 82713 & 1.37 \\
\hline 21 & 79235 & 74453 & 12.20 \\
\hline 22 & 72416 & 74441 & -5.28 \\
\hline 23 & 68190 & 72591 & -11.73 \\
\hline 24 & 66608 & 62577 & 11.22 \\
\hline 25 & 67569 & 64884 & 7.38 \\
\hline 26 & 64555 & 58527 & 17.18 \\
\hline 27 & 60430 & 57106 & 9.70 \\
\hline 28 & 50378 & 49997 & 1.20 \\
\hline 29 & 50175 & 51220 & -3.28 \\
\hline 30 & 48271 & 49089 & -2.62 \\
\hline 31 & 42759 & 42361 & 1.36 \\
\hline 32 & 53628 & 50100 & 10.95 \\
\hline 33 & 42734 & 42949 & -0.73 \\
\hline 34 & 46418 & 44567 & 6.14 \\
\hline 35 & 51159 & 47374 & 12.06 \\
\hline 36 & 41091 & 37720 & 12.01 \\
\hline 37 & 45209 & 46517 & -4.32 \\
\hline 38 & 43291 & 41026 & 7.80 \\
\hline 39 & 39149 & 40027 & -3.12 \\
\hline 40 & 36733 & 33959 & 10.43 \\
\hline 41 & 33701 & 31924 & 6.94 \\
\hline 42 & 33457 & 33174 & 1.10 \\
\hline 43 & 35269 & 35536 & -1.00 \\
\hline 44 & 32423 & 32049 & 1.47 \\
\hline 45 & 29096 & 30832 & -7.09 \\
\hline 46 & 29609 & 33998 & -17.40 \\
\hline 47 & 26487 & 27952 & -6.28 \\
\hline 48 & 25263 & 27273 & -8.77 \\
\hline 49 & 22910 & 23985 & -4.96 \\
\hline 50 & 20586 & 23218 & -12.58 \\
\hline
\end{tabular}


Table 2b. All Categories Combined, Low Inflation, Price Changes in Percents

\begin{tabular}{|c|c|c|c|}
\hline Price Change in \% & Positive & Negative & Z-Value \\
\hline 1 & 1654535 & 1292877 & 210.66 \\
\hline 2 & 987127 & 792036 & 146.26 \\
\hline 3 & 714404 & 610636 & 90.15 \\
\hline 4 & 572131 & 494293 & 75.37 \\
\hline 5 & 404874 & 363633 & 47.04 \\
\hline 6 & 330664 & 314028 & 20.72 \\
\hline 7 & 278831 & 273952 & 6.56 \\
\hline 8 & 256257 & 242442 & 19.56 \\
\hline 9 & 206590 & 214455 & -12.12 \\
\hline 10 & 186363 & 196416 & -16.25 \\
\hline 11 & 168146 & 176572 & -14.35 \\
\hline 12 & 151629 & 179133 & -47.82 \\
\hline 13 & 147464 & 154627 & -13.03 \\
\hline 14 & 129467 & 152450 & -43.29 \\
\hline 15 & 115764 & 141946 & -51.57 \\
\hline 16 & 122650 & 130178 & -14.97 \\
\hline 17 & 116947 & 133105 & -32.31 \\
\hline 18 & 103816 & 123467 & -41.22 \\
\hline 19 & 90744 & 108787 & -40.39 \\
\hline 20 & 98804 & 104223 & -12.03 \\
\hline 21 & 81917 & 101902 & -46.61 \\
\hline 22 & 88062 & 77087 & 27.01 \\
\hline 23 & 72590 & 79946 & -18.83 \\
\hline 24 & 68782 & 73531 & -12.59 \\
\hline 25 & 64974 & 60265 & 13.31 \\
\hline 26 & 66998 & 58793 & 23.13 \\
\hline 27 & 58916 & 56068 & 8.40 \\
\hline 28 & 50181 & 61586 & -34.11 \\
\hline 29 & 49239 & 55522 & -19.41 \\
\hline 30 & 42851 & 44625 & -6.00 \\
\hline 31 & 38489 & 42770 & -15.02 \\
\hline 32 & 37532 & 34864 & 9.92 \\
\hline 33 & 29729 & 33741 & -15.92 \\
\hline 34 & 33954 & 31617 & 9.13 \\
\hline 35 & 31013 & 26232 & 19.98 \\
\hline 36 & 28902 & 27289 & 6.80 \\
\hline 37 & 29610 & 19209 & 47.07 \\
\hline 38 & 27315 & 22345 & 22.30 \\
\hline 39 & 26582 & 18427 & 38.44 \\
\hline 40 & 21786 & 21579 & 0.99 \\
\hline 41 & 30072 & 20970 & 40.29 \\
\hline 42 & 21894 & 17748 & 20.82 \\
\hline 43 & 22440 & 16368 & 30.82 \\
\hline 44 & 19791 & 17235 & 13.28 \\
\hline 45 & 21168 & 19614 & 7.70 \\
\hline 46 & 16818 & 16723 & 0.52 \\
\hline 47 & 13292 & 15199 & -11.30 \\
\hline 48 & 13875 & 16580 & -15.50 \\
\hline 49 & 14877 & 14002 & 5.15 \\
\hline 50 & 13145 & 14266 & -6.77 \\
\hline
\end{tabular}


Table 3a. All Categories Combined, Deflation, Price Changes in Cents

\begin{tabular}{|c|c|c|c|}
\hline Price Change in Cents & Positive & Negative & Z-Value \\
\hline 1 & 1072926 & 797687 & 201.24 \\
\hline 2 & 614350 & 482632 & 125.76 \\
\hline 3 & 463687 & 368254 & 104.63 \\
\hline 4 & 359824 & 292415 & 83.47 \\
\hline 5 & 307434 & 244947 & 84.08 \\
\hline 6 & 256657 & 215861 & 59.35 \\
\hline 7 & 221610 & 188616 & 51.51 \\
\hline 8 & 187334 & 167618 & 33.09 \\
\hline 9 & 149559 & 127189 & 42.52 \\
\hline 10 & 129117 & 115699 & 27.12 \\
\hline 11 & 112853 & 103478 & 20.16 \\
\hline 12 & 106162 & 100130 & 13.28 \\
\hline 13 & 103670 & 95437 & 18.45 \\
\hline 14 & 89093 & 84736 & 10.45 \\
\hline 15 & 84646 & 78955 & 14.07 \\
\hline 16 & 72653 & 72355 & 0.78 \\
\hline 17 & 73377 & 64770 & 23.16 \\
\hline 18 & 65118 & 61508 & 10.14 \\
\hline 19 & 66383 & 65638 & 2.05 \\
\hline 20 & 57643 & 57811 & -0.49 \\
\hline 21 & 56121 & 52181 & 11.97 \\
\hline 22 & 49908 & 50648 & -2.33 \\
\hline 23 & 45871 & 49709 & -12.41 \\
\hline 24 & 43987 & 42410 & 5.37 \\
\hline 25 & 46329 & 43533 & 9.33 \\
\hline 26 & 44724 & 41961 & 9.38 \\
\hline 27 & 39843 & 41019 & -4.14 \\
\hline 28 & 35051 & 34816 & 0.89 \\
\hline 29 & 34420 & 33976 & 1.70 \\
\hline 30 & 34884 & 33819 & 4.06 \\
\hline 31 & 28460 & 29459 & -4.15 \\
\hline 32 & 36880 & 35455 & 5.30 \\
\hline 33 & 29696 & 30226 & -2.17 \\
\hline 34 & 32330 & 29349 & 12.00 \\
\hline 35 & 35189 & 32447 & 10.54 \\
\hline 36 & 27945 & 24826 & 13.58 \\
\hline 37 & 31099 & 31584 & -1.94 \\
\hline 38 & 28197 & 25999 & 9.44 \\
\hline 39 & 26146 & 26556 & -1.79 \\
\hline 40 & 25296 & 23063 & 10.15 \\
\hline 41 & 22027 & 22258 & -1.10 \\
\hline 42 & 21223 & 21430 & -1.00 \\
\hline 43 & 24978 & 25848 & -3.86 \\
\hline 44 & 20919 & 20625 & 1.44 \\
\hline 45 & 19661 & 19357 & 1.54 \\
\hline 46 & 21522 & 23253 & -8.18 \\
\hline 47 & 17895 & 18064 & -0.89 \\
\hline 48 & 18622 & 18908 & -1.48 \\
\hline 49 & 16249 & 17575 & -7.21 \\
\hline 50 & 14401 & 15968 & -8.99 \\
\hline
\end{tabular}


Table 3b. All Categories Combined, Deflation, Price Changes in Percents

\begin{tabular}{|c|c|c|c|}
\hline Price Change in \% & Positive & Negative & Z-Value \\
\hline 1 & 1141220 & 898901 & 169.65 \\
\hline 2 & 681315 & 540571 & 127.33 \\
\hline 3 & 496515 & 418860 & 81.17 \\
\hline 4 & 382480 & 340023 & 49.95 \\
\hline 5 & 283179 & 250915 & 44.15 \\
\hline 6 & 225844 & 213743 & 18.25 \\
\hline 7 & 190062 & 188157 & 3.10 \\
\hline 8 & 172890 & 166784 & 10.48 \\
\hline 9 & 138369 & 147775 & -17.58 \\
\hline 10 & 125667 & 133492 & -15.37 \\
\hline 11 & 117385 & 122344 & -10.13 \\
\hline 12 & 104715 & 128934 & -50.10 \\
\hline 13 & 103438 & 109879 & -13.95 \\
\hline 14 & 91527 & 106677 & -34.03 \\
\hline 15 & 77789 & 95260 & -42.00 \\
\hline 16 & 85445 & 92440 & -16.59 \\
\hline 17 & 78764 & 94632 & -38.11 \\
\hline 18 & 68349 & 84438 & -41.16 \\
\hline 19 & 61441 & 74405 & -35.17 \\
\hline 20 & 71493 & 73817 & -6.10 \\
\hline 21 & 53955 & 71276 & -48.95 \\
\hline 22 & 58647 & 54368 & 12.73 \\
\hline 23 & 48101 & 54147 & -18.91 \\
\hline 24 & 46712 & 50332 & -11.62 \\
\hline 25 & 46113 & 41600 & 15.24 \\
\hline 26 & 48012 & 41220 & 22.74 \\
\hline 27 & 39136 & 38728 & 1.46 \\
\hline 28 & 35798 & 43910 & -28.73 \\
\hline 29 & 33218 & 37130 & -14.75 \\
\hline 30 & 29206 & 30894 & -6.89 \\
\hline 31 & 25421 & 29572 & -17.70 \\
\hline 32 & 26895 & 25625 & 5.54 \\
\hline 33 & 21690 & 23114 & -6.73 \\
\hline 34 & 25150 & 21731 & 15.79 \\
\hline 35 & 21084 & 18316 & 13.94 \\
\hline 36 & 20576 & 20044 & 2.64 \\
\hline 37 & 21365 & 12417 & 48.68 \\
\hline 38 & 19234 & 15076 & 22.45 \\
\hline 39 & 18150 & 12685 & 31.12 \\
\hline 40 & 15093 & 14572 & 3.02 \\
\hline 41 & 20177 & 13296 & 37.61 \\
\hline 42 & 16177 & 10801 & 32.73 \\
\hline 43 & 14710 & 11249 & 21.48 \\
\hline 44 & 13787 & 11451 & 14.70 \\
\hline 45 & 14500 & 11752 & 16.96 \\
\hline 46 & 12246 & 10721 & 10.06 \\
\hline 47 & 9181 & 9836 & -4.75 \\
\hline 48 & 9559 & 9216 & 2.50 \\
\hline 49 & 10395 & 9177 & 8.71 \\
\hline 50 & 8778 & 9945 & -8.53 \\
\hline
\end{tabular}


Table 4. What Might Constitute a "Small" Price Change

Statistical Analysis of the Data by Product Category in Absolute (Cents) and Relative (\%) Terms

\begin{tabular}{|c|c|c|c|c|c|c|}
\hline & \multicolumn{2}{|c|}{ Entire Sample Period } & \multicolumn{2}{|c|}{ Low/Zero Inflation Period } & \multicolumn{2}{|c|}{ Deflation Period } \\
\hline & $\begin{array}{l}\text { Absolut } \\
\mathrm{e} \\
\text { (Cents) }\end{array}$ & $\begin{array}{l}\text { Relativ } \\
\text { e (\%) }\end{array}$ & $\begin{array}{l}\text { Absolute } \\
\text { (Cents) }\end{array}$ & $\begin{array}{l}\text { Relative } \\
(\%)\end{array}$ & $\begin{array}{l}\text { Absolut } \\
\mathrm{e} \\
\text { (Cents) }\end{array}$ & $\begin{array}{l}\text { Relative } \\
(\%)\end{array}$ \\
\hline Analgesics & 30 & 8 & 21 & 10 & 3 & 7 \\
\hline Bath Soap & 10 & 2 & 2 & 1 & 2 & 1 \\
\hline Bathroom Tissues & 11 & 4 & 9 & 1 & 10 & 1 \\
\hline Beer & 3 & 0 & 0 & 2 & 0 & 2 \\
\hline Bottled Juices & 13 & 5 & 21 & 11 & 9 & 5 \\
\hline Canned Soup & 13 & 8 & 9 & 7 & 6 & 8 \\
\hline Canned Tuna & 3 & 2 & 3 & 1 & 4 & 2 \\
\hline Cereals & 33 & 9 & 19 & 9 & 19 & 9 \\
\hline Cheeses & 18 & 6 & 9 & 3 & 5 & 3 \\
\hline Cigarettes & 14 & 8 & 1 & 8 & 1 & 3 \\
\hline Cookies & 11 & 6 & 11 & 6 & 11 & 8 \\
\hline Crackers & 15 & 6 & 15 & 5 & 15 & 8 \\
\hline Dish Detergent & 4 & 2 & 4 & 1 & 4 & 1 \\
\hline Fabric Softeners & 5 & 2 & 8 & 3 & 2 & 3 \\
\hline Front-end-candies & 7 & 9 & 6 & 8 & 6 & 5 \\
\hline Frozen Dinners & 6 & 1 & 3 & 1 & 3 & 1 \\
\hline Frozen Entrees & 30 & 5 & 17 & 8 & 8 & 6 \\
\hline Frozen Juices & 9 & 5 & 7 & 6 & 9 & 7 \\
\hline Grooming Products & 12 & 8 & 15 & 8 & 13 & 8 \\
\hline Laundry Detergents & 8 & 2 & 8 & 2 & 6 & 2 \\
\hline Oatmeal & 7 & 7 & 2 & 1 & 2 & 1 \\
\hline Paper Towels & 1 & 2 & 3 & 4 & 10 & 4 \\
\hline Refrigerated Juices & 10 & 6 & 8 & 4 & 4 & 2 \\
\hline Shampoos & 13 & 7 & 10 & 6 & 13 & 7 \\
\hline Snack Crackers & 7 & 5 & 7 & 5 & 7 & 3 \\
\hline Soaps & 7 & 4 & 9 & 4 & 5 & 3 \\
\hline Soft Drinks & 23 & 9 & 14 & 11 & 14 & 8 \\
\hline Tooth Brushes & 9 & 8 & 9 & 7 & 11 & 7 \\
\hline Tooth Pastes & 16 & 5 & 10 & 4 & 10 & 4 \\
\hline $\begin{array}{l}\text { Total (All } 29 \text { Categories } \\
\text { Combined) }\end{array}$ & 36 & 8 & 19 & 8 & 15 & 8 \\
\hline
\end{tabular}

Notes:

1. The figures reported in the table are the cutoff points of what might constitute a "small" price change for each category. For each category, the cutoff point is the first point at which the asymmetry is not supported statistically. Thus, for example, in the Analgesics category, when the entire sample is used and we consider the price changes in cents, we see that for price changes of up to 30 cents, there is asymmetry as our theory predicts. Beyond that point the asymmetry disappears.

2. In all tables, the critical values for $1 \%, 5 \%$ and $10 \%$ significance are $2.575,1.96$, and 1.645 , respectively. 


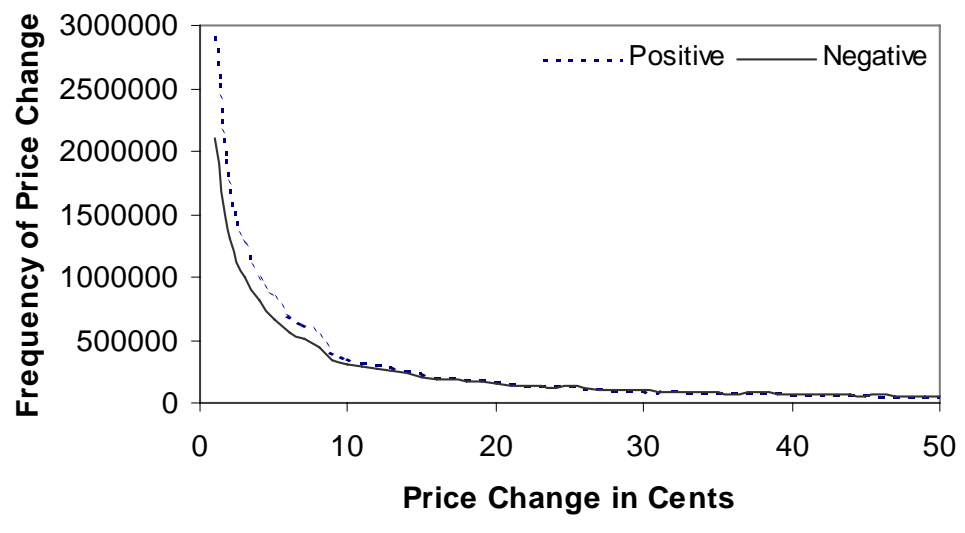

(a)

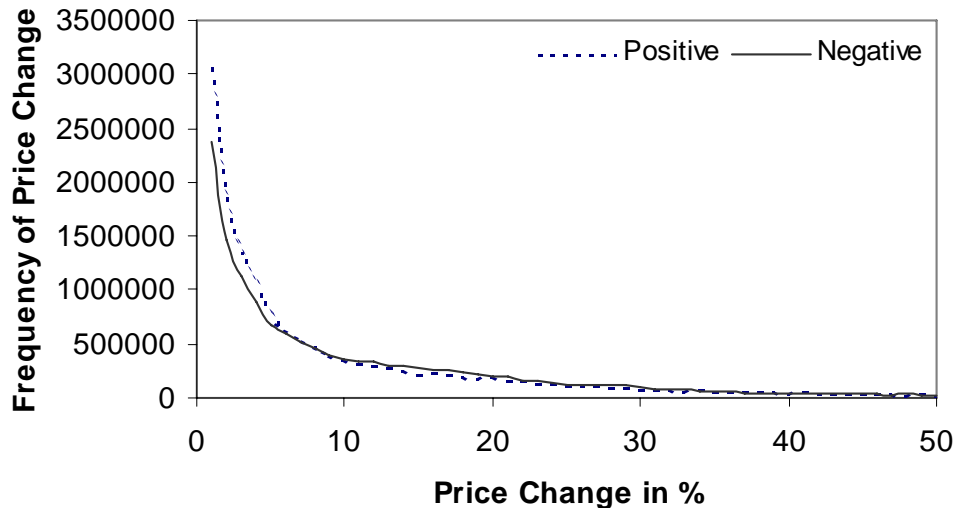

(b)

Figure 1: Frequency of Positive and Negative Wholesale Price Changes: All 29 Categories, Entire Period

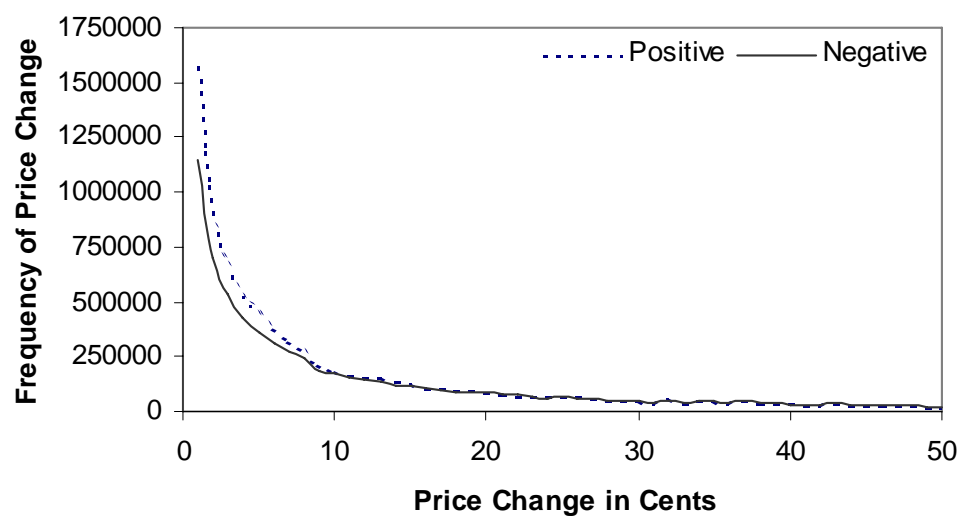

(a)

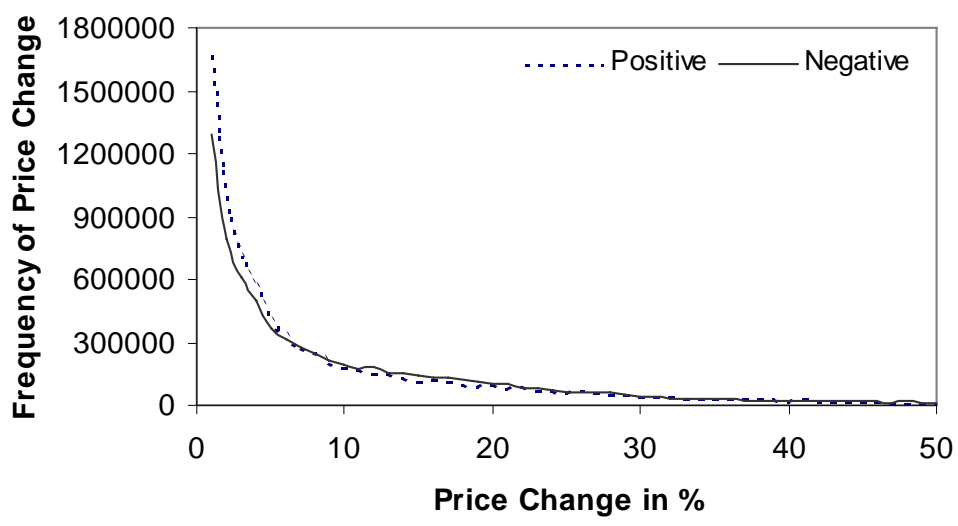

(b)

Figure 2: Frequency of Positive and Negative Wholesale Price Changes: All 29 Categories, Low Inflation Period 


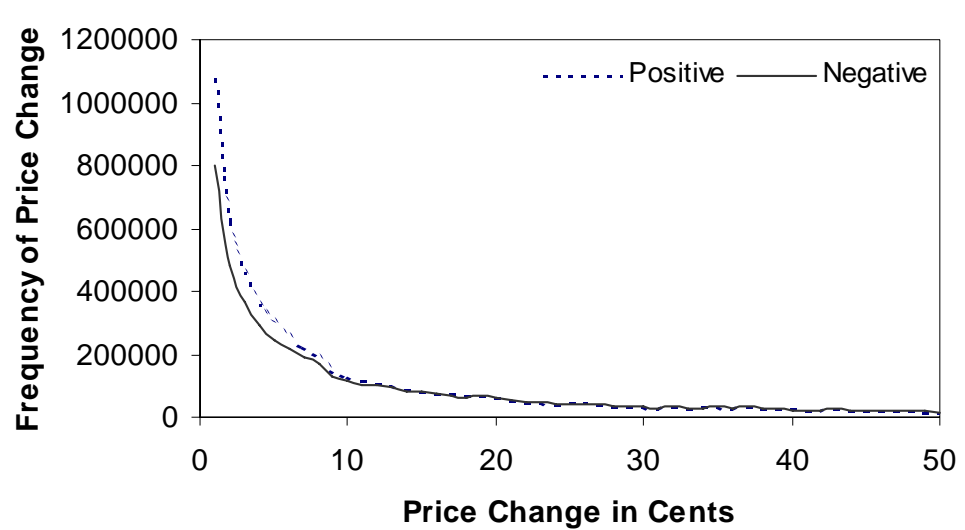

(a)

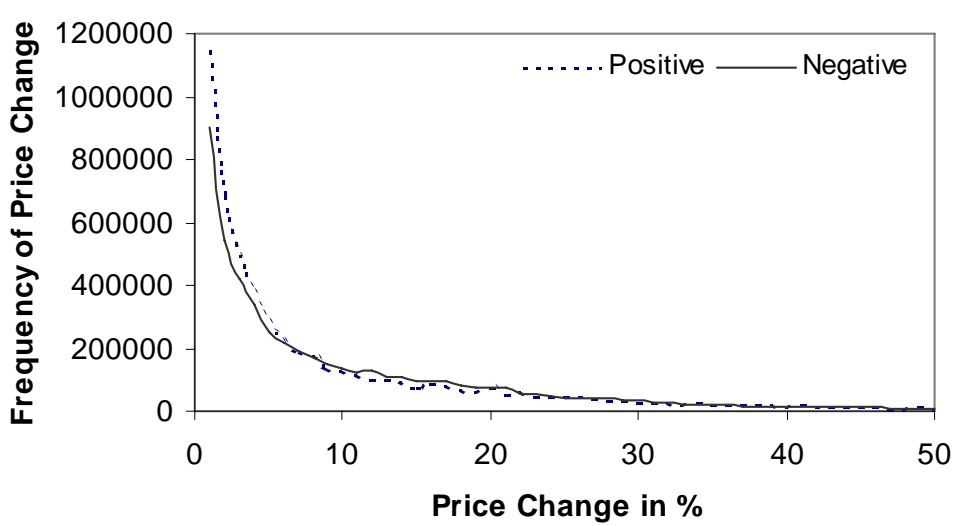

(b)

Figure 3: Frequency of Positive and Negative Wholesale Price Changes: All 29 Categories, Deflation Period

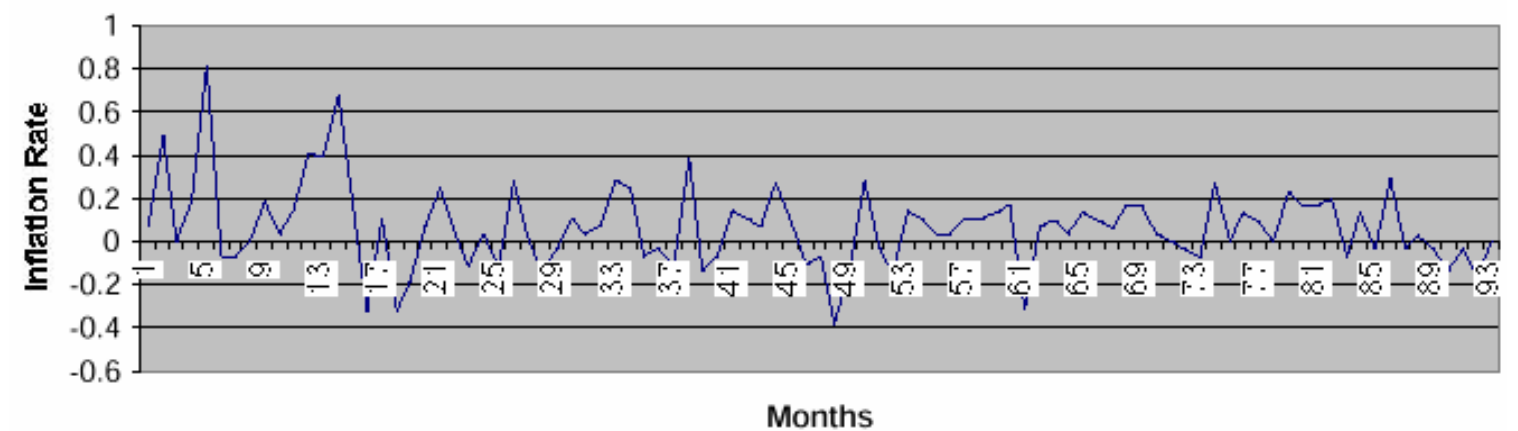

Figure 4. Monthly Inflation Rate Based on Producer Price Index, September 1989-May 1997 


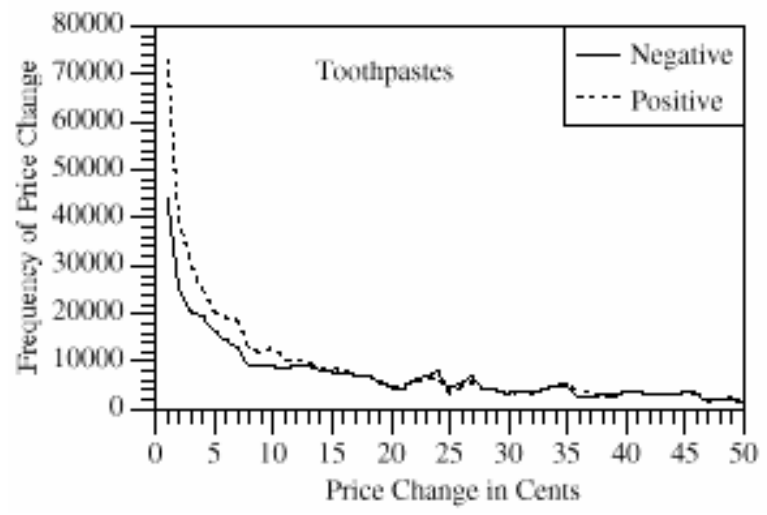

(a) Cents - Entire Period

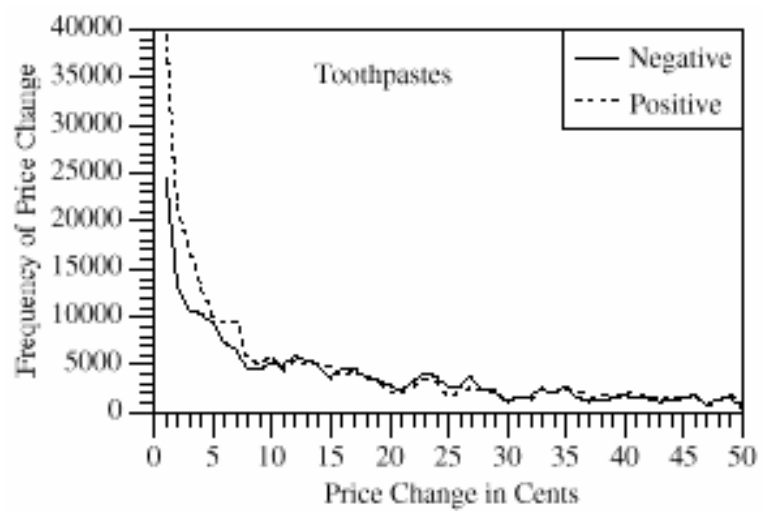

(c) Cents - Low/Zero Inflation Period

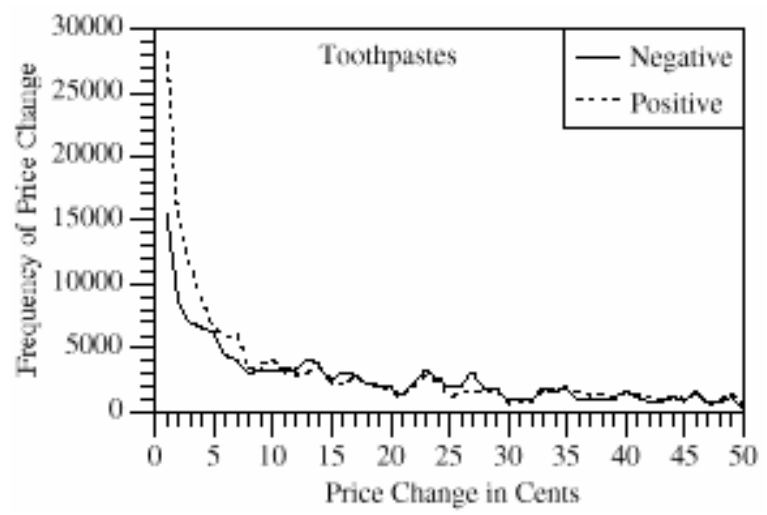

(e) Cents - Deflation Period

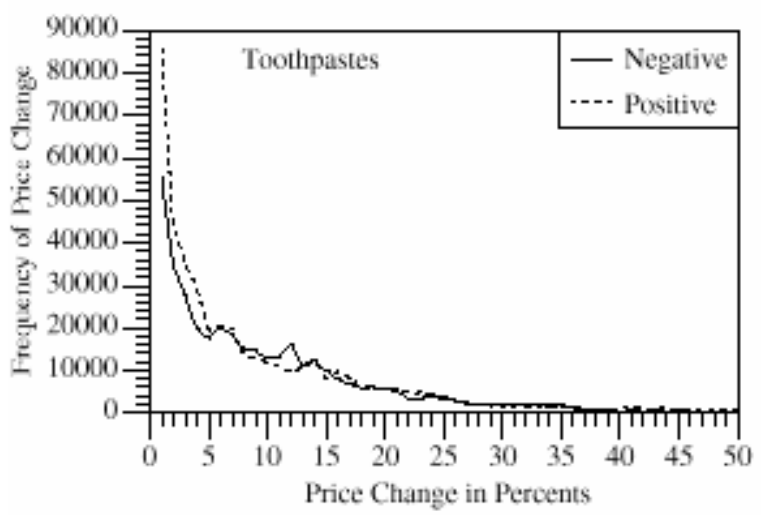

(b) Percents - Entire Period

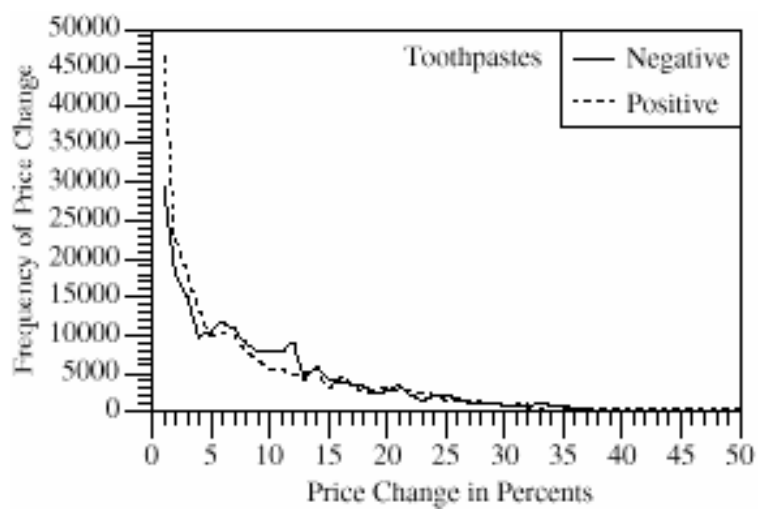

(d) Percents - Low/Zero Inflation Period

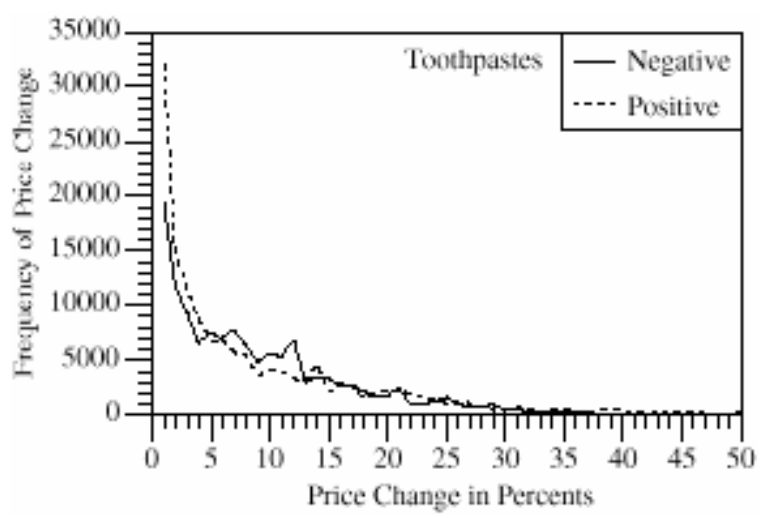

(f) Percents - Deflation Period

Figure 5: Frequency of Positive and Negative Wholesale Price Changes: Toothpaste 


\title{
TECHNICAL APPENDIX
}

\section{Asymmetric Wholesale Pricing: Theory and Evidence}

\author{
Sourav Ray* \\ Department of Marketing \\ DeGroote School of Business, McMaster University \\ Email: sray@mcmaster.ca \\ Haipeng (Allan) Chen \\ Department of Marketing, University of Miami \\ Email: hchen@exchange.sba.miami.edu \\ Mark E. Bergen \\ Department of Marketing and Logistics Management \\ Carlson School of Management, University of Minnesota \\ Email: mbergen@csom.umn.edu \\ Daniel Levy \\ Department of Economics, Bar-Ilan University \\ And \\ Department of Economics, Emory University \\ Email: levyda@mail.biu.ac.il
}

* Contact author 


\section{TECHNICAL APPENDIX - Data}

This appendix addresses the concern regarding our wholesale data: Could the Results be an Artifact of How the Wholesale Prices Are Calculated?

Our wholesale price, as reported in the Dominick's database, is based on the average acquisition cost (AAC). The AAC per unit is calculated as follows:

$$
A A C(t)=\frac{\{\operatorname{Purch}(t) \times \text { price }(t)\}+\{\text { EndInventory }(t-1)-\operatorname{sales}(t)\} \times A A C(t-1)}{\text { TotalInventory }(t)}
$$

where,

$\operatorname{Purch}(\mathrm{t})=$ Inventory bought in $\mathrm{t}$;

$\operatorname{price}(\mathrm{t})=$ Per unit wholesale price paid in $\mathrm{t}$;

EndInventory (t-1) = Inventory at end of t-1;

$\operatorname{Sales}(\mathrm{t})=$ Retail sales at $\mathrm{t}$;

TotalInventory $(\mathrm{t})=$ Total Inventory at $\mathrm{t}$

\section{Lagged adjustment of AAC}

Can it be claimed that our results could be just an artifact of the manner in which AAC is calculated? Manufacturers often inform the retailer in advance of an impending temporary price reduction, permitting the retailer to completely deplete its inventory and then "forward-buying" to overstock at the lower price (Peltzman, 2000). Since new purchases form a large proportion of the total inventory in this case, the large discount shows up as a commensurately large reduction in AAC. On the other hand, a retailer buys less when the wholesale price goes up. Consequently, a wholesale price increase of the same large magnitude as the decrease considered earlier, will translate into a relatively smaller increase in AAC (the so called, lagged adjustment). It is reasonable to expect that the observed asymmetry in wholesale prices therefore may be driven by such forward buying phenomenon.

In the absence of actual wholesale prices, how do we conduct a direct test to check for the above effect? One way of proceeding is to check the data for patterns implied by the above rationale. We discuss the following analyses in the same spirit. 


\section{National Brands versus Private Labels}

Note that the forward buying rationale suggests that if the manner of calculating AAC was the major driver of our results (asymmetry in the small), it should be more pronounced for products that are subjected to greater degree of forward buying. For products not subject to major fluctuations in its purchases driven by promotional prices, we should expect much lesser degree of such systematic distortion. This leads to the following null proposition which holds true if the manner of computing AAC was the major driver of our results. ${ }^{1}$

Forward Buying Proposition: Products subject to greater degree of forward buying will exhibit greater asymmetry than products that are subject to lesser degree of forward buying.

Unfortunately, we do not have direct data on the degree of forward buying. However, according to Hoch et al. (1995), private labels are not promoted as heavily, and hence are forward-bought less than national brands. Therefore, a comparison of national brands to private labels provides a natural context to test the above proposition. In essence, if forward buying is the main driver of our results, the predicted asymmetry should be stronger for national brands than for private labels. We therefore undertook two additional analyses to explore whether, and to what extent, can our results be attributed to the method of computing AAC. In the paragraphs below we first discuss the data and then the individual tests.

\section{National Brand versus Private Label Data}

For the purposes of the test we need data on comparable national brand (NB)-private label (PL) product pairs. We base our identification of such NB-PL pairs on a recently published study of Barsky, et al (2003), who use the same Dominick's data to investigate the size of markups for nationally branded products sold in the U.S. retail grocery industry. Their measure of markup is based on a comparison of the prices of matched pairs of NB-PL products. To implement their strategy, therefore, Barsky, et al. (2003) had to identify the product pairs based on several comparability criteria, which included, among other attributes, product's quality, size, packaging, etc. For quality comparison, they used Hoch and Banerji’s (1993) PL product quality rankings.

\footnotetext{
${ }^{1}$ This is not to be confused with our theoretical proposition earlier. Here we intend to check if the "null," (forward buying is a key driver of the observed asymmetry), can be rejected in favor of the "alternate" (that it is not).
} 
After filtering out the product pairs that were not comparable for various reasons (for example, size differences, quality differences, insufficient number of observations, etc.), Barsky, et al. (2003) were left with 231 matched NB-PL product pairs of comparable size and quality, covering 19 product categories. ${ }^{2}$ These categories are Analgesics, Bottled Juices, Cereals, Cheeses, Cookies, Crackers, Canned Soups, Dish Detergent, Frozen Entrees, Frozen Juices, Fabric Softeners, Grooming Products, Laundry Detergent, Oatmeal, Snack Crackers, Tooth Pastes, Toothbrushes, Soft Drinks, and Canned Tuna. However, Barsky, et al. (2003) argue that Toothbrushes category is an outlier for its unusually high markup ratio, in comparison to the remaining 18 categories. Consequently, they omit the Toothbrushes category from much of their analysis. ${ }^{3}$ Following their strategy, therefore, we also exclude the category of Toothbrushes from our analysis and were left with 18 categories with matched NB-PL pairs for our analyses.

\section{Analysis 1: Comparison of aggregate asymmetries between NB and PL}

We start by conducting an analysis identical to that used in the main paper and compare the aggregate asymmetry thresholds between NB and PL pairs for all the 18 categories. The hypothesis below is derived directly from the null proposition. ${ }^{4}$

Hypothesis 1: Aggregate asymmetry threshold for National Brands is greater than that for Private Labels.

Tables R2.1 and R2.2 below report the results of the analysis in terms of absolute changes (Cents) and relative changes (\%), respectively. The thresholds we obtain are marked in bold. In the absolute case we obtain an asymmetry threshold of 6 cents for the national brands (NB) and 5 cents for private labels (PL). In the relative case, we obtain identical thresholds of $4 \%$.

Two important observations are in order here. First, note the similarity of the magnitudes of the thresholds in both the tests. So, while we cannot subject Hypothesis 1 to a statistical test of significance and are limited to comparing two numbers, the prima facie evidence argues against the hypothesis.

\footnotetext{
${ }^{2}$ See Barsky, et al. (2003), Tables 7A.1-7A.19 for a detailed list of the NB-PL product pairs.

${ }^{3}$ See Barsky, et al., 2003, p. 194.

${ }^{4}$ This and all subsequent hypotheses derived from the null proposition are in the nature of null hypotheses which we aim to reject in favor of the alternate proposition that forward buying is not a key driver.
} 
Second, note the presence of significant asymmetry for the PL sample. This last point is important because if forward buying indeed were a primary driver of our observed asymmetry and if PLs are not subjected to significant forward buying, we should expect only insignificant asymmetry for the PL sample. But that is not the case and the asymmetry for PLs is not only significant but comparable to that of NBs.

Table R2.1: Frequencies of price changes for the 18 categories with NB-PL pairs (Cents)

\begin{tabular}{|c|c|c|c|c|c|c|}
\hline $\begin{array}{l}\text { Price Change } \\
\text { in Cents }\end{array}$ & Positive & $\begin{array}{c}\text { NB } \\
\text { Negative }\end{array}$ & Z-Value & Positive & $\begin{array}{c}\mathrm{PL} \\
\text { Negative }\end{array}$ & Z-Value \\
\hline 1 & 4496 & 3550 & 10.546 & 4788 & 3348 & 15.965 \\
\hline 2 & 2117 & 1683 & 7.040 & 2473 & 1833 & 9.753 \\
\hline 3 & 1398 & 1097 & 6.026 & 1482 & 1369 & 2.116 \\
\hline 4 & 1048 & 860 & 4.304 & 1121 & 912 & 4.635 \\
\hline 5 & 823 & 727 & 2.438 & 895 & 736 & 3.937 \\
\hline 6 & 661 & 517 & 4.196 & 682 & 644 & 1.044 \\
\hline 7 & 542 & 493 & 1.523 & 551 & 472 & 2.470 \\
\hline 8 & 489 & 429 & 1.980 & 361 & 397 & 1.308 \\
\hline 9 & 415 & 330 & 3.114 & 365 & 332 & 1.250 \\
\hline 10 & 382 & 306 & 2.897 & 324 & 272 & 2.130 \\
\hline 11 & 270 & 295 & 1.052 & 364 & 255 & 4.381 \\
\hline
\end{tabular}

Table R2.2: Frequencies of price changes for the 18 categories with NB-PL pairs (\%)

\begin{tabular}{|c|rrr|rrr|}
\hline $\begin{array}{l}\text { Price Change } \\
\text { in \% }\end{array}$ & \multicolumn{3}{|c|}{ NB } & \multicolumn{3}{c|}{$\begin{array}{c}\text { PL } \\
\end{array}$} \\
\hline 1 & Positive & Negative & Z-Value & Positive & Negative & Z-Value \\
2 & 4072 & 3304 & 8.942 & 4480 & 3220 & 14.359 \\
3 & 1893 & 1512 & 6.529 & 2156 & 1613 & 8.845 \\
\hline 4 & 1300 & 1056 & 5.027 & 1431 & 1138 & 5.781 \\
\hline 5 & 905 & $\mathbf{7 9 5}$ & $\mathbf{2 . 6 6 8}$ & 1061 & $\mathbf{8 8 7}$ & $\mathbf{3 . 9 4 2}$ \\
6 & 648 & 592 & 1.590 & 758 & 746 & 0.309 \\
7 & 566 & 526 & 1.210 & 634 & 612 & 0.623 \\
8 & 428 & 432 & 0.136 & 497 & 536 & 1.213 \\
9 & 416 & 394 & 0.773 & 415 & 467 & 1.751 \\
10 & 311 & 369 & 2.224 & 392 & 415 & 0.810 \\
11 & 321 & 292 & 1.171 & 459 & 362 & 3.385 \\
& 257 & 226 & 1.411 & 340 & 336 & 0.154 \\
\hline
\end{tabular}

Taken together, these observations provide strong evidence that our results are not entirely driven by the manner of computing AAC. In the subsequent analyses, we conduct further tests to explore the robustness of this statement. 
Let the degree of asymmetry in a given price change be the difference between the number of positive and negative changes expressed as a percentage of the number of positive changes. For example, the degree of asymmetry for 1 Cent difference is calculated as: (\#POS 1 Cent changes - \#NEG 1Cent changes)/\#POS 1 Cent changes. Like earlier, if forward buying is indeed the primary driver of the asymmetry in $\mathrm{AAC}$, we should expect that it would reflect in a greater mean degree of asymmetry for NB compared to PL. This leads to the following hypothesis.

Hypothesis 2: Aggregate degree of asymmetry for National Brands is greater than that for Private Labels.

The difference between hypothesis 1 and hypothesis 2 is that while the first considered asymmetry thresholds, the second considers the extent of asymmetry between positive and negative changes.

To conduct this test, we first calculated the degree of asymmetry for each price change and then compared the mean asymmetry between NB and PL with a paired t-test. We conducted the test for both absolute (Cents) and relative (\%) changes. Given the thresholds of 6 cents for NB and 5 cents for PL in absolute terms, and 4\% for both in relative terms, we restricted the comparison to small magnitudes (1-11 Cents and 1-11\%) in order to focus on the region of interest. ${ }^{5}$ Table R2.3a below reports the mean degrees of asymmetry we observe and the results of the paired t-tests. In the absolute case, we observe an average degree of asymmetry of $15.2 \%$ for NB and $15.0 \%$ for PL. For the relative case, the averages are $8.4 \%$ and $8.3 \%$ for NB and PL respectively. Notice that none of the comparisons are significant $(p=0.485$ and 0.493 respectively), i.e. we find no support for hypothesis 2 .

In order to make sure that we did not ignore any possible regions where such asymmetry might exist, we repeated the analysis successively for 1-5 Cents, 1-6 Cents, 1-7 Cents, 1-8 Cents, 1-9 Cents and 1-10 Cents as well as for 1-5\%, 1-6\%, 1-7\%, 1-8\%, 1-9\% and 1-10\% bands. In none of these 12 additional comparisons was there any significant difference in the average degree of asymmetry between NB and PL (all $p$ 's $>0.30$ ).

\footnotetext{
${ }^{5}$ This also has the added advantage of being a strong test because any difference between NB and PL due to forward buying is more likely to manifest in the small. We also checked even smaller ranges.
} 
Table R2.3a: Comparison of average degree of asymmetry between NB and PL

\begin{tabular}{|l|r|r|r|r|}
\hline \multirow{2}{*}{} & \multicolumn{2}{|c|}{ Absolute (Cents) } & \multicolumn{2}{c|}{ Relative (\%) } \\
\cline { 2 - 5 } & $\mathrm{NB}$ & $\mathrm{PL}$ & $\mathrm{NB}$ & $\mathrm{PL}$ \\
\hline $\begin{array}{l}\text { Mean Degree } \\
\text { of Asymmetry }\end{array}$ & $15.2 \%$ & $15.0 \%$ & $8.4 \%$ & $8.3 \%$ \\
\hline $\mathrm{t}$-stat & 0.039 & & 0.019 & \\
\hline $\mathrm{p}$ value & 0.485 & & 0.493 & \\
\hline & & & & \\
\hline
\end{tabular}

In addition to the tests above, we checked the degree of asymmetry of the PL sample. As argued earlier, if forward buying indeed were a primary driver of our observed asymmetry and if PLs are not subjected to significant forward buying, we should not expect any significant asymmetry for the PL sample. To test this we checked if the mean degrees of asymmetry of the PL sample were significantly greater than zero. The results are in Table R2.3b below. For both (absolute and elative) cases, the means are significantly greater than zero $(p<0.05)$.

Table R2.3b: Mean degree of asymmetry of PL sample

\begin{tabular}{|l|r|r|}
\hline & (Absolute - Cents) & (Relative - \%) \\
\hline Mean & 0.149965 & 0.083003 \\
\hline t-stat & 4.213 & 1.913 \\
\hline Sig. & $\mathrm{p}<0.05$ & $\mathrm{p}<0.05$ \\
\hline
\end{tabular}

(HO: $\mathrm{m} \neq 0$ )

Therefore, in keeping with the conclusions following Hypothesis 1, the results of the above analyses provide strong evidence that our results cannot be entirely driven by the manner of computing AAC. We now drill down further into the data and look at even more disaggregate comparisons. ${ }^{6}$

Analysis 2: Comparison of category level asymmetries between NB and PL

For this investigation, we conducted an analysis identical to that used in the main paper, and compared the asymmetry thresholds between NB and PL for individual categories. The hypothesis below is derived directly from the proposition.

Hypothesis 3: The average category level asymmetry threshold for National Brands is greater than that for Private Labels.

\footnotetext{
${ }^{6}$ Note however, that our sample size becomes very small as we drill down to more disaggregate levels.
} 
To test this hypothesis, we first obtained the asymmetry thresholds for both NB and PL in individual categories and then compared the average threshold with a paired t-test. The analysis is conducted for both absolute (Cents) as well as relative (\%) changes. Table R2.4a below reports the mean asymmetry thresholds we observe and the results of the paired t-tests. In the absolute case, we observe an average degree of asymmetry of 1.111 for NB and 1.389 for PL. For the relative case, the averages are $0.944 \%$ and $1.556 \%$ for NB and PL respectively. Notice that none of the comparisons are significant ( $p=0.280$ and 0.091 respectively), i.e. we find no support for hypothesis 3 .

Table R2.4a: Comparison of average category level asymmetry thresholds between NB and PL

\begin{tabular}{|l|r|r|r|r|}
\hline \multirow{2}{*}{} & \multicolumn{2}{|c|}{ Absolute (Cents) } & \multicolumn{2}{c|}{ Relative (\%) } \\
\cline { 2 - 5 } & $\mathrm{NB}$ & $\mathrm{PL}$ & $\mathrm{NB}$ & $\mathrm{PL}$ \\
\hline $\begin{array}{l}\text { Mean Threshold } \\
\text { of Asymmetry }\end{array}$ & 1.111 & 1.389 & $0.944 \%$ & $1.556 \%$ \\
\hline $\mathrm{t}$-stat & -0.589 & & -1.364 & \\
\hline $\mathrm{p}$ value & 0.280 & & 0.091 & \\
\hline & & & & \\
\hline
\end{tabular}

In addition, we also checked the average category level asymmetry thresholds for the PL sample. In keeping with the arguments made earlier, we should not expect significant asymmetry in this sample if forward buying was the primary driver of our observed asymmetry. We test if the average category level asymmetry thresholds for the PL sample are significantly greater than zero. The results are in table $\mathrm{R} 2.4 \mathrm{~b}$. In both (absolute and relative) cases, the average thresholds are significantly greater than zero $(\mathrm{p}<0.05)$

Table R2.4b: Average category level asymmetry threshold for PL sample

\begin{tabular}{|l|r|r|}
\hline & (Absolute - Cents) & \multicolumn{2}{|c|}{ (Relative - \%) } \\
\hline Mean & 1.389 & 1.556 \\
\hline T & 4.034 & 4.932 \\
\hline Sig. & $\mathrm{p}<0.05$ & $\mathrm{p}<0.05$ \\
\hline
\end{tabular}

$(\mathrm{HO}: \mathrm{m} \mp 0)$

Again, in keeping with the conclusions following Hypotheses 1 and 2, the results of the above analyses provide additional evidence that our results cannot be entirely driven by the manner of computing AAC. 
Nevertheless, in search of further robustness, we continue the investigation in greater detail by comparing individual category level thresholds in the following analysis. In conducting this analysis however, we feel compelled to point out the drastic loss of sample size that occurs. For example, the average number of observations per category in the data set, is 3,431,118, while the average number of observations for each NB-PL pair for a category is only 3,710, a reduction in excess of $99 \%$. Therefore, the comparisons should be kept in perspective - they are likely to be more illustrative in nature and perhaps more accurate in a relative sense than in an absolute sense.

Table R2.5 below reports the asymmetry thresholds we obtain for each NB-PL pair. The analysis is repeated for both absolute (cents) and relative (\%) changes. We also report the sample size for each pair in the last column.

The results reported in this table provide additional support to our claims following Hypotheses 1, 2 and 3, that our results cannot be entirely driven by the manner of computing AAC. This is based on the following three observations.

Observation 1: Out of the 18 product categories for which we have data, 3 didn't show asymmetry for either absolute or relative changes; 12 showed the asymmetry for either absolute or relative changes and showed an asymmetry threshold for private labels that is as large as or larger than national brands; 3 showed the asymmetry for either absolute or relative change and showed a larger asymmetry threshold for national brands than for private labels. Therefore, the proportion of product categories for which the prediction of forward buying is supported is less than chance level (i.e., $3 / 15<50 \% ; z=2.32 ; p<0.03$ ).

Observation 2: Out of $36(=18 \times 2)$ possible comparisons, there are five that are consistent with the prediction of forward buying (marked in bold in the table). However, 15 are in the opposite direction and in the remaining 16 cases the threshold is the same for private labels and national brands. ${ }^{7}$ Altogether, the majority of comparisons (i.e., 31, or more than $86 \%$ ) are inconsistent with the prediction of forward buying.

\footnotetext{
${ }^{7} 8$ of which have an asymmetry threshold of 0 for both NB and PL - an observation that we feel is driven by the severely limited sample size.
} 
Observation 3: For comparisons where there is a non-zero threshold for either NB or PL, there are 15 for which the threshold is larger for PL than for NB, compared to 5 for which the opposite is true. The difference is statistically significant $(z=2.27, p<.03)$.

Table R2.5: Asymmetry thresholds for the 18 categories with NB-PL pairs

\begin{tabular}{|l|c|c|c|c|c|}
\hline & \multicolumn{2}{|c|}{ Absolute (Cents) } & \multicolumn{2}{c|}{ Relative (\%) } & \\
\hline Categories & NB & PL & NB & PL & Sample Size \\
\hline Analgesics & 1 & 1 & 3 & 3 & 5149 \\
\hline Bottled Juices & 3 & 3 & 1 & 2 & 6735 \\
\hline Canned Soup & 3 & 3 & $\mathbf{4}$ & $\mathbf{2}$ & 6136 \\
\hline Canned Tuna & 0 & 0 & 0 & 0 & 919 \\
\hline Cereals & 3 & 3 & 3 & 4 & 6111 \\
\hline Cheeses & 1 & 1 & 0 & 1 & 3021 \\
\hline Cookies & 2 & 2 & 0 & 1 & 3513 \\
\hline Crackers & $\mathbf{1}$ & $\mathbf{0}$ & $\mathbf{1}$ & $\mathbf{0}$ & 2410 \\
\hline Dish Detergent & 0 & 2 & 0 & 1 & 2756 \\
\hline Fabric Softeners & 0 & 0 & 0 & 0 & 2060 \\
\hline Frozen Entrees & 0 & 5 & 0 & 3 & 636 \\
\hline Frozen Juices & 2 & 2 & 1 & 3 & 6587 \\
\hline Grooming Products & 0 & 0 & 0 & 0 & 667 \\
\hline Laundry Detergents & 0 & 2 & 0 & 1 & 3930 \\
\hline Oatmeal & 0 & 0 & 1 & 3 & 920 \\
\hline Snack Crackers & 0 & 0 & 0 & 1 & 1017 \\
\hline Soft Drinks & 0 & 1 & 0 & 3 & 10623 \\
\hline Tooth Pastes & $\mathbf{4}$ & $\mathbf{0}$ & $\mathbf{3}$ & $\mathbf{0}$ & 3593 \\
\hline $\begin{array}{l}\text { Total (all 18 categories } \\
\text { combined) }\end{array}$ & $\mathbf{6}$ & $\mathbf{5}$ & 4 & 4 & 66783 \\
\hline Bold: NB PL & & & & & \\
\hline
\end{tabular}

Bold: NB > PL

To conclude, we do not find any strong reason to believe that the forward buying hypothesis related to AAC is a primary driver of our results. We subject the data to a series of tests to check if there are patterns consistent with the forward buying hypotheses. None of the analyses, whether descriptive or statistical, provide support for these hypotheses. In the absence of such evidence, we conclude that it is highly unlikely that our empirical results are an artifact of the manner in which the wholesale prices have been calculated.

Such a conclusion must however, be tempered with the knowledge that we are after all dealing with a derived measure of wholesale prices and a better test of our theory would be with actual wholesale prices. Unfortunately, such data is not available. We are not unique in dealing with this problem. A number of other authors who have dealt with it bemoan the lack of proper wholesale price data ( $c f$. Cecchetti, 1986; Peltzman, 2000; Chintagunta, 2002; Levy, et al. 2002; 
Chevalier, et al. 2003 etc.). Creative approaches like estimating wholesale prices from regression which is particularly common in the empirical industrial organization literature (see Carlton and Perloff, 1994), using aggregate price indexes, such as wholesale price index, as a proxy (Cecchetti, 1985), rough accounting estimates (Nevo, 2001), even simulation (Tellis and Zufryden, 1995) are the norm in such cases. Others may ignore explicit consideration of wholesale prices altogether (Gerstner et al., 1994; Pesendorfer, 2001).

While the lack of accurate wholesale price data is unfortunate, we believe that should not hinder theory building in the domain of wholesale prices. Nevertheless, the onus is on the researcher to ensure that any empirical test of theory using weak wholesale data is actually robust to the weakness of the data. It is in that spirit that we conducted these additional checks.

To keep things in perspective therefore, it is necessary to understand that while we stand behind the spirit of our results, we recognize that the verity of the exact magnitudes of the asymmetry we report is subject to some uncertainty.

\section{Reverse Asymmetry in the large}

It may be worthwhile here, to consider the role of reverse asymmetry in the large vis-à-vis the forward buying proposition. When a manufacturer offers a temporary off-invoice discount to a retailer, the retailer tends to buy more of the product than it needs during the period of the sale. AAC typically falls by a large amount then. Theoretically, if this drop in AAC is not matched by a similar increase when prices do go up, one should see reverse asymmetry in the large. Since retailers are normally expected to purchase lesser amounts at higher prices, this leads us to believe that reverse asymmetry in the large - i.e. more large price decreases than increases, is a reasonable prediction if the rival forward buying hypothesis was a primary driver of our results.

The method we employed to test this is to compare, for each of the 29 product categories, the frequencies in which positive price changes exceeded negative price changes ("positive" asymmetry), with the frequencies in which the opposite holds true ("negative" asymmetry). If the alternative, lagged adjustment is the main driver, then we should observe relatively more frequent occurrences of negative than positive asymmetry in the large. If there is no such negative asymmetry in the large, as our theory predicts, then occurrences of the number of positive and negative asymmetries should be statistically equal. We report the number of 
occurrences of positive $(p)$ and negative asymmetries $(n)$ as a ratio $(p: n)$ in Table $\mathrm{R} 2.6^{8} \mathrm{We}$ carried out the analyses for the entire sample, as well as for a sample of low/zero inflation period and a sample of deflation period. We also did the analyses both in terms of absolute changes in cents and in terms of percentage changes.

Table R2.6: Number of Positive vs. Negative Asymmetry Beyond Threshold

\begin{tabular}{|c|c|c|c|c|c|c|}
\hline & \multicolumn{2}{|c|}{ Entire Sample Period } & \multicolumn{2}{|c|}{ Low/Zero Inflation Period } & \multicolumn{2}{|c|}{ Deflation Period } \\
\hline & $\begin{array}{l}\text { Absolute } \\
\text { (Cents) }\end{array}$ & $\begin{array}{l}\text { Relative } \\
(\%)\end{array}$ & $\begin{array}{l}\text { Absolute } \\
\text { (Cents) }\end{array}$ & $\begin{array}{l}\text { Relative } \\
(\%)\end{array}$ & $\begin{array}{l}\text { Absolute } \\
\text { (Cents) }\end{array}$ & $\begin{array}{l}\text { Relative } \\
(\%)\end{array}$ \\
\hline Analgesics & $16: 1$ & $17: 20$ & $21: 3$ & 13:18 & $28: 8$ & $14: 18$ \\
\hline Bath Soap & $11: 11$ & $26: 15$ & $13: 15$ & $24: 18$ & $12: 13$ & $21: 14$ \\
\hline Bathroom Tissues & $10: 15$ & $26: 12$ & $11: 18$ & $32: 10$ & $13: 15$ & $33: 10$ \\
\hline Beer & $2: 43^{\star *}$ & 29:14 & $3: 34^{\star \star}$ & 29:13 & $15: 21$ & $27: 12$ \\
\hline Bottled Juices & $15: 11$ & $26: 16$ & $9: 10$ & $24: 12$ & $20: 16$ & $25: 14$ \\
\hline Canned Soup & 19:11 & $21: 13$ & $17: 13$ & $17: 13$ & $21: 16$ & 19:16 \\
\hline Canned Tuna & $22: 10$ & $24: 13$ & $14: 17$ & 19:19 & $16: 14$ & $17: 15$ \\
\hline Cereals & $10: 1$ & $5: 27$ & $22: 2$ & $17: 19$ & $16: 8$ & $16: 21$ \\
\hline Cheeses & $14: 11$ & $25: 14$ & $13: 16$ & $22: 21$ & 20:11 & $21: 17$ \\
\hline Cigarettes & $23: 8$ & $20: 15$ & $22: 22$ & $14: 20$ & $9: 33^{* *}$ & 18:19 \\
\hline Cookies & $15: 19$ & 23:17 & 16:16 & $21: 19$ & $15: 19$ & $17: 19$ \\
\hline Crackers & $12: 13$ & $22: 18$ & $17: 15$ & $20: 19$ & $18: 15$ & 19:18 \\
\hline Dish Detergent & $16: 16$ & $23: 16$ & $8: 24^{\star *}$ & $23: 17$ & $9: 28^{* *}$ & $26: 16$ \\
\hline Fabric Softeners & $13: 21$ & $23: 19$ & $13: 20$ & $22: 13$ & $10: 19^{\star *}$ & $21: 15$ \\
\hline Front-end-candies & $21: 15$ & $11: 25^{\star *}$ & $14: 24$ & $8: 31^{* *}$ & $18: 18$ & $6: 34^{\star *}$ \\
\hline Frozen Dinners & $21: 17$ & $22: 20$ & 29:11 & $22: 21$ & $24: 13$ & $19: 22$ \\
\hline Frozen Entrees & $7: 8$ & $18: 24$ & $10: 15$ & $13: 26^{* *}$ & 19:17 & $17: 24$ \\
\hline Frozen Juices & $8: 21^{\text {** }}$ & $23: 15$ & $13: 21$ & $24: 11$ & $17: 17$ & $19: 8$ \\
\hline Grooming Products & $18: 11$ & $26: 13$ & $12: 12$ & $26: 14$ & 19:12 & $26: 11$ \\
\hline Laundry Detergents & $13: 12$ & $21: 23$ & $8: 21^{\star *}$ & $19: 23$ & $14: 11$ & $17: 20$ \\
\hline Oatmeal & $36: 2$ & $17: 20$ & $41: 3$ & $21: 21$ & $26: 8$ & 19:21 \\
\hline Paper Towels & $19: 12$ & $26: 8$ & $16: 15$ & $22: 16$ & $9: 16$ & $23: 12$ \\
\hline Refrigerated Juices & $20: 7$ & $26: 16$ & $18: 15$ & $25: 17$ & 19:14 & $22: 17$ \\
\hline Shampoos & $11: 13$ & $27: 16$ & $24: 11$ & $23: 18$ & $20: 13$ & $22: 18$ \\
\hline Snack Crackers & $25: 11$ & 29:12 & $15: 21$ & $22: 20$ & $17: 20$ & $25: 19$ \\
\hline Soaps & $7: 10$ & 29:10 & $19: 4$ & $32: 7$ & $22: 4$ & $33: 8$ \\
\hline Soft Drinks & $19: 7$ & $13: 25^{\star *}$ & $20: 11$ & $14: 24$ & $15: 17$ & $16: 24$ \\
\hline Tooth Brushes & $17: 15$ & $23: 15$ & $13: 16$ & $21: 18$ & $16: 17$ & $20: 20$ \\
\hline Tooth Pastes & $12: 11$ & $23: 17$ & $12: 21$ & $26: 15$ & $13: 20$ & $27: 12$ \\
\hline $\begin{array}{l}\text { Total (All } 29 \text { Categories } \\
\text { Combined) }\end{array}$ & $7: 4$ & $20: 20$ & $12: 12$ & $17: 23$ & $15: 11$ & $19: 22$ \\
\hline
\end{tabular}

** There are more frequent occurrences of negative asymmetry than positive asymmetry $(p<.05)$.

The results in Table R2.6 do not support the alternative explanation that lagged adjustment is driving our result. Specifically, with any of the six tests we did, there were three or fewer

\footnotetext{
${ }^{8}$ For example, the ratio 13:12 for Laundry Detergents suggests that there were 13 occurrences of positive to 12 occurrences of negative asymmetries.
} 
product categories in which there were more negative than positive asymmetry in the large, in a statistically significant sense $(\mathrm{z}>1.65, \mathrm{p}<0.05)$. Similarly, when all the 29 product categories were combined, there was statistically equal number of positive and negative asymmetry in the large.

However, we acknowledge that it is not clear whether this by itself is a strong test. Reverse asymmetry in the large appears to be highly contextual and dependent on several factors. After procuring a large amount of the product at a low cost, the retailer normally quits buying for several periods while going through its inventory. How AAC adjusts subsequently, is a function of a number of things including the remaining inventory, quantity purchased, and wholesale prices when the retailer starts buying again. The hypothesized reverse asymmetry will hold if the retailer starts buying small quantities before the forward bought inventory is largely depleted. However, if the retailer waits till the entire inventory is depleted before restocking its entire inventory at a higher price, then we may not see the reverse asymmetry in the large. ${ }^{9}$

In our analysis it is difficult to control for these different inventory practices. Nevertheless, for situations where the reverse asymmetry is not predicted, i.e. where the retailer restocks at a higher price only after depleting its forward bought inventory, it is not clear that asymmetry in the small will be driven by forward buying. It is possible that for such products forward buying is no longer a rival explanation for our finding of asymmetric pricing in the small. For the other inventory practices (re-ordering in small quantities before depletion of the forward bought inventory) on the other hand, it appears theoretically reasonable to predict reverse asymmetry in the large simultaneously with asymmetry in the small.

We understand either can be true, and maybe it's a combination of both practices. Nevertheless, even if it is a combination of both practices, reverse asymmetry in the large may be a reasonable check. Either the inventory pattern occurs often enough to be a rival explanation for our asymmetric pricing patterns (in which case one should expect reverse asymmetry to be prevalent) or it does not happen often enough to generate reverse asymmetry (in which case asymmetric pricing should not be prevalent, so the rival explanation of forward buying is not a

\footnotetext{
${ }^{9} \mathrm{We}$ assume that the entire inventory is replenished in this case and that the prices go back up at the point of repurchase. For certain cases, prices may not go back up to previous levels. For such smaller increases, the prediction of reverse asymmetry holds along with that of asymmetry in the small.
} 
problem for our theory). So, we believe, albeit not perfect, the lack of reverse asymmetric pricing in the large is not a wholly unreasonable metric of the validity of our results.

We do not find any evidence of such reverse asymmetry in our data. In combination with the results comparing national brands and private labels, we would like to believe this is further corroborating evidence that our empirical results (asymmetry in the small) are not driven by forward buying.

\section{Changes in Manufacturer's Pricing Policies from September 1994}

The last check on the measure of wholesale price data concerns a change in the manufacturers' pricing policies during the sample period. Starting September 1994, manufacturers in the Dominick's dataset adopted retrospective discounts, whereby they offered rebates based on sales in a specified period rather than offering a direct discount. It is not clear how this change might affect the AAC. Earlier studies using the same dataset therefore often restrict their sample up to September 1994 (e.g. Peltzman, 2000; page 472). To rule out that our results may be driven by this change, we conduct an additional analysis by restricting the sample to the period September 1989 to August 1994. We find that our central result - that of asymmetry in the small and symmetry in the large consistently holds in this restricted sample.

Table R2.7 reports the absolute (cents) and relative (\%) thresholds obtained for the preSeptember 1004 sample, while Table R2.8 reports the number of instances of positive and negative asymmetries observed beyond the thresholds for the same sample. There are statistically equal numbers of positive and negative asymmetries when the entire sample is considered ( $>0.05$ ). In a category level analysis, in 40 out of 58 (i.e., 69\%) instances, there are statistically equal numbers of positive and negative asymmetries. More positive than negative asymmetry is observed only in 8 instances out of 58 possible comparisons (13.8\%). It happened for 3 product categories in terms of absolute changes, and 5 product categories in terms of relative changes. More negative than positive asymmetry happened in only 10 instances out of 58 possible comparisons (17.2\%). It happened for 6 product categories in terms of absolute changes, and 4 product categories in terms of relative changes. Overall therefore, our central results (asymmetry in the small but symmetry in the large remains unchanged for the pre-September 1994 sample, thereby ruling out the pricing policy change as a driver of our results. 
Table R2.7. What Might Constitute a "Small” Price Change?

Statistical Analysis of the Data by Product Category in Absolute ( $\not$ ) and Relative (\%) Terms Subsample: Sept. 1989 - - August 1994

\begin{tabular}{|c|c|c|}
\hline Categories & Absolute (Cents) & Relative (\%) \\
\hline Analgesics & 26 & 25 \\
\hline Bath Soap & 5 & 5 \\
\hline Bathroom Tissues & 5 & 2 \\
\hline Beer & 12 & 6 \\
\hline Bottled Juices & 14 & 9 \\
\hline Canned Soup & 14 & 13 \\
\hline Canned Tuna & 3 & 3 \\
\hline Cereals & 23 & 10 \\
\hline Cheeses & 12 & 14 \\
\hline Cigarettes & 1 & 1 \\
\hline Cookies & 4 & 9 \\
\hline Crackers & 3 & 2 \\
\hline Dish Detergent & 7 & 3 \\
\hline Fabric Softeners & 8 & 4 \\
\hline Front-end-candies & 6 & 7 \\
\hline Frozen Dinners & 7 & 3 \\
\hline Frozen Entrees & 1 & 1 \\
\hline Frozen Juices & 0 & 0 \\
\hline Grooming Products & 14 & 9 \\
\hline Laundry Detergents & 14 & 4 \\
\hline Oatmeal & 10 & 7 \\
\hline Paper Towels & 1 & 1 \\
\hline Refrigerated Juices & 10 & 3 \\
\hline Shampoos & 10 & 3 \\
\hline Snack Crackers & 3 & 2 \\
\hline Soaps & 9 & 11 \\
\hline Soft Drinks & 2 & 3 \\
\hline Tooth Brushes & 15 & 1 \\
\hline Tooth Pastes & 10 & 6 \\
\hline $\begin{array}{l}\text { Total (all } 29 \text { product } \\
\text { categories combined) }\end{array}$ & 20 & 10 \\
\hline
\end{tabular}

Below the thresholds of number of positive changes are significantly more than number of negative changes $(\mathrm{p}<0.05)$. 
Table R2.7. Number of Positive vs. Negative Asymmetry Beyond Threshold Subsample: Sept. 1989 - - August 1994

\begin{tabular}{|c|c|c|c|c|}
\hline & \multicolumn{2}{|c|}{ Absolute (Cents) } & \multicolumn{2}{|c|}{ Relative (\%) } \\
\hline & $\begin{array}{l}\text { Positive } \\
\text { asymmetry }\end{array}$ & $\begin{array}{l}\text { Negative } \\
\text { asymmetry }\end{array}$ & $\begin{array}{l}\text { Positive } \\
\text { asymmetry }\end{array}$ & $\begin{array}{l}\text { Negative } \\
\text { asymmetry }\end{array}$ \\
\hline Analgesics & 16 & 13 & 9 & 11 \\
\hline Bath Soap & 12 & 16 & 20 & 13 \\
\hline Bathroom Tissues & 16 & 19 & $12^{*}$ & $27^{*}$ \\
\hline Beer & 17 & 15 & 19 & 19 \\
\hline Bottled Juices & $8^{*}$ & $21^{*}$ & 15 & 14 \\
\hline Canned Soup & 17 & 9 & $27^{* *}$ & $6^{\star \star}$ \\
\hline Canned Tuna & 17 & 20 & 19 & 12 \\
\hline Cereals & $13^{\star \star}$ & $3^{\star \star}$ & 15 & 17 \\
\hline Cheeses & 17 & 9 & $17^{* *}$ & $5^{\star \star}$ \\
\hline Cigarettes & $0^{*}$ & $12^{*}$ & $1^{*}$ & $13^{*}$ \\
\hline Cookies & 21 & 14 & 27 ** & $13^{\star *}$ \\
\hline Crackers & 16 & 20 & 26 & 15 \\
\hline Dish Detergent & 12 & 17 & 17 & 19 \\
\hline Fabric Softeners & $9^{*}$ & $22^{*}$ & 14 & 22 \\
\hline Front-end-candies & $5^{*}$ & $21^{*}$ & $27 * *$ & $3^{* *}$ \\
\hline Frozen Dinners & 15 & 22 & 15 & 16 \\
\hline Frozen Entrees & 27 & 19 & 18 & 24 \\
\hline Frozen Juices & 16 & 19 & 26 & 16 \\
\hline Grooming Products & $7^{*}$ & $20^{*}$ & $8^{*}$ & $24^{*}$ \\
\hline Laundry Detergents & 12 & 15 & 17 & 19 \\
\hline Oatmeal & 15 & 8 & 11 & 13 \\
\hline Paper Towels & 17 & 16 & 21 & 15 \\
\hline Refrigerated Juices & $9 *$ & $24^{*}$ & 19 & 12 \\
\hline Shampoos & 13 & 13 & 24 & 14 \\
\hline Snack Crackers & 18 & 11 & 25 & 15 \\
\hline Soaps & $22^{\star \star}$ & 10 ** & $20 * *$ & $8 * \star$ \\
\hline Soft Drinks & $27^{\star \star}$ & $13^{\star *}$ & $14^{*}$ & $31^{*}$ \\
\hline Tooth Brushes & 16 & 12 & 22 & 13 \\
\hline Tooth Pastes & 14 & 17 & 20 & 16 \\
\hline $\begin{array}{l}\text { Total (all } 29 \text { product } \\
\text { categories combined) }\end{array}$ & 14 & 11 & 23 & 14 \\
\hline
\end{tabular}

**: More positive than negative asymmetry.

*: More negative than positive asymmetry. . $(\mathrm{p}<.05)$. 


\section{TECHNICAL APPENDIX - Future Extension of Model}

\section{$\underline{\text { Speculative comments regarding extending the model to n-periods }}$}

In the paper, we have shown why asymmetric adjustment of wholesale prices is a subgame perfect equilibrium in a 2-period model. It is interesting to posit what the nature of the equilibrium will be when we extend the game to longer time horizons. Such extension can be done in several ways.

One way of extending the game would be to consider additional time periods. For simplicity, we can begin with assuming no additional change in upstream costs beyond those existing in the current model. If for example, the manufacturer was to set price for $n-1$ future periods instead of just one. Since now the retailer would face a cost $x$ in each future period, it may allow the manufacturer to incorporate the cumulative degree of retailer's rigidity in the price it sets following the initial period. Knowing this, the retailer would of course set a

commensurately different initial price. The magnitude of the wholesale asymmetry $\left|\Delta w^{*}\right|$ derived for the 2-period solution will then be modified by at least two factors - (a) the number of time periods being considered, $n$, and (b) the magnitude of discount factor, $\delta$. Taking the liberty to speculate, it stands to reason that the magnitude of the modification will likely be some transformation $G\left(\left|\Delta w^{*}\right| ; n, \delta\right)$, where $\sum G / \sum n>0$ and $\sum G / \sum \delta<0$. Substantively therefore, this is unlikely to be different from the results and conclusions we draw from our simpler model. It could be further complicated with additional changes in costs (and related uncertainty), which will likely lead to similar results, although it is not clear how these complexities would be likely to change the central results of the two period model.

We can also consider another model emphasizing repeated price setting games, with the manufacturer actions being asymmetric or symmetric pricing in each period. Manufacturer payoffs in any given period in such a game could be contingent on its historical pricing behavior. This could be achieved in several ways, e.g. by explicitly giving the retailer the choice of imposing penalties or even by invoking some sort of reputation mechanisms. The equilibrium outcome is less certain here. For an infinitely repeated 2-player game, the Folk Theorem would predict that "any combination of actions observed in any finite number of repetitions is the unique outcome of some subgame perfect equilibrium" as long as the rate of time preference (the discount factor) is sufficiently small and the probability that the game ends in any repetition is 
sufficiently small (Rasmusen, 2002; page 112). This would suggest that asymmetric pricing cannot be completely ruled out, yet may be only one of many possible outcomes, even when manufacturers expect to be in a continued relationship with the retailer. Nevertheless, these extensions are beyond the scope of our model and we can merely speculate as to the likely outcomes of such a setup.

In this context, an observation relevant for our purposes is that there is significant uncertainty in the duration of relationships between manufacturers and retailers. While manufacturers and retailers often engage over long time horizons, supermarkets frequently drop not only individual SKUs but sometimes also entire categories from their product portfolio. As Peltzman (2000, p. 500) notes, "Occasionally (the) leading items in a category is either introduced or replaced (within a given observation period)." Turnover in brands is also not uncommon. Manufacturers may also change the pricing format (see Peltzman's paper, page 500). These suggest that it may be more accurate to model the pricing game as being of a finite duration. In that case, it is reasonable to speculate that our results will hold and asymmetry will be an equilibrium outcome. ${ }^{10}$ Again, these conjectures are beyond the scope of the model we currently have in the paper. However, these are certainly interesting and worthy of future research in the area.

Conjectures aside, in the final analysis, a benefit of making the retailers forward looking in the model is that - in equilibrium retailers are not disadvantaged by asymmetric pricing in the small - they adjust their initial pricing decisions to reflect this economic reality. That was another reason why this was such a valuable extension of the model. ${ }^{11}$ So it is not clear that a richer space of punishments, relationships or prices would necessarily be of any improvement to the retailer in this situation. The costs of price adjustment are real, and as such any solution would have to factor them into the equilibrium.

\section{$\underline{\text { References }}$}

Barsky, Robert, Mark Bergen, Shantanu Dutta, and Daniel Levy (2003), "What Can the Price Gap between Branded and Generic Products Tell Us About Markups?” in Scanner Data

\footnotetext{
${ }^{10}$ See the discussion in Rasmusen (2002) of the Chainstore Paradox originally explained by Selten (1978).

${ }^{11}$ We thank the reviewers and editors for guiding us to explore this direction - it greatly improved the paper.
} 
and Price Indexes, edited by R. Feenstra and M. Shapiro, National Bureau of Economic Research, the University of Chicago Press, 165-225.

Carlton, Dennis, and Jeffrey Perloff (1994), Modern Industrial Organisation (NY, NY: Harper Collins).

Cecchetti, Steve (1986), "The Frequency of Price Adjustment: A study of the Newsstand Prices of Magazines," Journal of Econometrics 31, 255-274.

Chevalier, Judith, Anil Kashyap, and Peter Rossi (2003), “Why Don’t Prices Rise During Periods of Peak Demand? Evidence from Scanner Data," American Economic Review 93(1), 15-37.

Chintagunta, Pradeep (2002); "Investigating Category Pricing Behavior in a Retail Chain," Journal of Marketing Research, v.39(2), 141-154.

Gerstner, Eitan; James D. Hess and Duncan M. Holthausen (1994); “Price Discrimination Through a Distribution Channel: Theory and Evidence," The American Economic Review, v.84(5), 1437-1445.

Hoch, Stephen J., Byung Do Kim, Alan L. Montgomery and Peter E. Rossi (1995), "Determinants of Store-Level Price Elasticity," Journal of Marketing Research, Vol. 32, $17-29$.

Hoch, Steve and Shumeet Banerji (1993), "When Do Private Labels Succeed?" Sloan Management Review 34(4), Summer, 57-67.

Levy, Daniel, Shantanu Dutta, and Mark Bergen (2002), "Heterogeneity in Price Rigidity: Evidence from a Case Study Using Micro-Level Data," Journal of Money, Credit, and Banking 34 (1), 197-220.

Nevo, Aviv (2001), "Measuring Market Power in the Ready-to-Eat Cereal Industry," Econometrica, v.69(2), 307-342.

Peltzman, Sam (2000), "Prices Rise Faster Than They Fall,” Journal of Political Economy, Vol. 108(3), 466-502.

Pesendorfer, Martin (2002); "Retail Sales: A Study of Pricing Behavior in Supermarkets," Journal of Business, v.75(1), 33-66.

Rasmusen, Eric (2002); Games and Information: An Introduction to Game Theory, $3^{\text {rd }}$ edition; Blackwell Publishers, Malden, MA, USA.

Selten, Reinhard (1978), “The Chain-Store Paradox,” Theory and Decision, Volume 9, 127-59. 
Tellis, Gerard J. and Fred S. Zufryden (1995), “Tackling the Retailer Decision Maze: Which Brands to Discount, How Much, When and Why?" Marketing Science, v.14(3), 271-299. 


\section{TECHNICAL APPENDIX - FIGURES}

Category Level Plots of Asymmetric Wholesale Pricing 

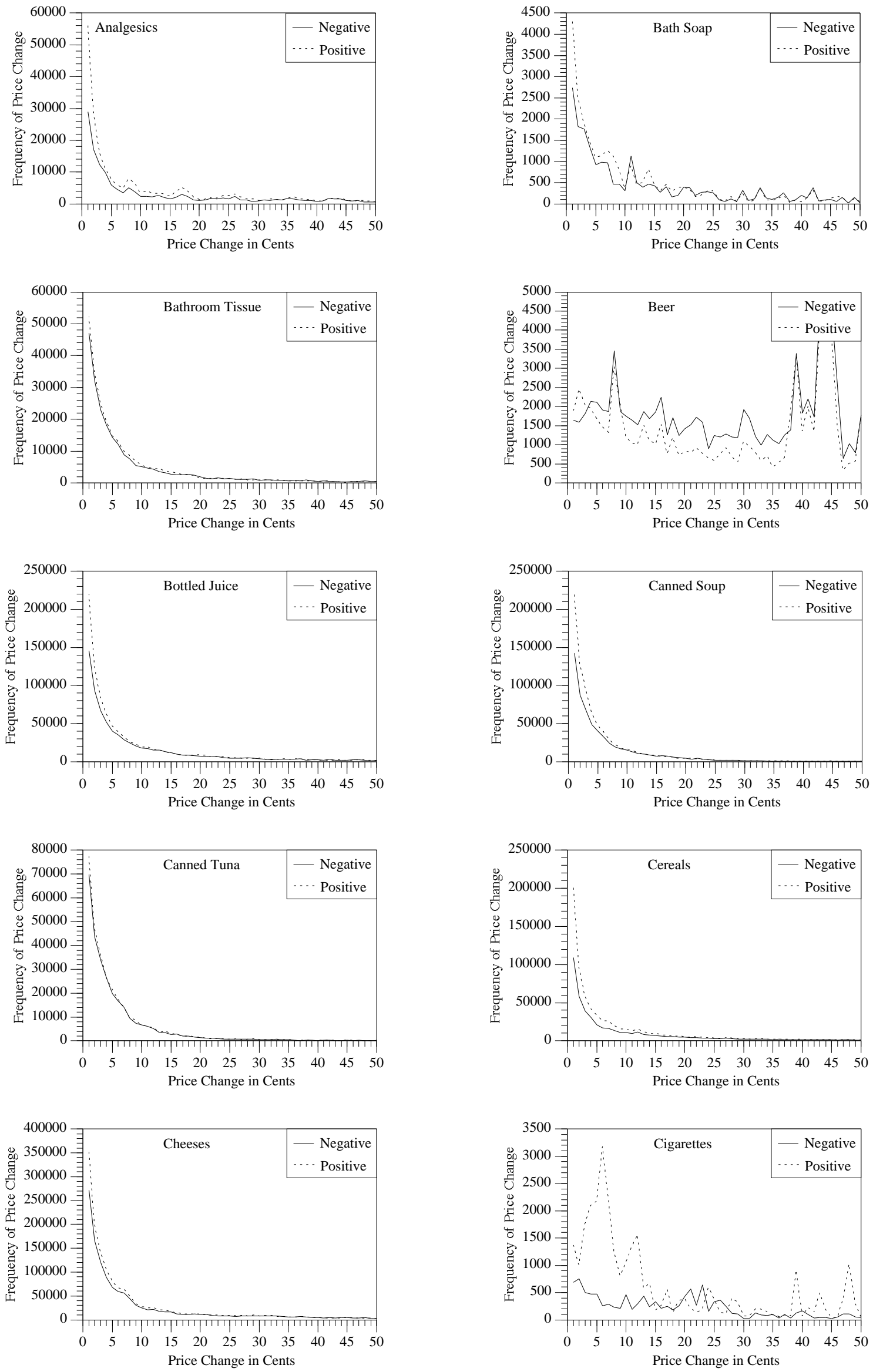

Figure 1.1a. Frequency of Positive and Negative Wholesale Price Changes in Cents by Category 

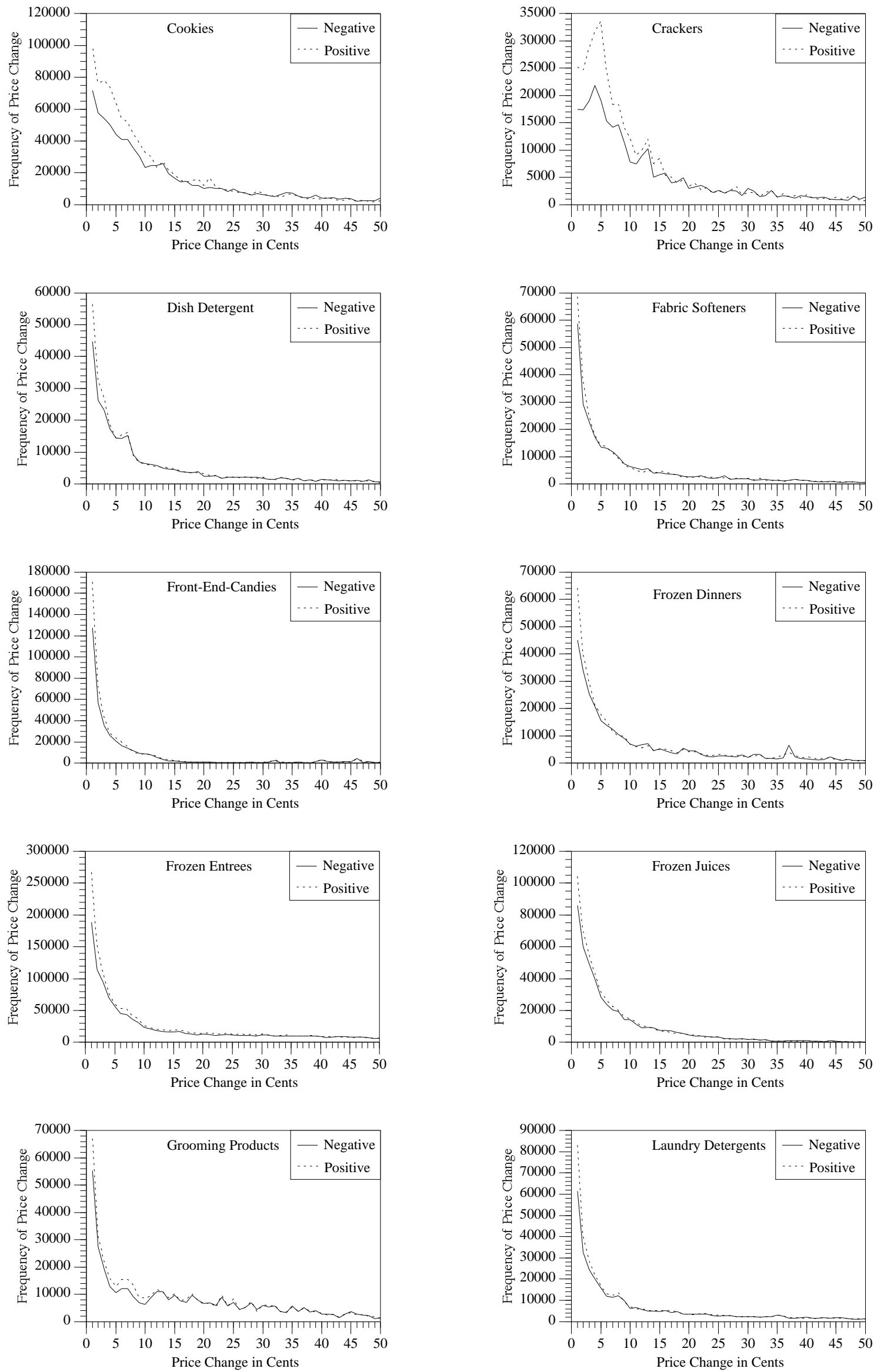

Figure 1.1b. Frequency of Positive and Negative Wholesale Price Changes in Cents by Category 

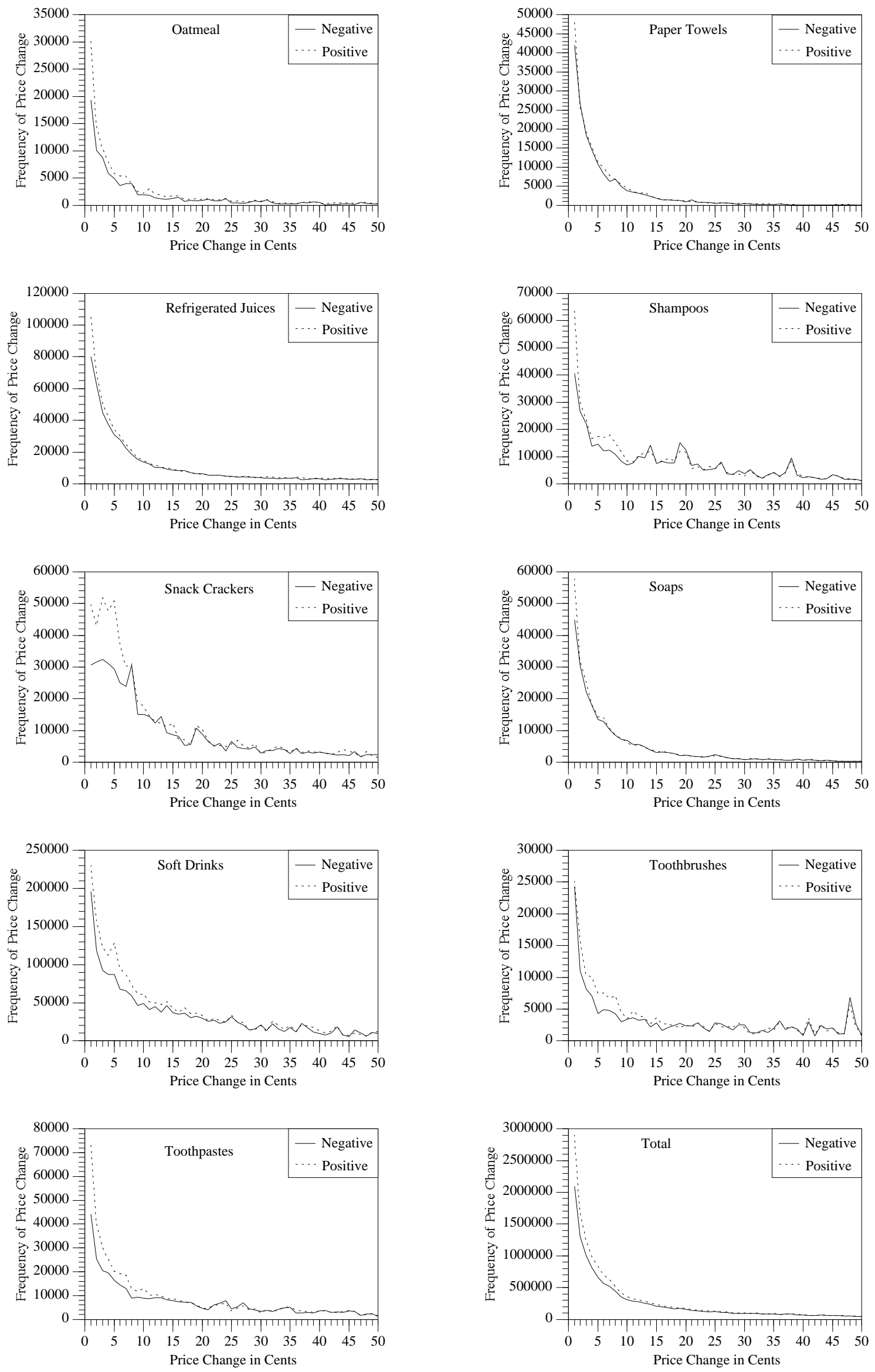

Figure 1.1c. Frequency of Positive and Negative Wholesale Price Changes in Cents by Category 

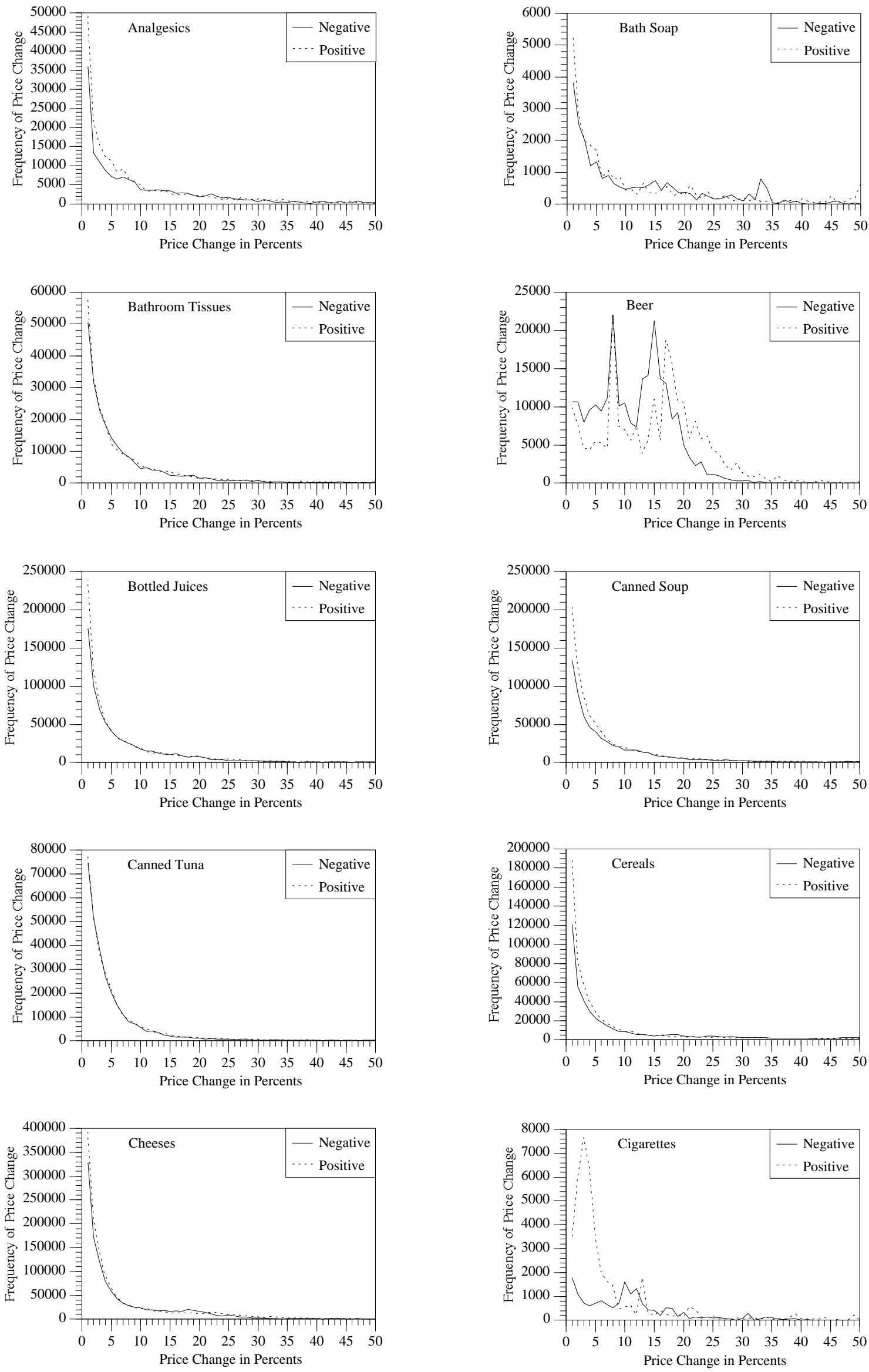

Figure 1.2a. Frequency of Positive and Negative Wholesale Price Changes in Percents by Category 

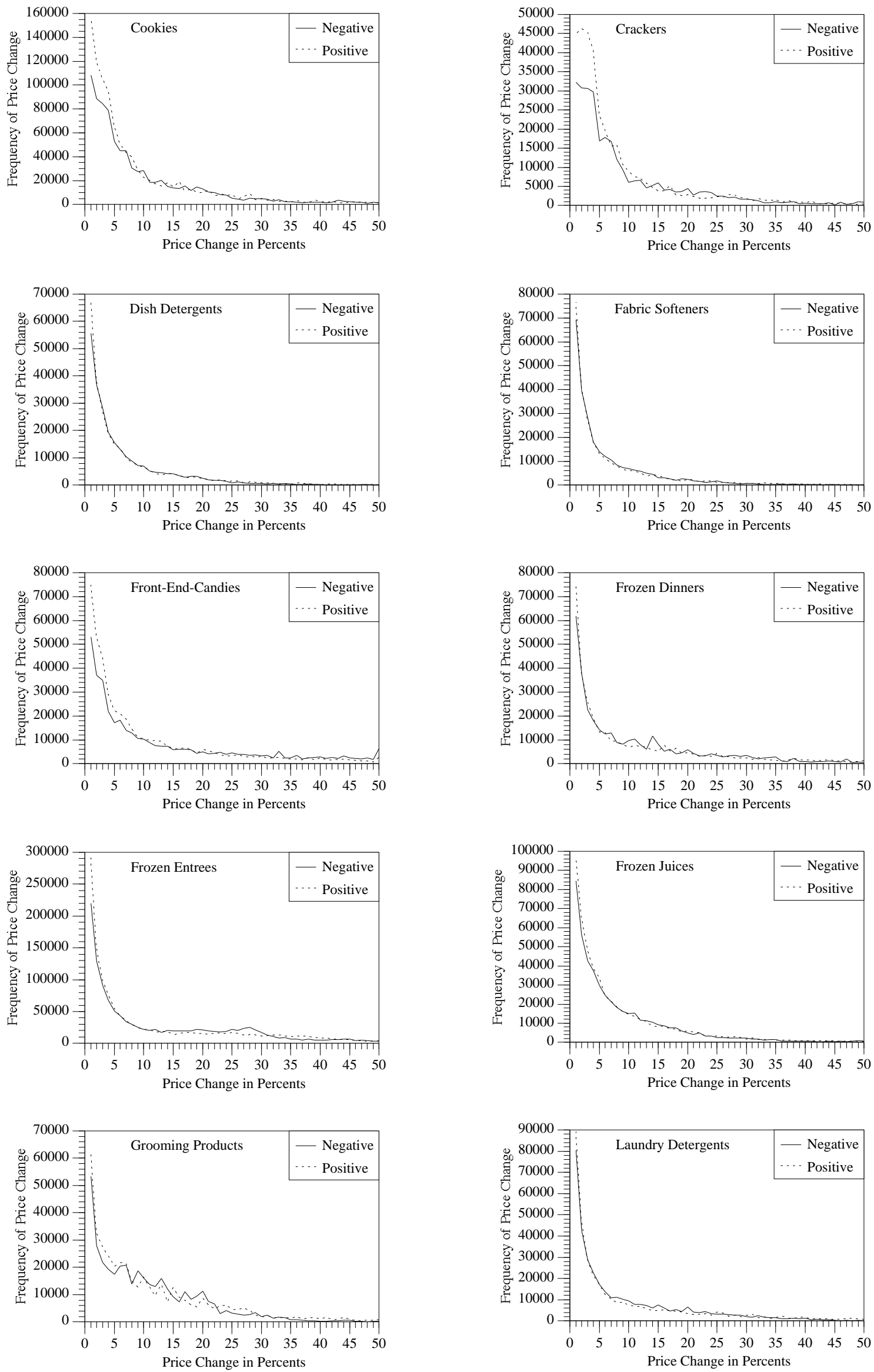

Figure 1.2b. Frequency of Positive and Negative Wholesale Price Changes in Percents by Category 

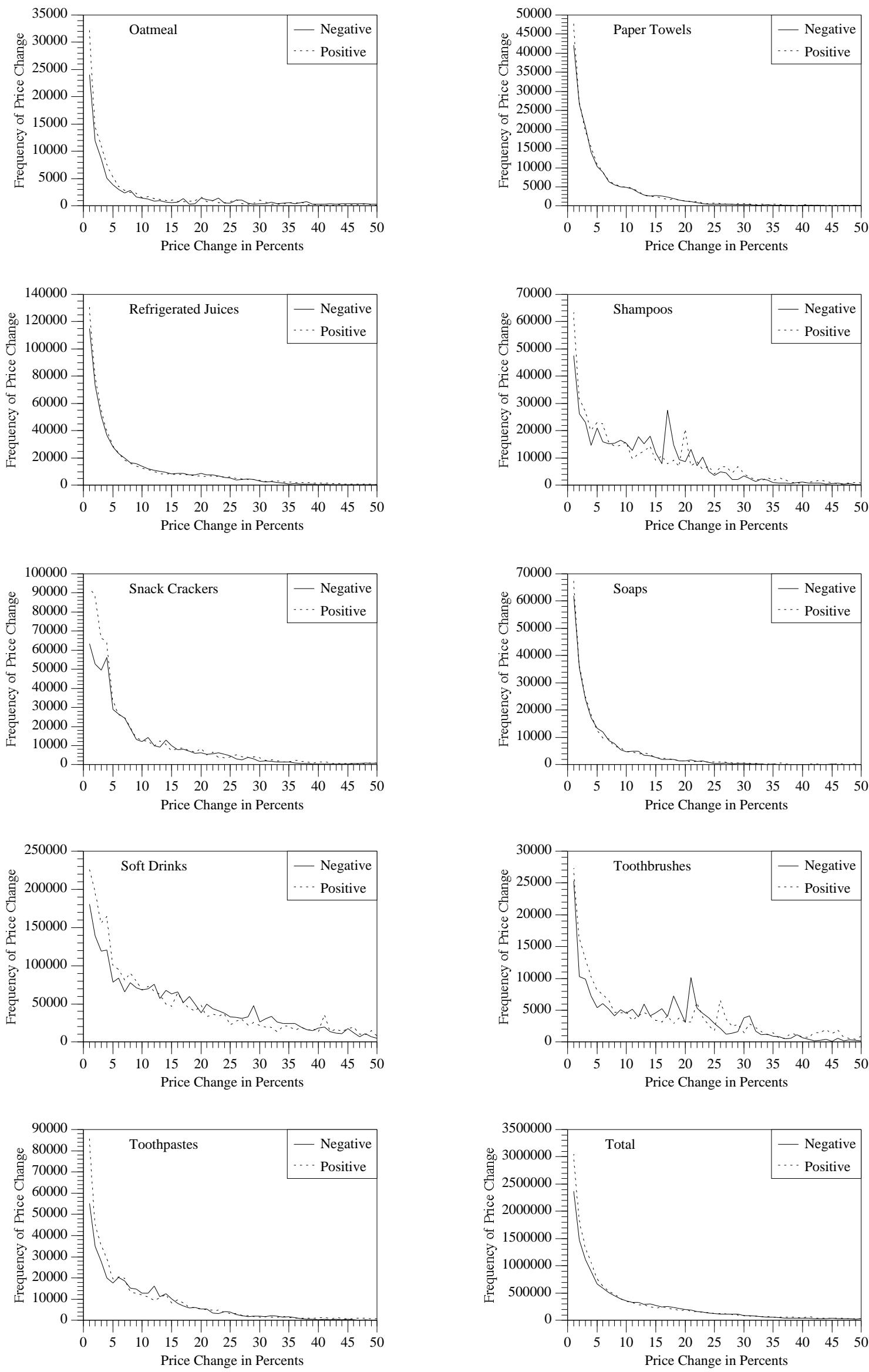

Figure 1.2c. Frequency of Positive and Negative Wholesale Price Changes in Percents by Category 

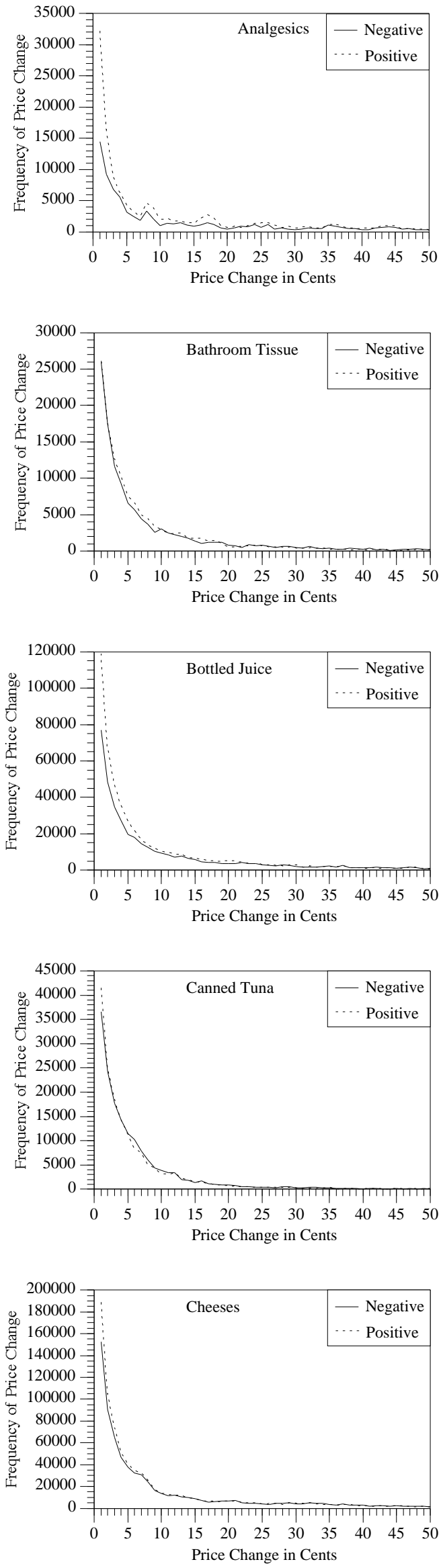
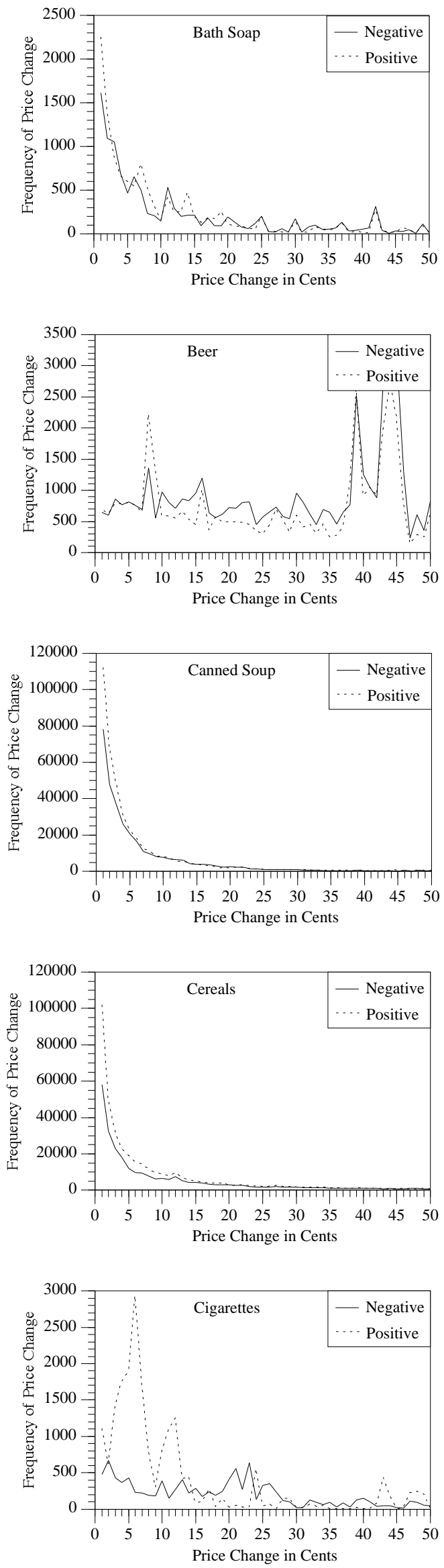

Figure 2.1a. Frequency of Positive and Negative Wholesale Price Changes in Cents by Category, 

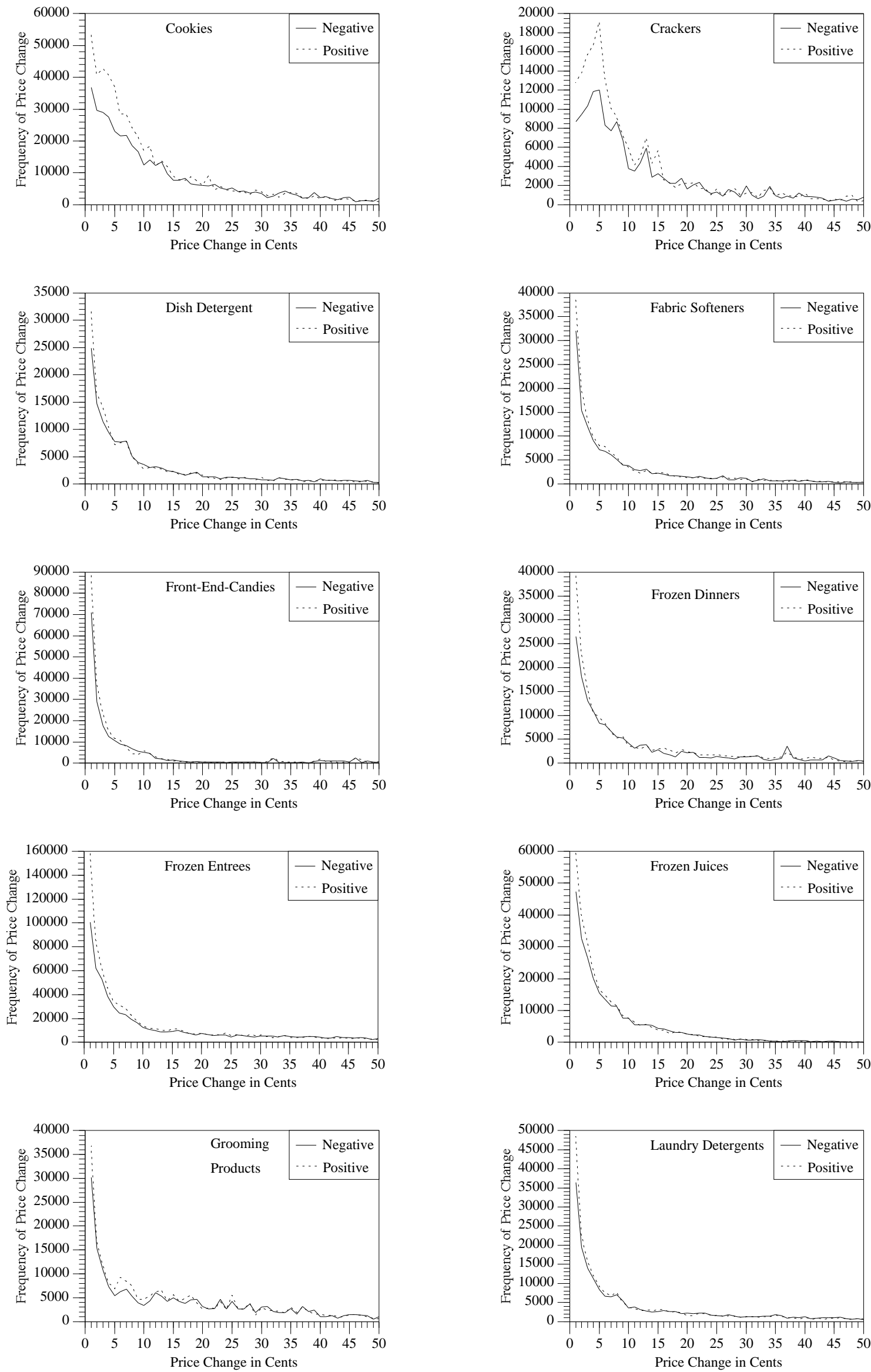

Figure 2.1b. Frequency of Positive and Negative Wholesale Price Changes in Cents by Category, Low/Zero Inflation Period 
Wholesale Price Asymmetry (Ray, Chen, Bergen, Levy)
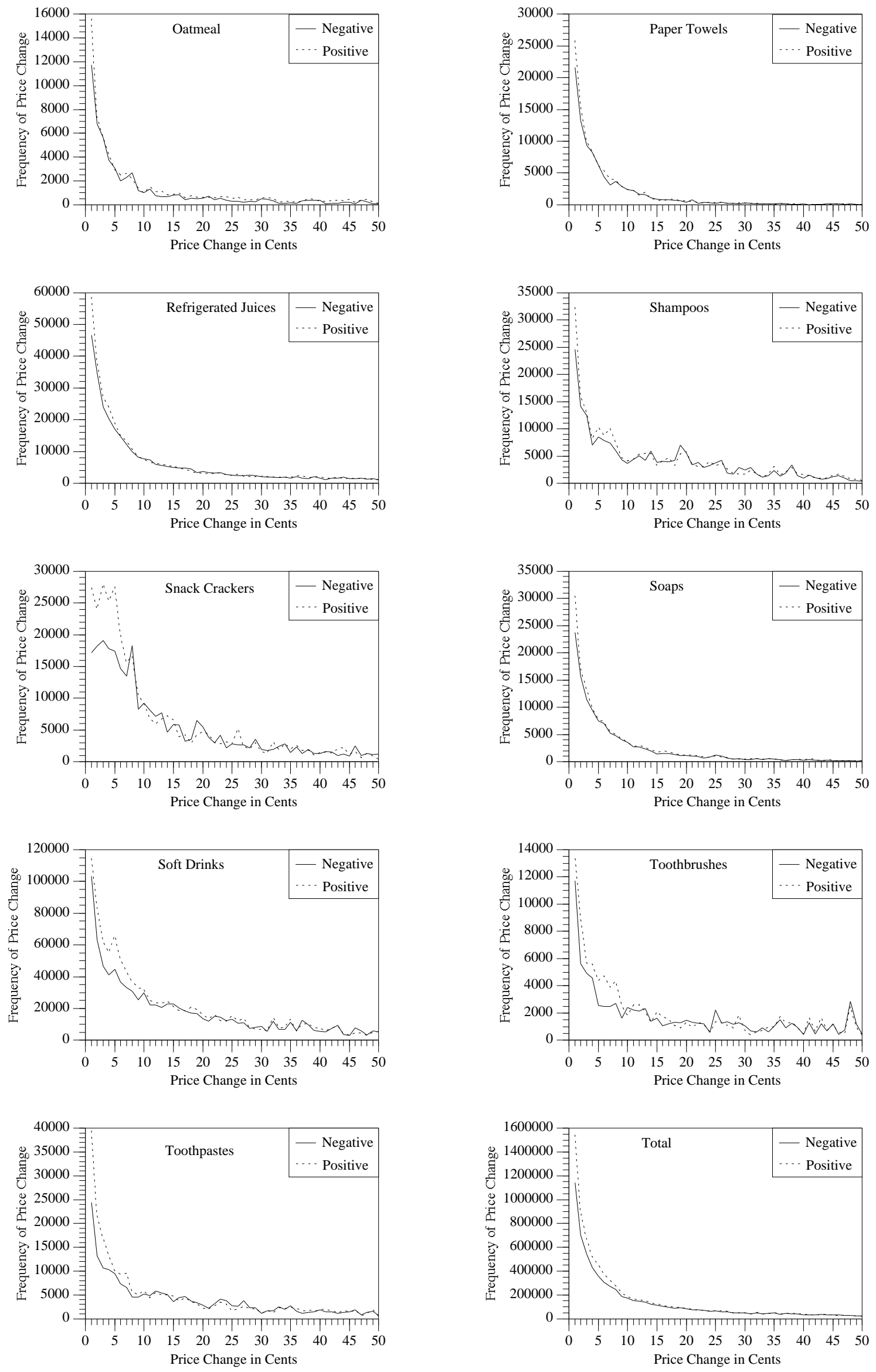

Figure 2.1c. Frequency of Positive and Negative Wholesale Price Changes in Cents by Category, Low/Zero Inflation Period 

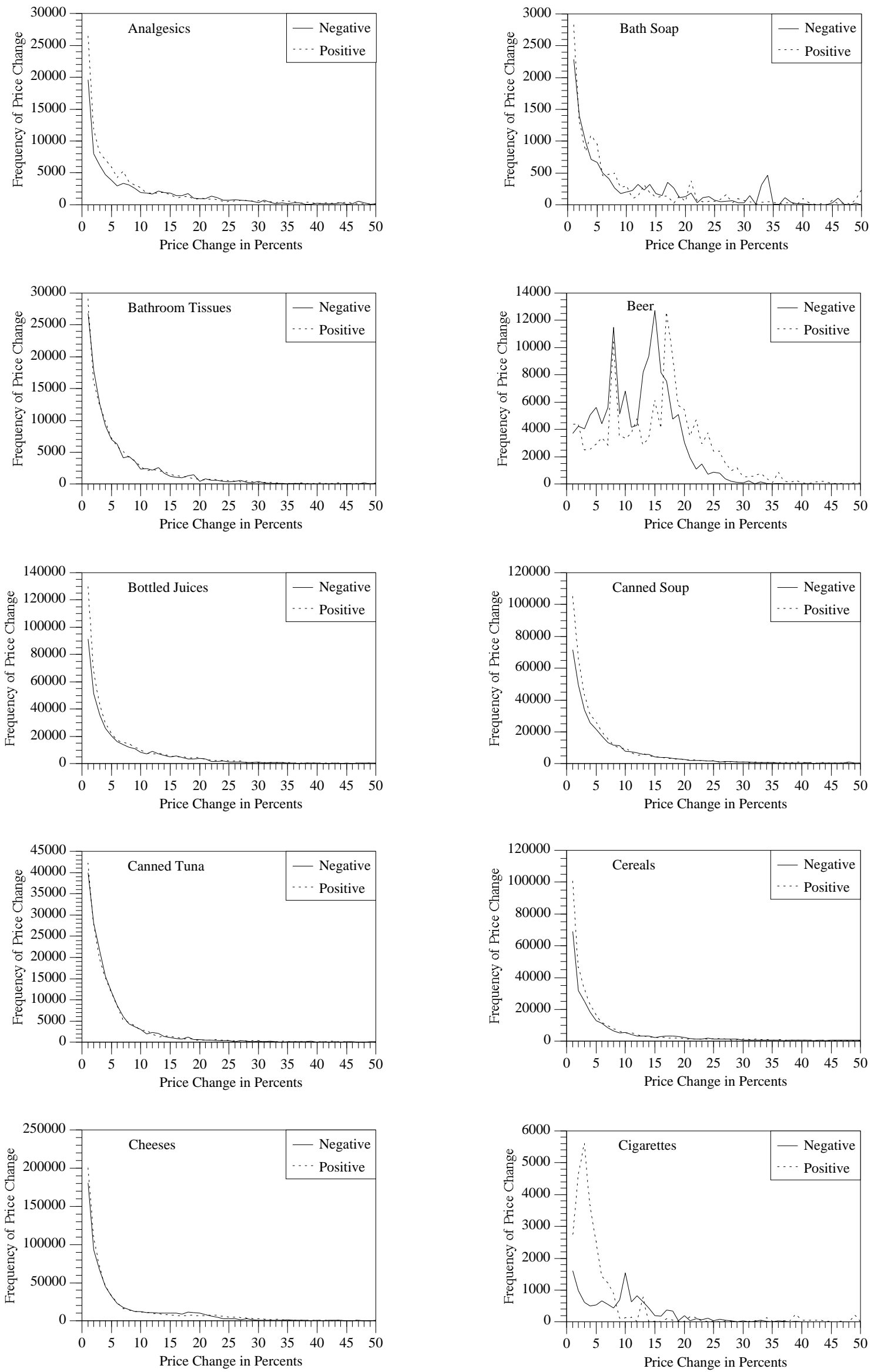

Figure 2.2a. Frequency of Positive and Negative Wholesale Price Changes in Percents by Category, Low/Zero Inflation Period 

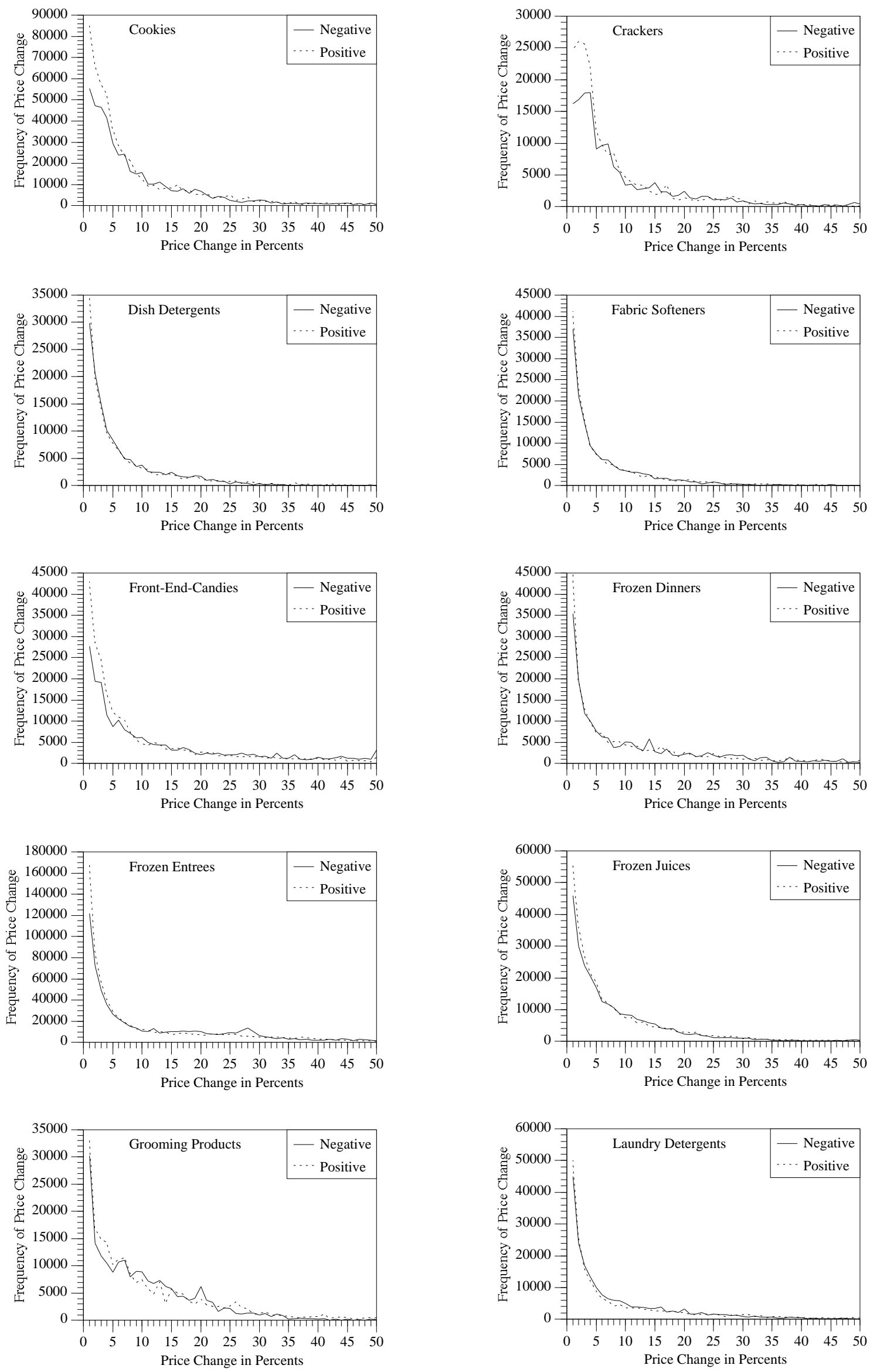

Figure 2.2b. Frequency of Positive and Negative Wholesale Price Changes in Percents by Category, 
Wholesale Price Asymmetry (Ray, Chen, Bergen, Levy)
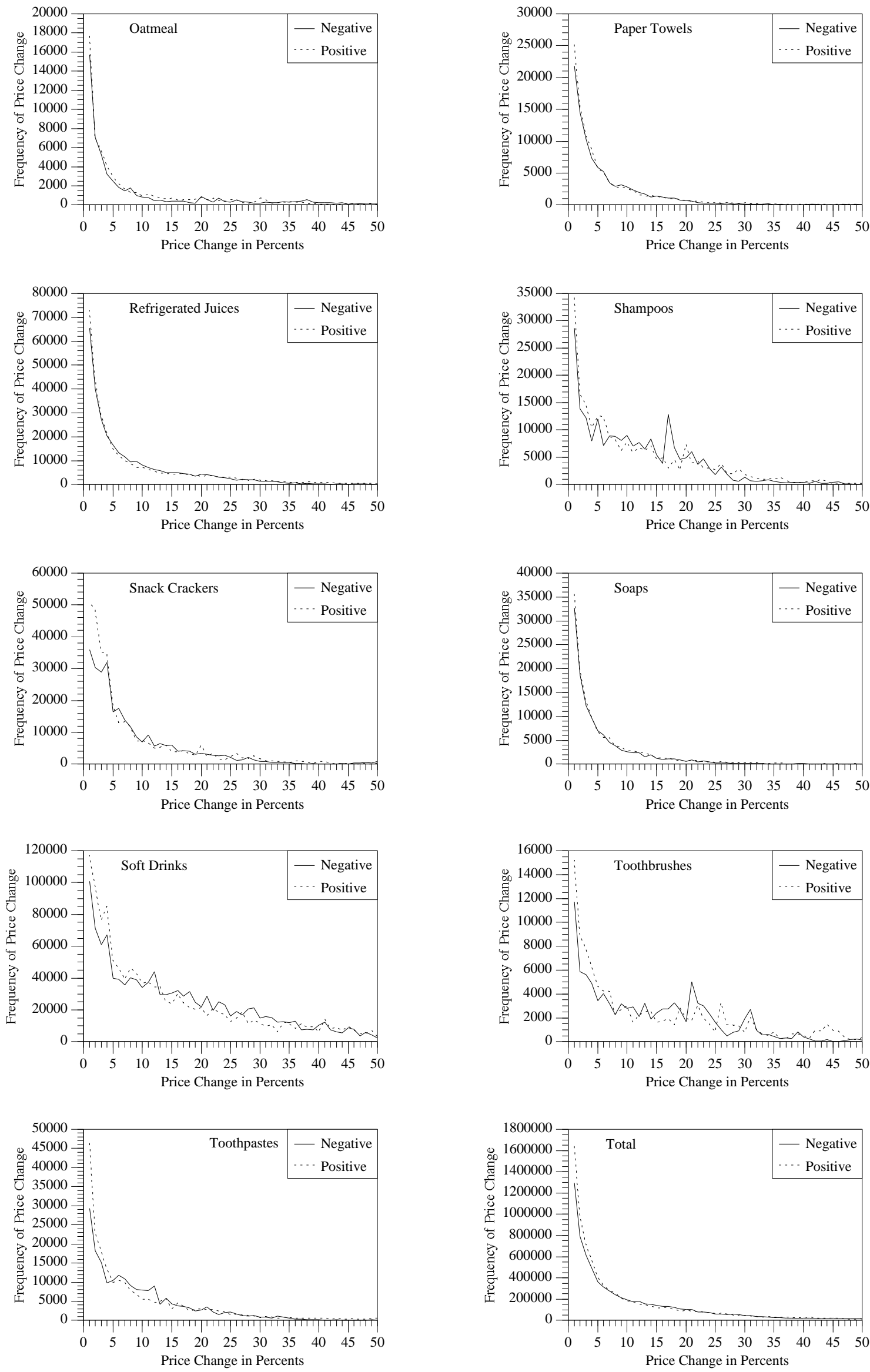

Figure 2.2c. Frequency of Positive and Negative Wholesale Price Changes in Percents by Category, Low/Zero Inflation Period 

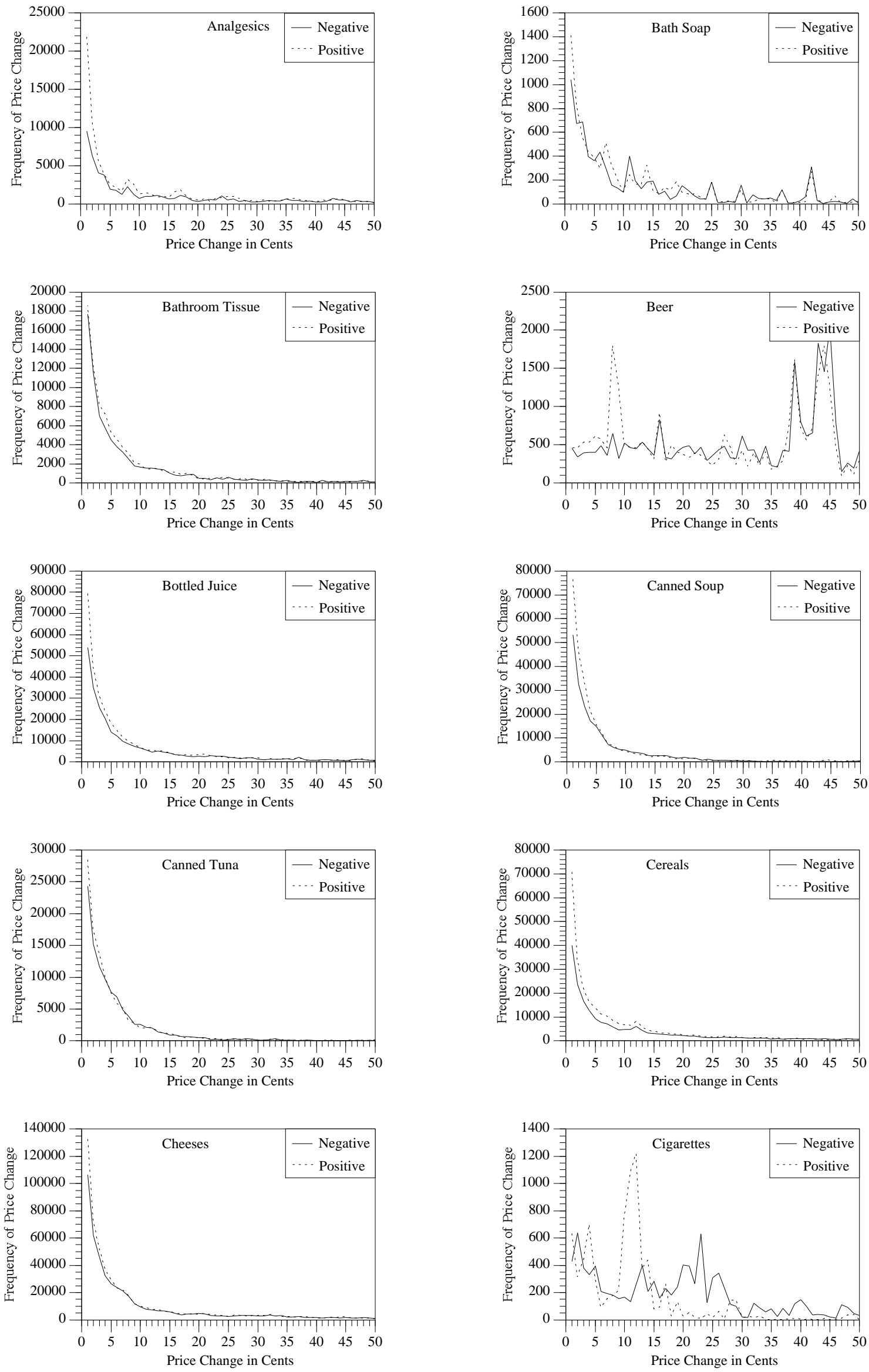

Figure 3.1a. Frequency of Positive and Negative Wholesale Price Changes in Cents by 

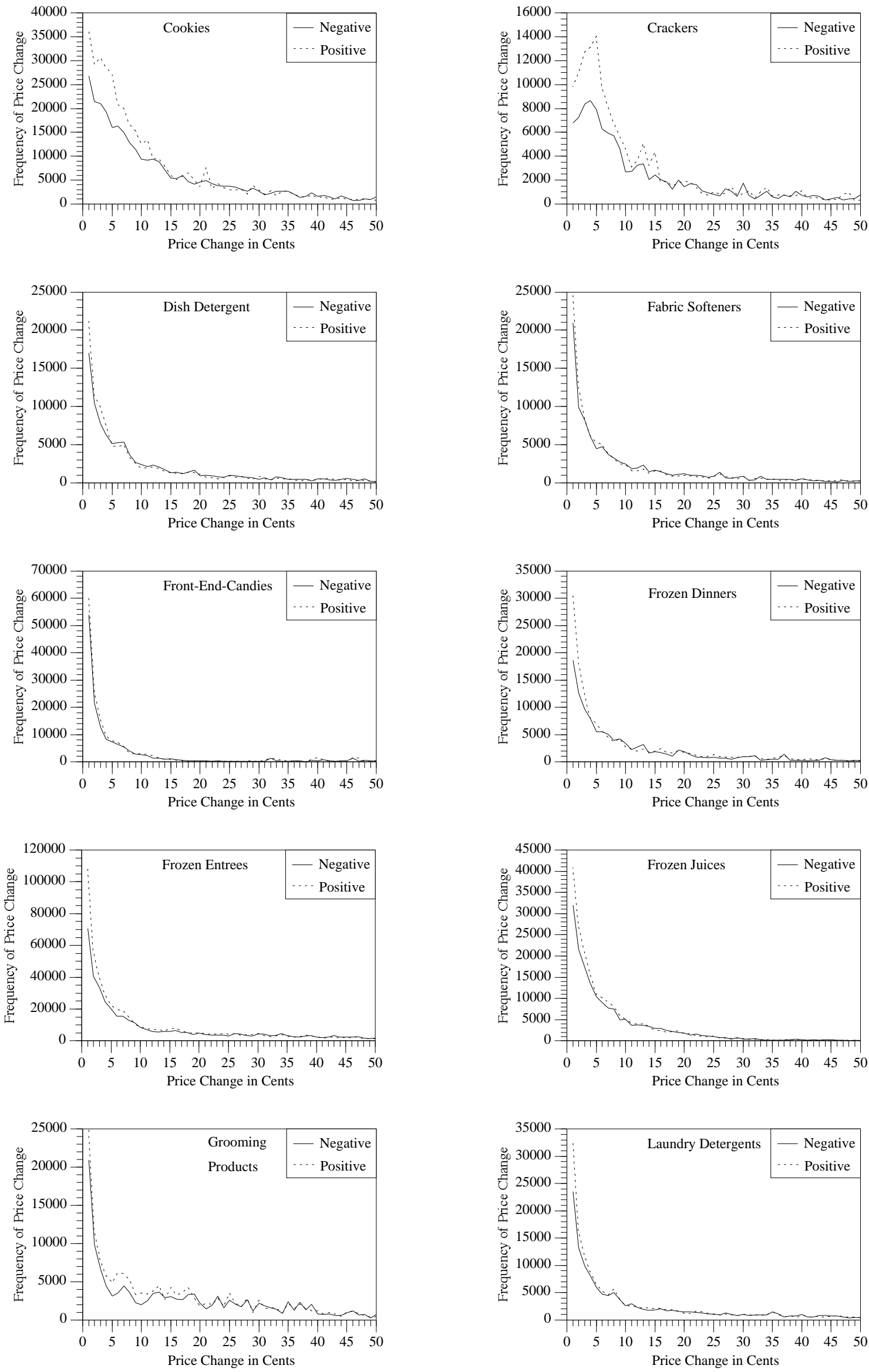

Figure 3.1b. Frequency of Positive and Negative Wholesale Price Changes in Cents by 

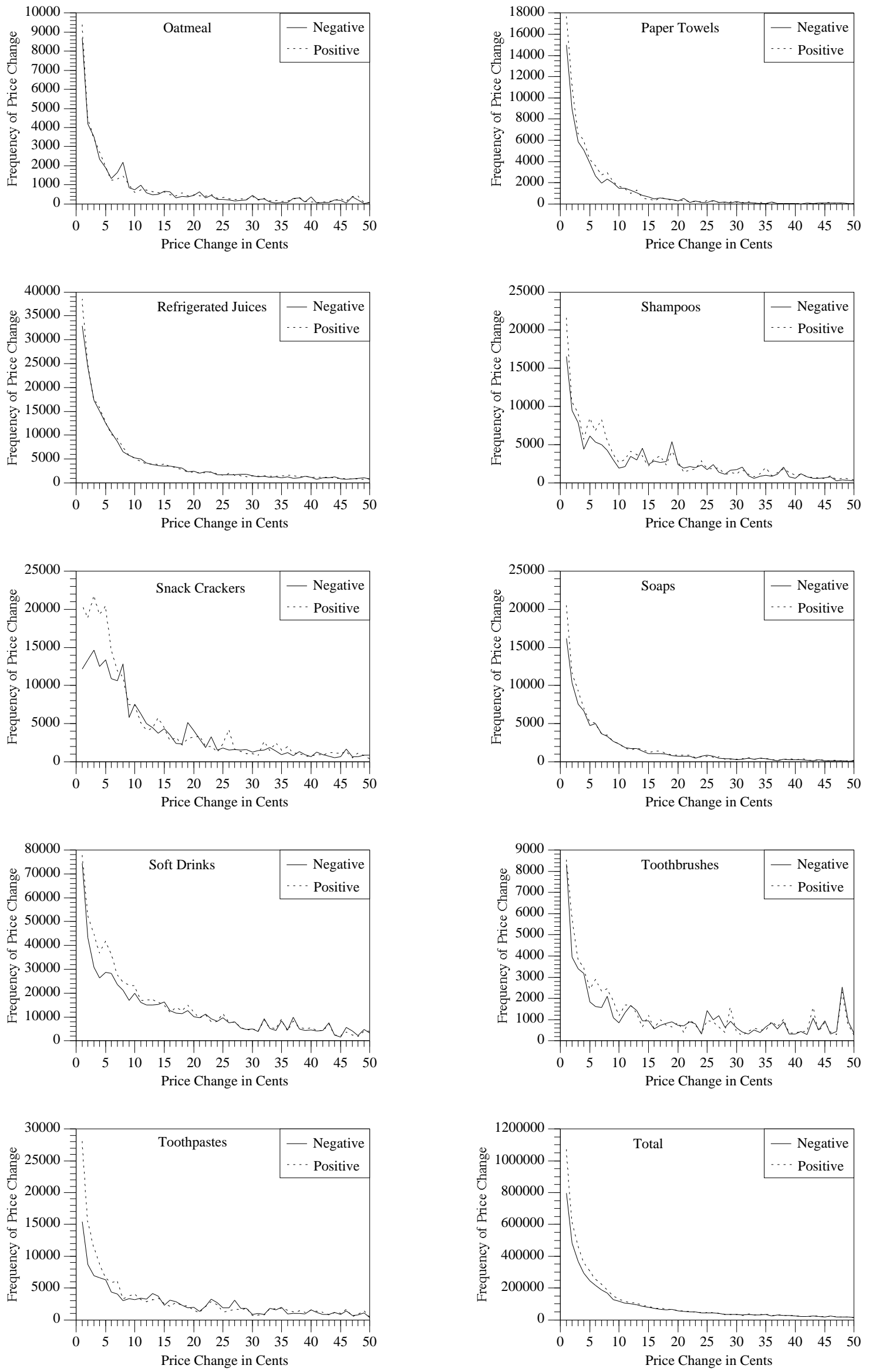

Figure 3.1c. Frequency of Positive and Negative Wholesale Price Changes in Cents by 

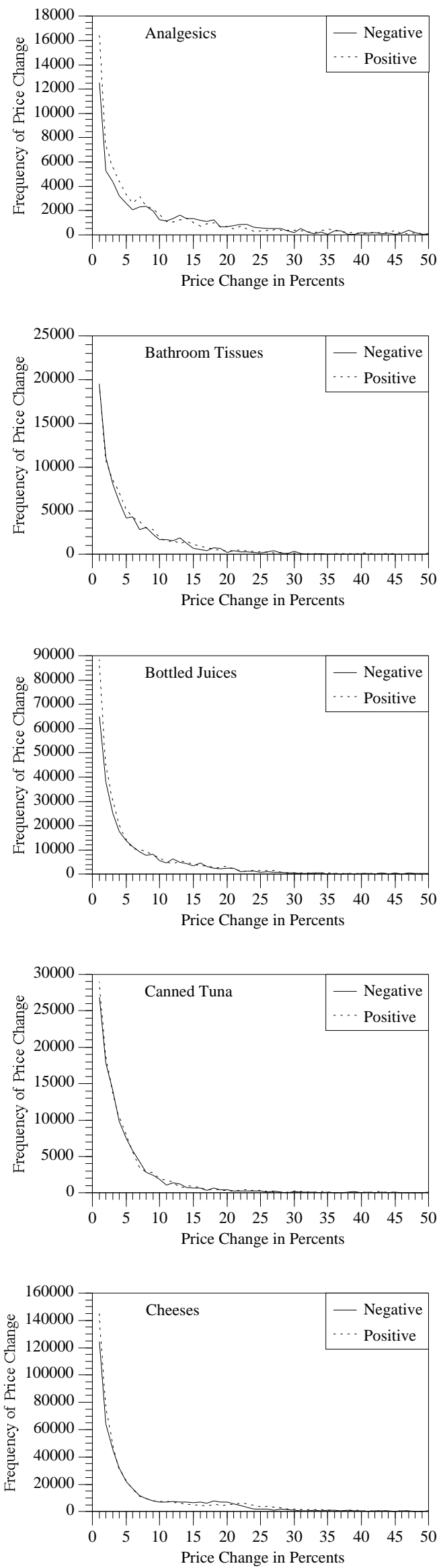
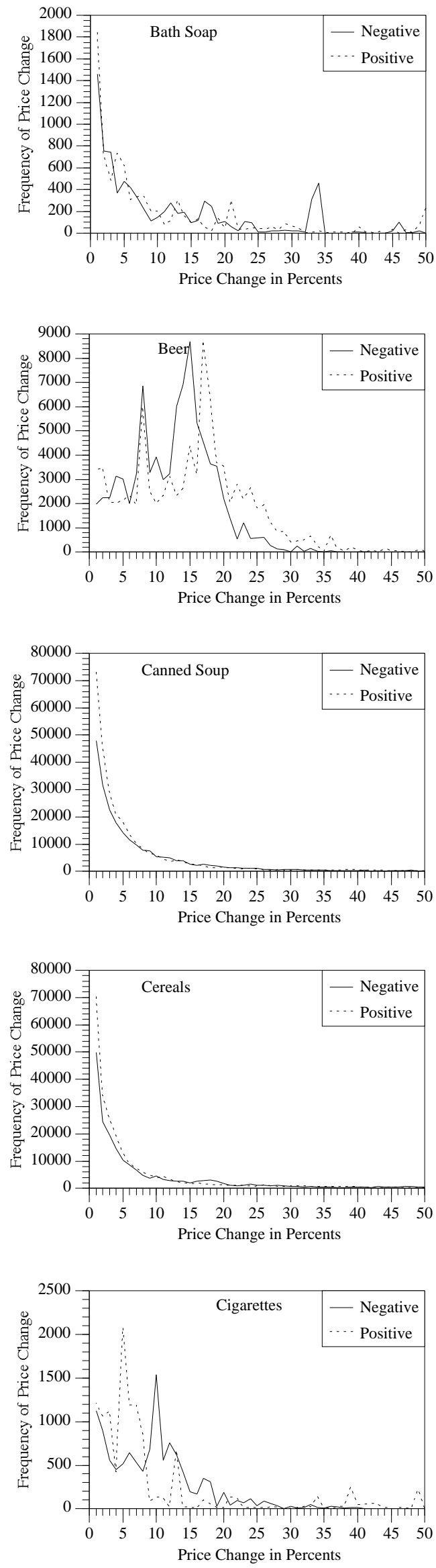

Figure 3.2a. Frequency of Positive and Negative Wholesale Price Changes in Percents by Category, Deflation Period 

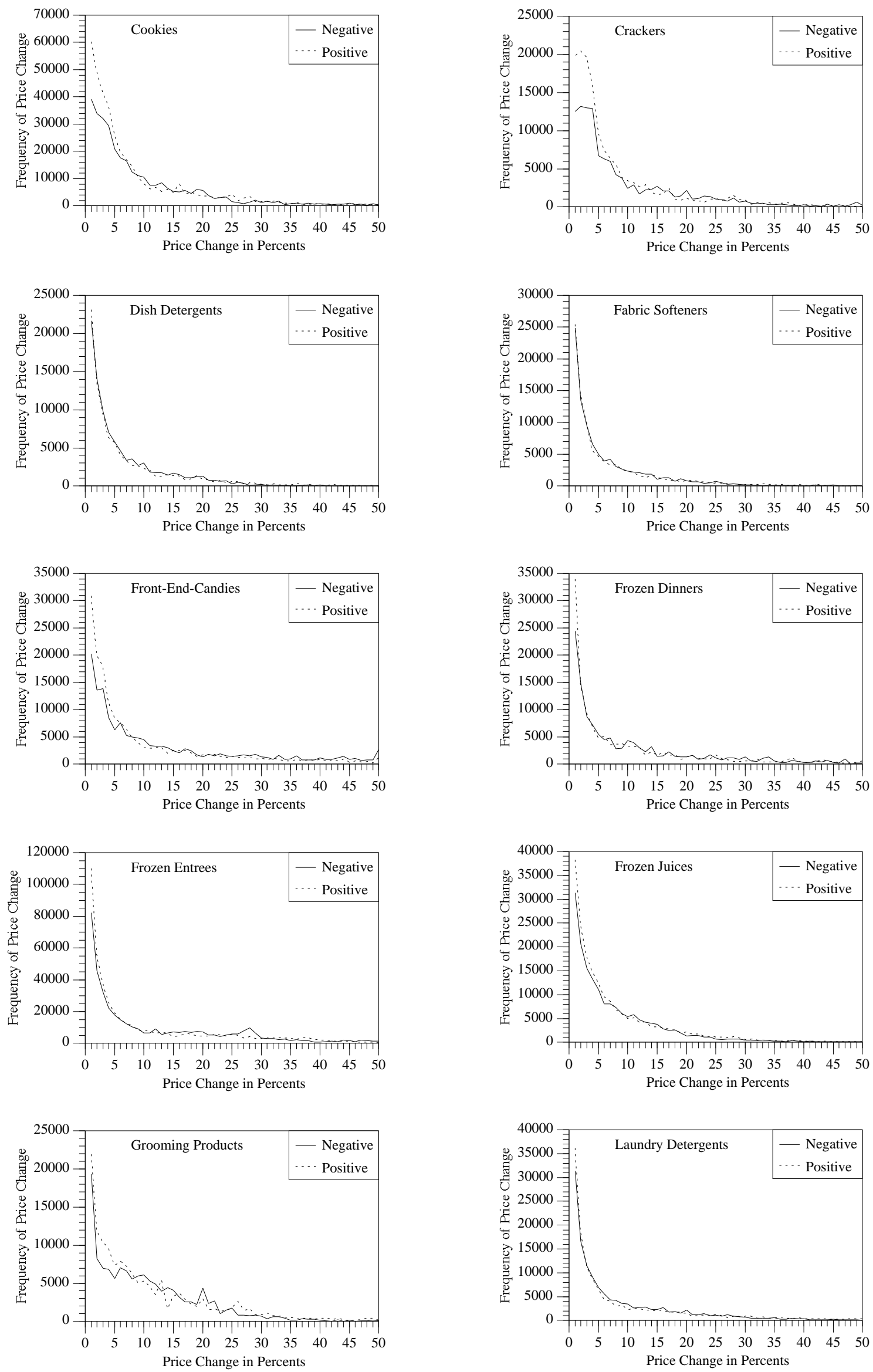

Figure 3.2b. Frequency of Positive and Negative Retail Wholesale Changes in Percents by 

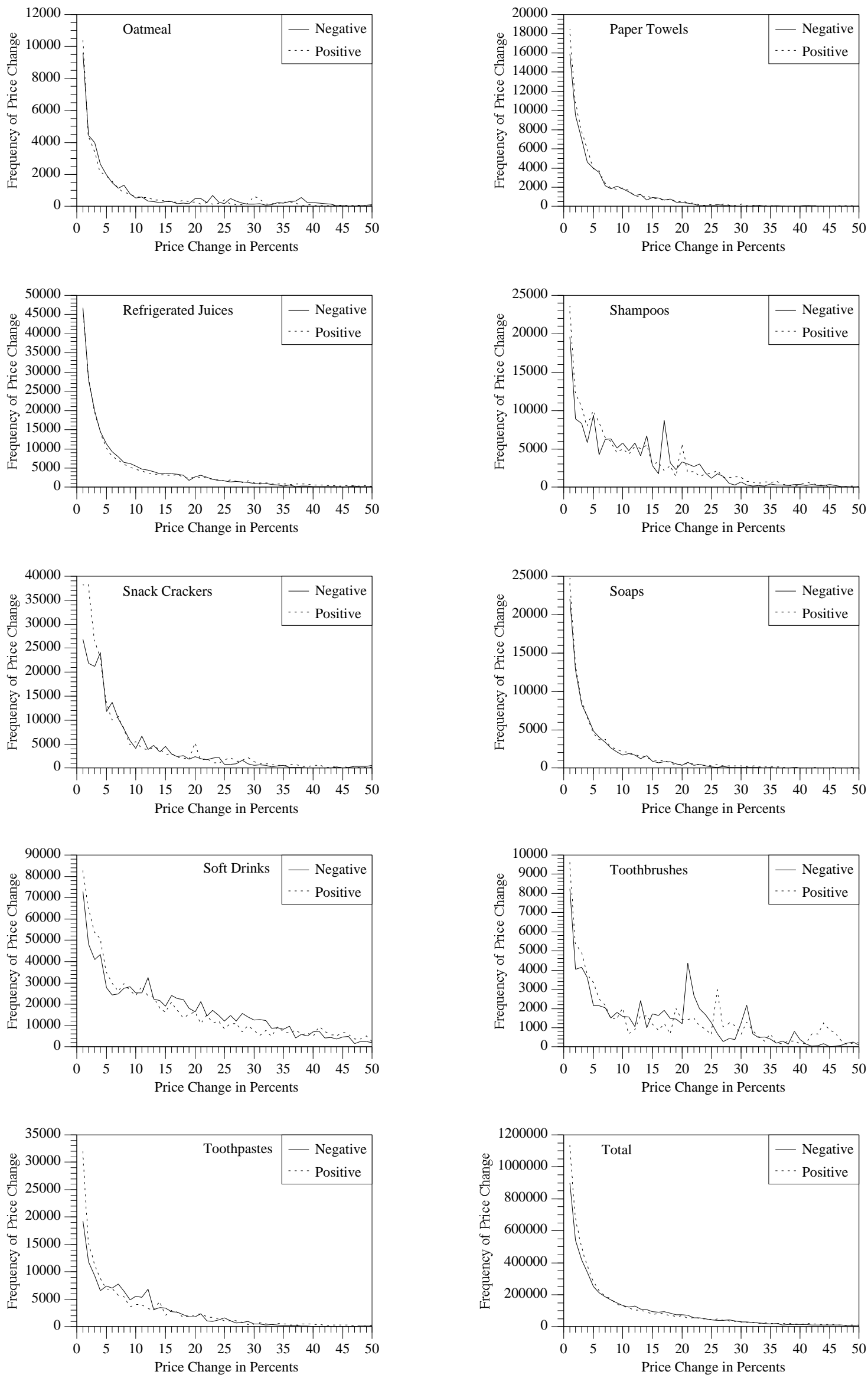

Figure 3.2c. Frequency of Positive and Negative Wholesale Price Changes in Percents by 